

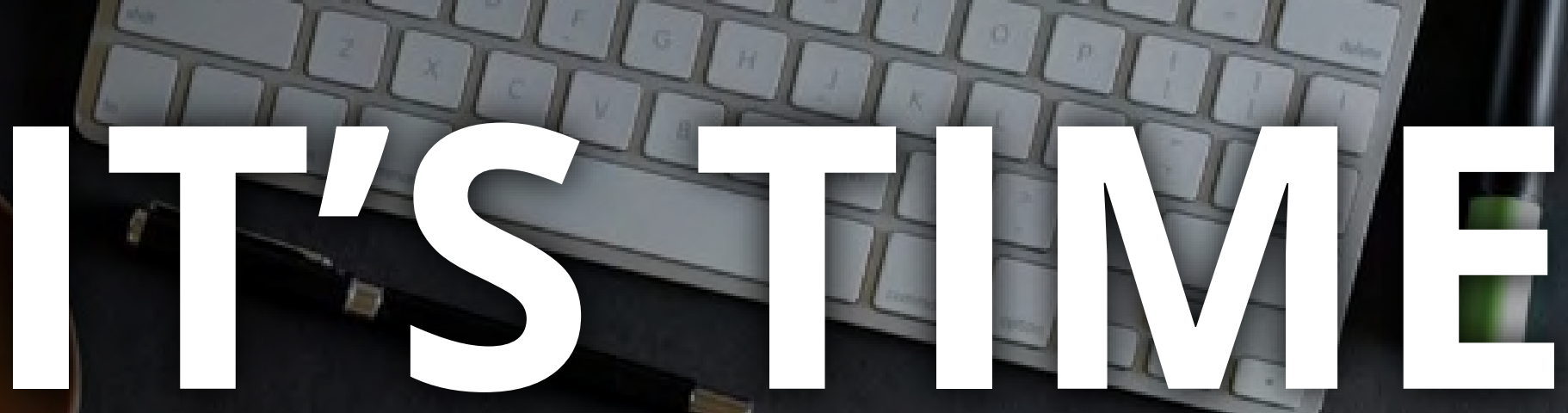

Australia is moving to MASH tested Crash Cushions on December 31st 2019 and the time to prepare, is NOW!

\section{DECEMBER 2019}

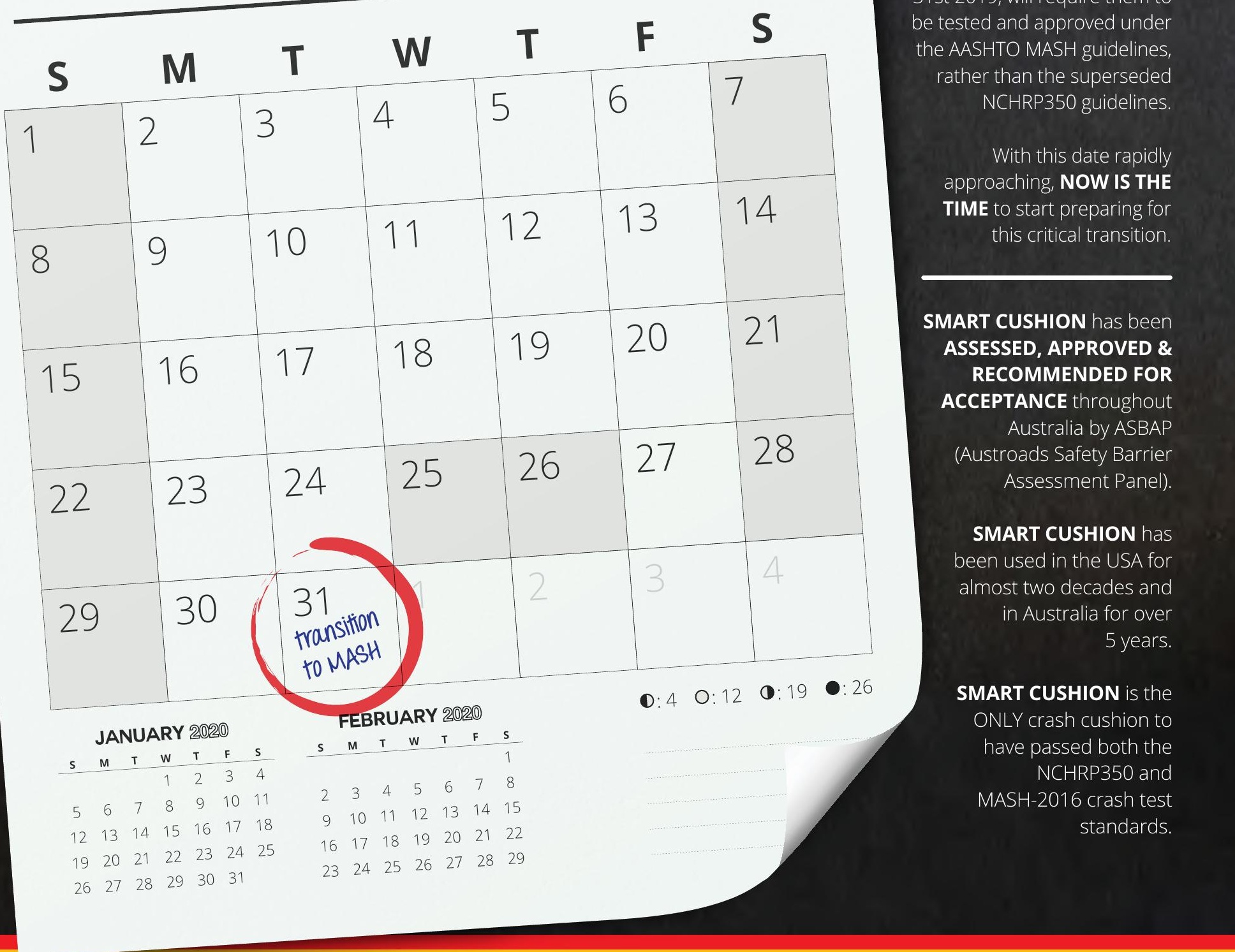

According to the Austroads / ASBAP Transition to MASH process, tenders called for new crash cushions installed on Australian roads after December 31st 2019, will require them to be tested and approved under he AASHTO MASH guidelines than the superse

With this date rapidly approaching, NOW IS THE ME to start preparing for this critical transition

ART CUSHION has been ASSESSED, APPROVED \& RECOMMENDED FOR TANCE throughou A

SMART CUSHION has been used in the USA for most two decades and for over

MART CUSHION is the ONLY crash cushion to assed both the 6 crash tes standards.

\section{SMART CUSHION| (9) Speed Dependent Crash Attenuators T: 0296318833 www.lbaustralia.com.au}




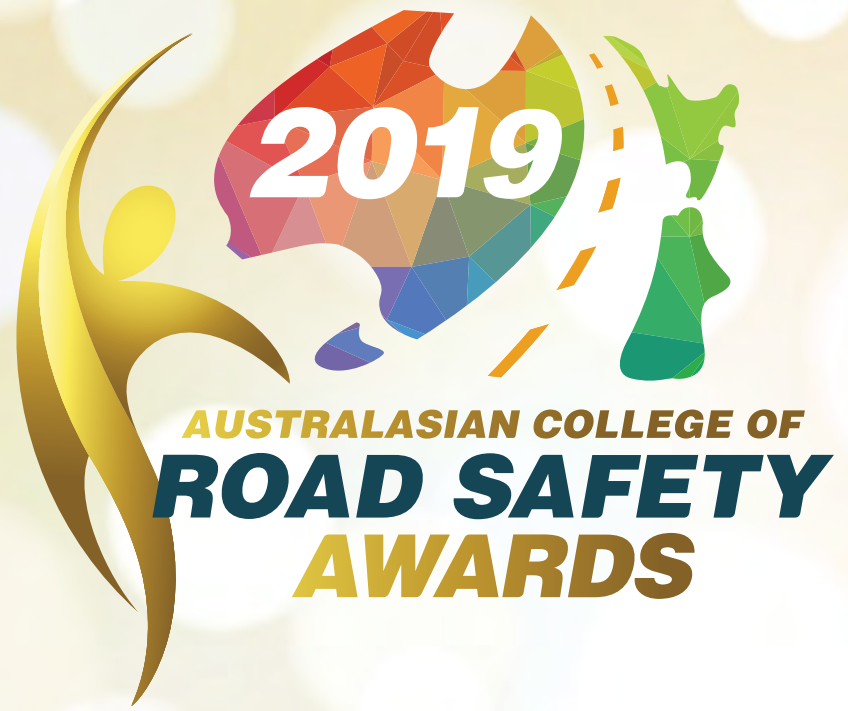

ACRS Awards - held at the Gala Dinner during the ARSC2019 Conference

25-27 September

Adelaide Convention Centre

\section{Adelaide}

Convention

Centre

\section{September 2019}

The Australasian College of Road Safety Awards continue the tradition of the original Australasian road safety awards and conferences by recognising and celebrating exemplary projects and people working hard across our region to save lives and reduce injuries on our roads.

\section{These awards include the following presentations:}

- The prestigious Australasian College of Road Safety Fellowship Award in recognition of exemplary contribution being made by an individual to road safety in Australasia.

- Australasia's premier road safety award recognising projects that exhibit exemplary innovation and effectiveness to save lives and injuries on roads - the 3M-ACRS Diamond Road Safety Award. This award is entering its 8th year and is recognised as Australasia's premier road safety award recognising an outstanding road trauma reduction project.

- ARSC Conference Awards (presented in the closing session of the Australasian Road Safety Conference)

- Other awards as deemed appropriate by the joint hosts for the ARSC Conference: ACRS, Austroads and invited hosts for each year.

Austroads, ACRS and CASR look forward to your participation in ACRS2019 which aligns with international, Australasian and national road safety efforts, and is a significant step forward in Australasia's road safety strategy. Most importantly we encourage your participation at this important event, which recognises our outstanding individuals, organisations and projects as we all strive to reduce road trauma.

More information is available at:

\section{Presentation of a trip to USA for exemplary road safety efforts!}




\section{Contents}

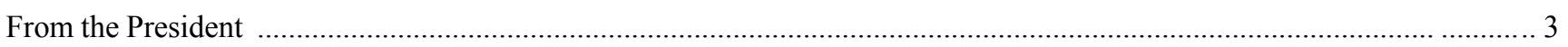

From the $\mathrm{CEO}$

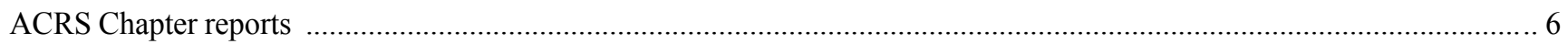

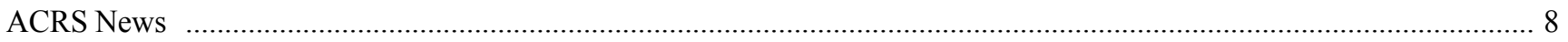

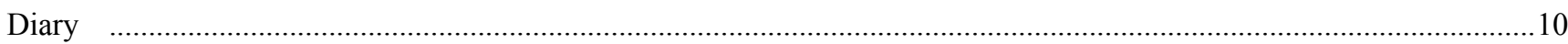

\section{Peer-reviewed papers}

\section{Original Road Safety Research}

Safety solutions on mixed use urban arterial roads

- Blair Turner, Rob Partridge, Shane Turner, Bruce Corben, Jeremy Woolley, Chris Stokes, Jennifer Oxley,

Karen Stephan, and Lisa Steinmetz

For whom didn't it click? A study of the non-use of seat belts in motor vehicle fatalities in New Zealand

- Lily Hirsch, Hamish Mackie, Richard Scott, John de Pont, Simon Douglas, and Dylan Thomsen

The frequency and nature of aggressive acts on Australian roads

- Amanda Stephens and Michael Fitzharris

The crash performance of seagull intersections and intersections with left turn slip lanes

- Shane Turner, Fergus Tate, and Graham Wood

Road Traffic Fatalities in Malawi: The Role of Pedestrian Behaviour Factors

- Gibson Mpokonyoka Ngwira, Benjamin Bolaane, and Bhagabat P. Parida

\section{$\underline{\text { Road Safety Policy \& Practice }}$}

Contemporary Guidance on Management of Road Safety Audits

- Auttapone Karndacharuk and Paul Hillier

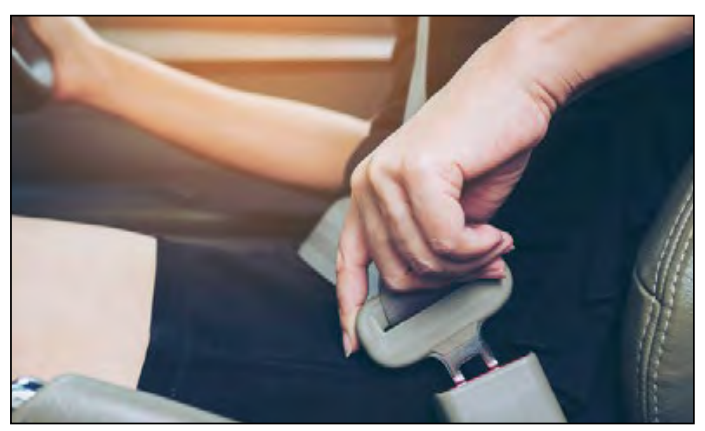

\section{Cover image}

Lack of seat belt use is often identified as a substantial issue contributing to deaths and serious injuries on our roads. In New Zealand, vehicle occupant fatalities where a seat belt was not worn accounted for $19-30 \%$ of the total road fatalities between 2006-2016. The research identified five occupant profiles for people who did not wear a seat belt and died on New Zealand's roads: 'rurally located'; 'young and risky'; 'driving for work'; 'elderly and retired'; 'overseas passengers'. See Original Road Safety Research article: Hirsch, L., Mackie, H., Scott, R., de Pont, J., Douglas, S. and Thomsen, D. (2019). "For whom didn't it click? A study of the non-use of seat belts in motor vehicle fatalities in New Zealand”. Journal of the Australasian College of Road Safety, 30(3), 18-26). Image designed by Freepik (www.Freepik.com). 
The Journal of the Australasian College of Road Safety (formerly RoadWise between 1988 and 2004) ISSN 1832-9497. Published quarterly by the Australasian College of Road Safety.

Managing Editor: Dr Chika Sakashita Australasian College of Road Safety \& Global Road Safety Solutions Washington DC, USA. journaleditor@acrs.org.au

Editor-in-Chief: Prof Raphael Grzebieta (FACRS) Emeritus Professor (Road Safety), Transport and Road Safety (TARS) Research Centre, School of Aviation, UNSW Adjunct Professor, Victorian Institute of Forensic Medicine, Monash University.

Associate Editor: Prof Jake Olivier

Professor, School of Mathematics and Statistics, UNSW

New South Wales, Australia

\section{Subscriptions}

All issues of this Journal are mailed to personal members or corporate delegates of the Australasian College of Road Safety. Organisations and persons who are not members of the College may subscribe to the Journal on payment of an annual subscription.

\section{Advertising and sponsorship}

Advertising rates and, specifications are on the College website at http://acrs.org.au/publications/journals/advertising/ or available by email from faa@acrs.com.au. Discounts are available for prepaid advertising booked to run for more than one issue. The College also welcomes sponsorship of the Journal. For more information about becoming a Journal sponsor, please contact the Managing Editor.

\section{Editorial Policy}

The Journal of the Australasian College of Road Safety aims to publish high quality papers and provides a means of

communication for the considerable amount of evidence being built for the delivery of road safety, to inform researchers, policymakers, advocates, government and non-government organisations, post-crash carers, engineers, economists, educators, psychologists/ behavioural scientists, communication experts, insurance agencies, private companies, funding agencies, and interested members of the public. The Journal accepts papers from any country or region and has an international readership.

All papers submitted for publication undergo a peer-review process, unless the paper is submitted as a Perspectivel Commentary on Road Safety or Correspondence or the authors specifically request the paper not to be peer-reviewed at the time of original submission. Submissions under the peer-review stream are refereed on the basis of quality and importance for advancing road safety, and decisions on the publication of the paper are based on the value of the contribution the paper makes in road safety. Papers that pass the initial screening process by the Managing Editor and Peer-Review Editor will be sent out to peer reviewers selected on the basis of expertise and prior work in the area. The names of the reviewers are not disclosed to the authors. Based on the recommendations from the reviewers, authors are informed of the decision on the suitability of the manuscript for publication.

When papers are submitted and the authors specifically request the paper not to be peer-reviewed at the time of original submission, the papers will be published under the non peer-review stream. Submissions under the non peer-review stream, Perspectivel Commentary on Road Safety and Correspondence are reviewed initially by the Managing Editor, who makes a decision, in consultation with the Peer-Review Editor and/or Editorial Board when needed, to accept or reject a manuscript, or to request revisions from the author/s in response to the comments from the editor/s.
As a rule of thumb, all manuscripts can undergo only one major revision. Any editorial decisions regarding manuscript acceptance by the Managing Editor and Peer-Review Editor are final and further discussions or communications will not be entered into in the case of a submission being rejected.

For all articles which make claims that refute established scientific facts and/or established research findings, the paper will have to undergo peer-review. The Editor will notify the author if peerreview is required and at the same time the author will be given the opportunity to either withdraw the submission or proceed with peer-review. The Journal is not in the business of preventing the advancement or refinement of our current knowledge in regards to road safety. A paper that provides scientific evidence that refutes prevailing knowledge is of course acceptable. This provision is to protect the Journal from publishing papers that present opinions or claims without substantive evidence.

All article types must be submitted online via the Editorial Manager: http://www.editorialmanager.com/jacrs/default.aspx. Online submission instructions can be downloaded from: http://acrs.org.au/contact-us/em-journal-conference-contacts/.

\section{Important information for authors}

It is essential that authors writing for the Journal obtain and follow the Instructions for authors. These are updated regularly and can be downloaded from the College website at http://acrs.org.au/ contact-us/em-journal-conference-contacts/

\section{Authors are responsible for complying with all the requirements (including Article types, Article structure, References, Ethics in publishing, Originality \& plagiarism, Author declaration) before submitting their papers. The College has adopted guidelines developed by the Committee on Publication Ethics, which are available at http://acrs.org.au/ publications/journals/ethics-and-malpractice-statement/.}

Authors retain the copyright in their papers. However, by submitting a paper, authors give their permission to the College to make minor editorial changes to conform to the College in-house style manual; to print the paper in the Journal of the Australasian College of Road Safety; to send it for indexing to Ebsco, SafetyLit, Informit and other relevant databases; to make the full text of the paper available online through the ACRS website and Informit; and to promote the paper through media releases or by giving permission to re-print it in full or part in other hard copy or online resources that promote road safety. All photographs and diagrams for which the author or the author's employing organisation does not hold copyright must be accompanied by permission from the copyright holder to be used as indicated above.

\section{ACRS office contact details}

Ms Claire Howe, Chief Executive Officer, ceo@acrs.org.au: For inquiries regarding membership and College activities.

Dr Chika Sakashita, Managing Editor, journaleditor@acrs.org.au: For inquiries regarding submissions, current and back issues, advertising and sponsorship for the Journal.

Contact faa@acrs.org.au for inquiries regarding Journal subscriptions and changes of postal address.

Mailing address: PO Box 198, Mawson, ACT 2607 Australia

Phone: (02) 62902509

Head office: Pearce Centre, Collett Place, Pearce ACT Australia 


\section{Editorial Board}

\begin{tabular}{|c|c|c|}
\hline Editorial Board & Affiliation & Country/State \\
\hline Dr Rebecca Brookland & $\begin{array}{l}\text { Senior Research Fellow, Dept Preventive and Social Medicine, } \\
\text { Dunedin School of Medicine, University of Otago }\end{array}$ & New Zealand \\
\hline Prof Judith Charlton & Director, Monash University Accident Research Centre & Victoria, Australia \\
\hline Dr Judy Fleiter & $\begin{array}{l}\text { Global Manager, Global Road Safety Partnership, } \\
\text { International Federation of Red Cross \& Red Crescent Societies } \\
\text { Visiting Fellow, School of Psychology and Counselling, } \\
\text { Queensland University of Technology }\end{array}$ & Switzerland \\
\hline Prof Clay Gabler & Samuel Herrick Professor of Engineering, Virginia Tech & Virginia, USA \\
\hline Prof Rebecca Ivers & Head of School, Public Health \& Community Medicine, UNSW & New South Wales, Australia \\
\hline Prof Soames Job (FACRS) & $\begin{array}{l}\text { Global Lead Road Safety, World Bank } \\
\text { Head, Global Road Safety Facility }\end{array}$ & Washington DC, USA \\
\hline A/Prof Michael Keall & $\begin{array}{l}\text { Research Associate Professor, Department of Public Health, } \\
\text { University of Otago Medical School }\end{array}$ & New Zealand \\
\hline Dr Nadine Levick & Director, Objective Safety LLC & New York, USA \\
\hline Prof Andrew McIntosh & $\begin{array}{l}\text { Director, McIntosh Consultancy \& Research } \\
\text { Adjunct Professor, ACRSIP FedUni } \\
\text { Adjunct Associate Professor, Monash University Accident Research Centre }\end{array}$ & Victoria, Australia \\
\hline Prof Lynn Meuleners & Director, School of Population and Global Health, University of Western Australia & Western Australia, Australia \\
\hline Prof Jake Olivier & Professor, School of Mathematics and Statistics, UNSW & New South Wales, Australia \\
\hline A/Prof George Rechnitzer & $\begin{array}{l}\text { Adjunct Associate Professor, Transport and Road Safety (TARS) Research Centre, } \\
\text { UNSW } \\
\text { Adjunct Associate Professor, Victorian Institute of Forensic Medicine, Monash } \\
\text { University }\end{array}$ & $\begin{array}{l}\text { New South Wales, Australia } \\
\text { Victoria, Australia }\end{array}$ \\
\hline Prof Michael Regan & $\begin{array}{l}\text { Human Factors, Research Centre for Integrated Transport Innovation, } \\
\text { School of Civil and Environmental Engineering, UNSW }\end{array}$ & New South Wales, Australia \\
\hline Prof Gordon Smith & $\begin{array}{l}\text { Stuart M. and Joyce N. Robbins Distinguished Professor, School of Public Health, } \\
\text { West Virginia University } \\
\text { Adjunct Professor, University of Maryland School of Medicine }\end{array}$ & West Virginia \& Maryland, USA \\
\hline A/Prof Richard Tay & VC Senior Research Fellow, RMIT University & Victoria, Australia \\
\hline Prof Barry Watson (FACRS) & $\begin{array}{l}\text { Adjunct Professor, CARRS-Q, } \\
\text { Queensland University of Technology }\end{array}$ & Queensland, Australia \\
\hline Prof Fred Wegman & Emritus Professor of Traffic Safety, Delft University of Technology & The Netherlands \\
\hline Prof Ann Williamson (FACRS) & Director, Transport and Road Safety (TARS) Research Centre, UNSW & New South Wales, Australia \\
\hline
\end{tabular}

\section{From the President}

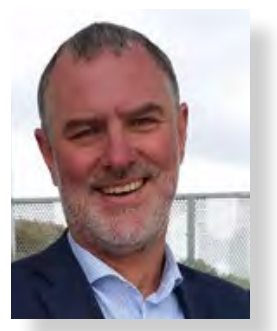

The Australasian College of Road Safety is committed to the elimination of serious road trauma, to the professional development of people with responsibilities to achieve this goal, and to the exchange of ideas and information necessary to drive road safety forward.

The College advocates road safety initiatives which are grounded in good injury prevention and safety management principles and which are backed by evidence of what initiatives are known to be effective or are highly likely to be effective. We are particularly concerned with advocating those initiatives which promote systemic change in favour of protecting human life and health on the road.

The Journal of the Australasian College of Road Safety plays a defining role in these efforts. It provides an ongoing platform for researchers and practitioners alike to share important information and insights into the problem. Each Issue adds to our collective understanding of what is happening in our road traffic system and to our capacity to investigate further safety issues and opportunities.

At a time when road safety performance has worsened so much in New Zealand, and Australia continues to underperform, we must implement the substantial policy decisions and investment strategies which we know will work now. But we must also be looking ahead.

From a public policy perspective, all governments in Australasia have committed themselves to the Safe System approach - the starting point of which is the harm elimination agenda we share.

To achieve this, or to get close to achieving this, we must increase our long-term commitment to research and development, and knowledge transfer activity. One-off contracts or short term arrangements encourage short term perspectives amongst researchers or consultancies. Generic 
research programs (road transport, injury prevention, urban planning etc) encourage generic responses when the focus must be on safety results.

We encourage public agencies to invest in further research and development work, and to do so in a manner which maintains and further develops intellectual endeavour in road safety and practical action. This requires commitments over an extended period of time, and research programs which are co-designed to meet both longer and shorter term safety objectives.

It was therefore pleasing to see that in its most recent budget the Australian Government has introduced a new Road Safety Innovation Fund to support research and development in priority areas. Allied with a decision from the Government to re-establish a national lead agency for road safety in Australia, we must be hopeful of a stronger research and development platform in the years ahead.

Austroads has played a constant and positive role, and this is reflected in the papers in this Issue. The paper on mixed use arterials illustrates the need to convert this into action I regularly use Unley Road, and there is no justification for this road to be set above the default urban speed limit. Other papers addressing critical design issues at intersections, updating road safety audit, profiling non-use of seatbelts, and aggressive driving illustrate the breadth and depth of College members at work in Australia and New Zealand.

And a special thank you for the contribution from Malawi on pedestrian safety. Walking is the dominant travel mode in Africa, and more pedestrians are killed in the world than any other road user. Our vision for safety is not constrained by geography and, as someone who has the privilege of working throughout Asia and Africa, I'm delighted to see road safety research in low and middle-income countries published in our Journal.

We must value and nourish those people and institutions who are capable of driving our knowledge base forward.

Martin Small

ACRS President

\section{From the CEO}

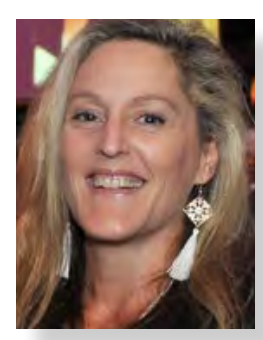

I am delighted to have the opportunity to provide regular updates on Canberra Head Office activities through this avenue of the Journal of the Australasian College of Road Safety (JACRS).

Under the careful management of our JACRS Managing Editor Dr Chika Sakashita, and our JACRS Editor-

in-Chief, Emeritus Professor Raphael Grzebieta, our Journal is steadily evolving to become an internationally recognised repository of up-to-date innovation and research outcomes across the broad spectrum of road safety. Recent improvements to JACRS have seen the considerable strengthening of the Journal oversight body - the Editorial Board - to include 18 eminent road safety academics spread across the globe. We have also seen the implementation of Digital Object Identifiers (DOI's) for each issue and individual paper. This allows us to monitor article and full issue downloads, and moves us closer to gaining an Impact Factor (a measure of the number of times a journal article has been cited) and subsequent journal ranking. We encourage all who publish to regularly utilise JACRS articles in their work, and I thank Chika and Raph in particular for their continued outstanding work to progress JACRS.

Concurrently with the work taking place on JACRS we have made significant progress across a number of areas, including:
ARSC2019 - Adelaide Convention Centre 2-27

September 2019 (https://australasianroadsafetyconference. com.au/) - Now only mere weeks away! Progress has been solid this year and we are proud to present a comprehensive program across 3 days, plus a pre-day of satellite meetings and events. I encourage you to review the Draft Program (https://acrs.org.au/wp-content/uploads/ Program-for-WEBSITE.pdf) and to join us at this landmark annual event which has become the largest road safetydedicated event in the Southern Hemisphere. We are also delighted at the opportunity to announce many prestigious awards recognising our road safety stars across research, practitioners, leadership and much more, so please also take a moment to review the Awards Website (https:// theaustralasianroadsafetyawards.com.au/) and our past winners on that website, our Hall of Fame.

New Zealand visit - Thanks to Tourism New Zealand, Jo Wilson-Ridley (an ACRS ACT \& Region Chapter executive member and ACT region local government road safety officer), and our Professional Conference Organiser, Shanna Sheldrick, joined me on a 5-day trip to New Zealand in May. Our itinerary was packed with visits to potential conference venues across Auckland, Christchurch and Wellington, and I was delighted at the high level of interest in ACRS presentations in each of these three cities with around 170 road safety stakeholders attending across the week. These presentations garnered interest in ACRS membership benefits, our recent Strategic Review outcomes, as well as our conferences, and gave a solid boost to our New Zealand Chapter which is ably Chaired by Dr Paul Graham from the New Zealand Transport Agency. We are likely to hold our conference in Christchurch and will be seeking support from the New Zealand government to bring the event to 
New Zealand. All feedback throughout the trip, including from the New Zealand Assistant Minister for Road Safety Julie Anne Genter, was very positive around bringing the conference to New Zealand. All in all a very successful trip and we're looking forward to putting in place arrangements to progress the event for 2021 .

\section{Darwin visit - and a new Northern Territory Chapter} - I am thrilled to report that following a successful visit to the Northern Territory we now have a brand-new Northern Territory Chapter located in Darwin. A special welcome to our first ever NT Chair Sergeant Mark Casey! Mark reports that the $1^{\text {st }}$ meeting of the Chapter has been held with another due shortly. We look forward to hearing progress and sharing this with ACRS members.

\section{Welcome to new ACRS Finance Manager - Patrick} Watts. With Patrick's assistance, we are very excited at the new direction our financial management system is moving in, which is a considerable step change for the College. Financial management is being substantially streamlined, which will result in a far more efficient and effective system in terms of daily financial activities through to financial reporting to our members.

\section{Welcome to our first Senior Communications Officer}

- Samantha Crothers. Sam is filling a crucial gap in our expertise and has a strong background in digital project management, which is vital at this point to manage work on our new ACRS Website, our new Journal Website and to assist and guide us with our other communications channels. Our new ACRS website will deal with member renewals and updates of information so there will be a significant amount of work involved to streamline the data transfer between financial management and membership management. Chika and Raph are also involved in the development of the College's brand new Journal website. Another very exciting project that I look forward to keeping you up to date with.

Awards - Many nominations have been received for both the 3M-ACRS Diamond Road Safety Award \& our ACRS Fellowship, and by the time you will be reading this the judging process will be well underway, all ready for announcement at the ARSC2019 Conference Gala Dinner and Awards on 26 September in Adelaide. The Deputy Prime Minister is locked in to attend and present the awards so we hope many of our members will be joining us again this year. We are also in the process of implementing a brand new award - the ACRS Oration Award - to provide a keynote presentation opportunity to a young road safety professional who is performing inspirational work. More on this shortly and keep an eye on ARSC2019 and beyond for details.
The new Australian federal Office of Road Safety - I am fortunate to have had the opportunity for a very positive meeting with the new Office of Road Safety (ORS), which was officially launched by the Deputy Prime Minister Hon Michael McCormack, on 1 July 2019. The ORS is situated within the Department of Infrastructure, Transport, Cities and Regional Development, and has the key objective to provide national leadership in eliminating road trauma in Australia. Establishment of this office is a direct result of the comprehensive 2017-18 Inquiry into the National Road Safety Strategy. Recommendation 2 (of 12) from that Inquiry is to 'Establish a national road safety entity reporting to the Cabinet minister with responsibility for road safety. Find out more about the evolution of this Inquiry, ably chaired by ACRS Fellows A/Professor Jeremy Woolley FACRS and Dr John Crozier AM FRACS FACRS, with advisors (and also ACRS Fellows) Mr Lauchlan McIntosh AM FACRS and Mr Rob McInerney FACRS here: https:// www.linkedin.com/pulse/outcome-2018-national-roadsafety-strategy-inquiry-providing-howe/

New (re-elected) Australian Government - With the bedding in of a re-elected government, we have been busy staying up to speed with the resulting changes in key leadership positions, and have welcomed back the Deputy Prime Minister, Hon Michael McCormack, including to the position of Minister for Infrastructure and Transport, and to our new Assistant Minister for Road Safety Hon Scott Buccholz. We have also welcomed Hon Catherine King as the Shadow Minister for Infrastructure and Transport, and Senator Glenn Sterle as the Shadow Assistant Minister for Road Safety.

ACRS Strategic Review planning - As a result of the recent ACRS Strategic Review and ratification of resultant recommendations by members at the AGM, we are pressing ahead with important strategic work including implementing appropriate planning documents for the College and undertaking a significant re-write of our Constitution. It's important to note that the College continues to be in the fortunate position of expansion in terms of turnover and workload so we need to remain flexible to take this in to account as we undertake new work, ensuring we maintain our highly valued member benefits.

Lastly, and perhaps most importantly of all, we have been busy since our AGM in mid-May working with our new President, Martin Small, and a revamped Executive Committee to formalise outcomes from the AGM. I'll look forward to keeping you updated with this aspect of the College in future CEO's Reports, and until then...

Stay safe, and best wishes,

Claire Howe

Chief Executive Officer - ACRS 


\section{ACRS Chapter reports}

Chapter reports were sought from all Chapter Representatives. We greatly appreciate the reports we received from $A C T, N S W$ and Queensland.

\section{Australian Capital Territory (ACT) and Region}

\section{Introduction}

The Chapter has been preparing with its partners for projects to be undertaken in 2019 .

Our AGM was held on 8 May 2019 and two of our major projects for the year have been developed.

A workshop on Wildlife crashes will be held on 24 July and a forum on the regulatory framework for the introduction of Electric Transport Personal Vehicles early September.

\section{AGM}

The three current office bearers were re-elected unopposed and agreed to continue in their respective roles for 2018-19:

Eric Chalmers: Chair and National Exec Representative; Keith Wheatley: Secretary;

Steve Lake: Treasurer were re-elected unopposed. committee meetings are open to all members and interested persons. The meeting reiterated that committee meetings are open to all members and interested persons.

The meeting also agreed that emphasis during the following twelve months on the Wildlife project, the implementation of national and ACT Road Safety Action Plans and a project to be proposed by the ACT Government.

\section{ACT Graduated Licence Scheme Review}

The ACT Government has announced a revised Graduated Licensing Scheme following a review of the current program during the second half of 2018. The Chapter assisted in this review by developing with the ACT Justice and Community Safety Directorate a public Forum that considered proposals received in a public consultation process.

The new arrangements include a wider range of provisions aimed at improving the safety of new drivers and brining ACT provisions up to best Australian practice. The scheme will be introduced on 1 January 2020.

\section{Wild life collisions in ACT and surrounding area}

This is a joint project involving the Chapter, ACT Health and the Royal Australasian College of Surgeons on concerns about the number and seriousness of casualties presenting at Canberra Hospital resulting from crashes with wild life on ACT and surrounding NSW roads.

The initiative for the project arose from concerns expressed by the ACT Trauma Unit and the Royal Australasian College of Surgeons about the number and severity of admissions to ACT A\&E departments.

A workshop will be held on 24 July 2019. It will involve speakers representing ACT Health, major Australian motor vehicle insurers, ACT transport, safety and police directorates and parks and conservation authorities.

The workshop has also drawn interest from authorities in surrounding areas of New South Wales and other States.

The Chapter's intention has been to bring as many interested parties as possible together to quantify more accurately the extent and severity of such crashes in the region so that suitable cost-effective countermeasures can be developed. We also intend to publish the report of the workshop and individual presentations on the ACRS website in due course.

\section{Electrical Personal Transport Vehicles}

The ACT Government has commenced public consultation on the introduction of electrical personal transport vehicles in the Territory. As part of this process, the Chapter will work with the Justice and Community Safety Directorate to develop and manage a public forum to review the responses to the initial consultations which closes on 19 July 2019

A Forum will be held on 3 September focusing on e-scooters and similar devices.

ACT Chapter Chair and Secretary

Mr Eric Chalmers \& Mr Keith Wheatley

\section{New South Wales (NSW)}

The NSW Chapter held its Annual General Meeting on 7 May 2019 at the Novotel, Sydney Central Hotel, with access online provided to members who were unable to attend in person.

The AGM was preceded by a free seminar titled Local Government Road Safety, which included three presentations and a panel discussion session. The presentations provided different perspectives and talking points about road safety 
and local councils from David McTiernan, ARRB, Sanjiv

Sathiah, Local Government NSW and Lisa Pears, Ryde City Council.

The NSW Chapter Committee Members for 2018/19 were David McTiernan (Chair), ARRB, Liz de Rome (Deputy Chair), Bianca Albanese (Secretary), Neura, Brendyn Williams (Treasurer \& Membership co-ord.), Duncan McRae (Website co-ord.), Teresa Senserrick, TARS, UNSW, Gray Knight, UNSW and Robyn Preece, TfNSW.

The Chapter Chair thanks all members of the Committee for their participation and work with the Chapter especially the extra effort to assist with the ARSC2018.

Chapter Activities during 2018/19 included hosting the Australasian Road Safety Conference 2018, meeting with Office of Minster for Roads, Maritime and Freight and an ongoing presence on IPWEA (NSW) Road Safety Panel. The Chapter was also involved in and supported the delivery of the following free seminars:

- $\quad$ Reality Check on the Road to Automated Vehicles (Jessica Jermakian, IIHS and Prof. Ann Williamson, TARS).

- $\quad$ The NSW CrashLink Reporting System (Bernard Carlon, ED, NSW Centre for Road Safety, TfNSW).

- $\quad$ Driver Reactions to Vehicle Automation (Prof. Neville Stanton, University of Southampton and Prof. Mike Regan, UNSW).

- $\quad$ Emerging Technologies Influencing Distracted Drivers (Prof. David Strayer, University of Utah).

The Chapter is grateful to Transport for NSW for providing funding assistance to the Chapter via the Community Grants Program. This support ensures appropriate venues are able to be booked for participants and where necessary appropriate cost for presenters are covered.

Nominations for the NSW Chapter Committee were received and considered by those attending the AGM. Appointment to the Committee positions were agreed at the first meeting of the Chapter Committee in May 2019. The NSW Chapter Committee for 2019/20 is as follows:

- David McTiernan, ARRB (Chapter Chair)

- Duncan McRae (Chapter Vice Chair)

- $\quad$ Faisal Magableh, ARRB (Secretary)

- $\quad$ Liz de Rome, Lder Consulting
- $\quad$ Prof. Mike Regan, UNSW

- Robyn Preece, TfNSW

- Prasannah Prabhakharan

We are all looking forward to developing more seminar topics to inform ACRS members about road safety issues and initiatives.

NSW Chapter Chair

Mr David McTiernan

\section{Queensland (QLD)}

Queensland Chapter held the AGM on Tuesday $4^{\text {th }}$ June 2019 at QUT, Kelvin Grove Campus A Block, Room A105 at $1 \mathrm{pm}$ followed by a seminar.

AGM:

Chair - Dr Mark King (CARRS-Q)

Deputy Chair - Simon Kirkpatrick (Gateway Motor

Services)

Secretary/Treasurer - Veronica Baldwin (CARRS-Q)

Committee:

Ms Vyk Le (Queensland Police Service)

Joel Tucker (RACQ)

Associate Professor Ioni Lewis (CARRS-Q)

Professor Barry Watson (CARRS-Q)

Dr Angela Watson (CARRS-Q)

Dr Candice Potter (Department of Transport and Main Roads)

\section{SEMINAR TOPIC:}

Conflicts between healthy development during adolescence, societal norms and young driver road safety.

\section{Presenter:}

Professor Teresa Senserrick, CARRS-Q

Teresa has focused her research on road safety for over 20 years. With her background in developmental psychology, young drivers have been a particular interest group.

Adolescence is a peak period of development, intersecting with the typical age we start to drive, among other challenges on the path to independence. How we manage these developments has implications for the safety of all young drivers, and all of us with whom they share the roads.

QLD Chapter Chair

Dr Mark King 


\section{ACRS News}

\section{AUSTRALIA'S DEPUTY PRIME MINISTER MICHAEL MCCORMACK LOCKED IN TO PRESENT PRESTIGIOUS AWARDS AT ARSC2019 GALA DINNER AND AWARDS}

\begin{abstract}
We are delighted to let you know that Australia's Deputy Prime Minister, Hon Michael McCormack MP, has confirmed his acceptance to participate at ARSC2019, including presentation of the prestigious Australasian College of Road Safety Awards during the ARSC2019 Gala Dinner and Awards.
\end{abstract}

Michael McCormack has been the leader of the National Party and Deputy Prime Minister of Australia since February 2018, and has remained a firm supporter for the work and achievements of the Australasian College of Road Safety, and our members and support networks, over many years. Michael is also Australia's current federal Minister for Infrastructure, Transport and Regional Development, having previously served as Minister for Defence Personnel and Minister for Veterans’ Affairs from 2017 to 2018.

Prior to and during Michael's term as a federal politician he has been actively engaged with road safety stakeholders, and a staunch advocate for road trauma reductions, including being an active participant in the Brasilia 2nd Global High-Level Conference on Road Safety. Readers will remember that during that event, Michael presented the 2015 Australasian Road Safety Conference (ARSC2015) Declaration for Trauma Free Roads to the World Health Organisation

The formal presentation was made by Australia's federal Assistant Minister to the Deputy Prime Minister, Hon Michael McCormack MP, and was attended by ACRS Presdient Mr Lauchlan McIntosh AM, and Austroads Safety Taskforce Chair Mr Iain Cameron.

As Australia's Deputy Prime Minister Michael has remained a strong supporter of the Inquiry into the National Road Safety Strategy, and as such launched the NRSS Inquiry Report at Canberra's Parliament House on 12 September 2018, with bipartisan support from Hon Anthony Albanese MP, the Shadow Minister for Infrastructure and Transport, and other key politicians and stakeholders.

Michael attended the 2018 Australasian Road Safety Conference (ARSC2018) last October and announced a first step in terms of implementing the Report Recommendations, with a National Road Safety Governance Review to take place by March 2019 (Recommendation 6). The Terms of Reference (ToR) for the National Road Safety Governance Review - Recommendation 6 of the Inquiry Report was announced in January 2019.

Michael has been a member of the House of Representatives since 2010, representing the Division of Riverina in New South Wales, and was a newspaper editor before entering politics.

\section{HIGH-PROFILE KEYNOTE SPEAKERS AND PANELLISTS CONFIRMED FOR ARSC2019}

We are delighted to announce our additional recently confirmed high-profile Keynote Speakers and Panellists for ARSC2019:

Hon Micheal McCormack - Deputy Prime Minister \& Minister for Infrastructure and Transport

- Mr Kenneth Svensson - Special Adviser Traffic Safety - Swedish Transport Administration

- $\quad$ Dr Nadia Anderson - Global Public Policy Lead, Road \& Traffic Safety - Uber

- $\quad$ A/P Jeremy Woolley - Director, Centre for Automotive Safety Research, University of Adelaide \& coChair, Inquiry into the Effectiveness of the National Road Safety Strategy 2011-2020

- $\quad$ Ms Christine Thiel - Manager, MACC Marketing \& Road Safety Northern Territory

- Dr Steven Kennedy - Secretary of the Department of Infrastructure, Regional Development and Cities

- $\quad$ Mr Doug Bradbrook MIEAust - Principal Transport Engineer, Mornington Peninsula Shire

- Mr Neil Scales OBE - Director-General, Chief Executive Officer \& Chair, Department of Transport \& Main Roads

- Ms Samantha Cockfield - Transport Accident Commission

- Hon Corey Wingard MP - SA Minister, Police \& Emergency Services Minister

- $\quad$ Mr Nick Koukoulas - Chief Executive of Austroads Ltd

- $\quad$ Mr Christopher Davis - Mildura Rural City Council Road Safety Officer

- $\quad$ Ms Terri-Anne Pettet - Deputy member of the Road Safety Council of WA and Director on the Board of Injury Matters 
- Mr Martin Small-ACRS President

- Mr Shane Ellison - CEO, Auckland Transport

- Mr Rob McInerney - Chief Executive Officer for the International Road Assessment Programme (iRAP)

- Dr Jeff Potter - Chair of the Victorian Chapter of the Australasian College of Road Safety

- Mr David O'Loughlin - President of the Australian Local Government Association

\section{DEPUTY PRIME MINISTER}

MICHAEL MCCORMACK ANNOUNCES COMMENCEMENT OF A FEDERAL OFFICE OF ROAD SAFETY WITHIN THE DEPARTMENT OF INFRASTRUCTURE, TRANSPORT, CITIES AND REGIONAL DEVELOPMENT

"New Office to Accelerate Federal Road Safety Leadership"

The Federal Liberal and Nationals Government's new Office of Road Safety is now operational and will get to work on improving leadership and co-ordination across governments to reduce deaths and serious injuries on the nation's roads.
Deputy Prime Minister and Minister for Infrastructure, Transport and Regional Development Michael McCormack said the Office would initially focus on establishing the functions needed to perform its lead agency role while delivering priority road safety programs.

"The key objective of the Office of Road Safety is to provide national leadership in eliminating road trauma in Australia," Mr McCormack said. "In August, the Transport and Infrastructure Council will consider a range of actions in response to the Inquiry into the National Road Safety Strategy 2011-20, the outcomes of the Governance Review and the initiatives stemming from the Inquiry and the Review. This will be an important input to the longer term role of the Office."

Assistant Minister for Road Safety and Freight Transport Scott Buchholz said the Office would operate as the primary policy adviser to the federal ministers for road safety on delivering safer roads, vehicles, speeds and drivers.

"The Office will draw together interdisciplinary expertise and experience to learn, share and channel effort towards proven approaches to reducing national road trauma," $\mathrm{Mr}$ Buchholz said. "In doing this, it will work collaboratively with counterpart agencies across the states and territories, as well as expert agencies."

The Office will actively seek partnerships to develop and prioritise proposals that achieve these reductions.

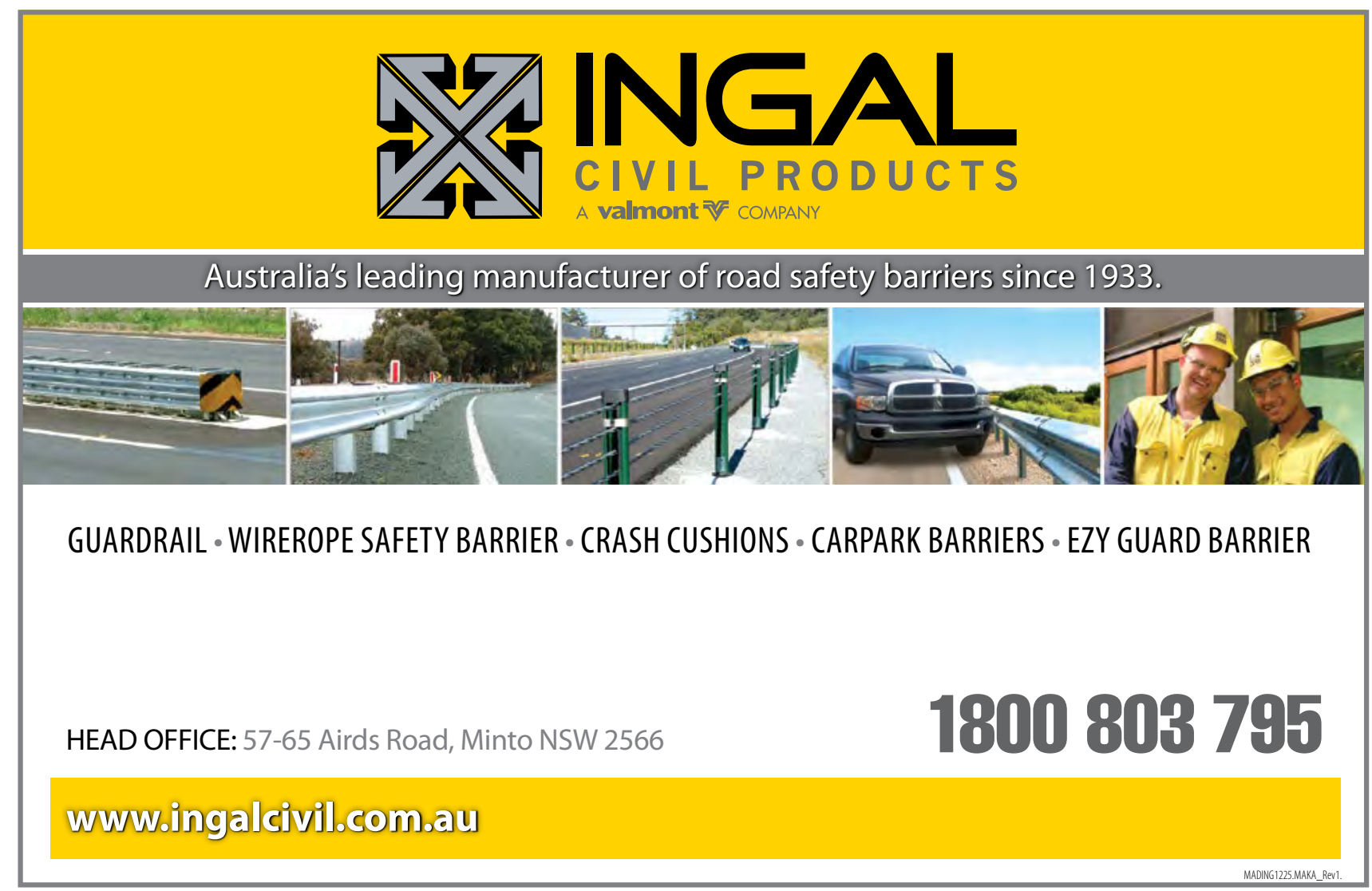




\section{Diary}

13-14 August 2019

8th International Symposium on Naturalistic Driving

Research

https://mailchi.mp/b2fe9d6f5001/ndrs-2019-conferencecall-for-abstracts

Melbourne, Australia

\section{8-21 August 2019}

22nd International Council on Alcohol, Drugs and Traffic Safety Conference

https://t2019.org/

Edmonton, Canada
25-27 September 2019

Australasian Road Safety Conference

http://australasianroadsafetyconference.com.au/

Adelaide, Australia

6-10 October 2019

26th World Road Congress

www.piarcabudhabi2019.org

Abu Dhabi, United Arab Emirates

\section{8-20 Nov 2019}

$8^{\text {th }}$ International Cycling Safety Conference

https://www.icsc2019.com/

Brisbane, Australia 


\section{Peer-reviewed papers}

\section{Original Road Safety Research}

\section{Safety solutions on mixed use urban arterial roads}

Blair Turner ${ }^{1}$, Rob Partridge ${ }^{2}$, Shane Turner ${ }^{2}$, Bruce Corben ${ }^{3}$, Jeremy Woolley ${ }^{4}$, Chris Stokes ${ }^{4}$, Jennifer Oxley ${ }^{5}$, Karen Stephan $^{5}$, Lisa Steinmetz ${ }^{1}$

${ }^{1}$ Australian Road Research Board, Melbourne, Australia

${ }^{2}$ Stantec, Christchurch, New Zealand

${ }^{3}$ Corben Consulting, Melbourne, Australia

${ }^{4}$ Centre for Automotive Safety Research, Adelaide, Australia

${ }^{5}$ Monash University Accident Research Centre, Melbourne, Australia

Corresponding Author: Blair Turner, 80a Turner St, Port Melbourne, Vic 3207, Australia, blair.turner@arrb.com.au, +6139881 1661 .

\section{Key Findings}

- A significant proportion of fatal and serious injury crashes occur on urban arterial roads with a mixed use function

- There are effective infrastructure solutions that when used as part of a comprehensive package can deliver significant safety improvements

- Further innovation and broader application of infrastructure solutions is required to deliver Safe System outcomes, and these need to be supported by other pillars of the Safe System approach

- A clear functional classification for urban roads is needed before substantive improvements can be made on urban arterial roads, and this requires greater levels of community consultation.

\section{Abstract}

Urban arterials and intersections account for a large proportion of high severity crashes in Australia and New Zealand, particularly involving vulnerable road users. Safety gains appear to be slower in these 'mixed use' environments than in other areas. Austroads commissioned research to help identify solutions that might be applied on mixed use arterial roads to improve safety through the provision of Safe System infrastructure.

The project involved assessment of six case studies around Australia and New Zealand. Concept designs were developed for each of the routes based on analysis of safety issues and the likely safety benefits were assessed. This paper presents information on the safety solutions identified, as well as the broader issues that need to be considered when addressing safety on mixed use urban arterial roads.

\section{Keywords}

Safety, urban, arterial, mixed use, crash reduction

\section{Introduction}

Urban arterial roads account for a large proportion of high severity crashes, particularly involving vulnerable road users (Austroads 2015a). In these environments there are often different types of road users mixing and interacting within limited road space. These road users include car drivers, pedestrians, cyclists, motorcyclists, as well as the drivers of commercial vehicles, buses, and other forms of public transport. Safety gains appear to be slower in this mixed use environment than in other areas. For example, the casualty crash rate on arterial strip shopping road segments in metropolitan Melbourne was around 46 per 100 million vehicle kilometres travelled (VKT) (Stephan 2015) compared to an average of 24 per 100 million VKT in urban Melbourne (Jurewicz \& Bennett 2008; note that these crash rates are from different time periods and so are only broadly comparable). Vulnerable road users are often 
highly-represented in these busy urban environments. In the five year period from 2005 to 2009 , the median rate of police-reported crashes on strip shopping road segments was 20.8 crashes per $\mathrm{km}$. More than a quarter $(26.6 \%)$ of the crashes involved pedestrians and almost half of these crashes $(45 \%)$ resulted in a pedestrian death or serious injury. Approximately one-sixth of these police-reported crashes involved cyclists, although the true size of the problem is likely to be underestimated (Stephan 2015).

Austroads commenced this project to help identify safety solutions, particularly those based on infrastructure improvements that might be applied to help achieve Safe System outcomes in these road environment types. The objective of the project was to better understand how the Safe System approach can be applied to mixed use urban arterials. The project used a case study approach to identify solutions that might be applied. Based on workshops, issues relating to safety were explored and safety solutions identified. Full results from this work were published in a report by Austroads (2017), while this paper summarises information on effective treatments as well as broader implementation issues to move towards Safe System objectives on mixed use urban arterial roads.

\section{Methods}

In order to meet the key objectives, the project involved identifying a range of case study sites across Australia and New Zealand. These case study locations were selected following an application process. 36 applications were received, with each evaluated against an assessment criteria. The following six sites were eventually included in the study:

- $\quad$ Grey Street, Hamilton East (New Zealand)

- Glen Huntly Road, Elsternwick (Victoria)

- Unley Road, Unley (South Australia)

- Bondi Road, Bondi Junction (New South Wales)

- Melrose Drive, Woden (Australian Capital Territory)

- $\quad$ York Street, Launceston (Tasmania).

A team of Safe System infrastructure researchers and experts led a series of workshops to identify the issues and challenges at each site, and develop potential initiatives to address these. Participants at these workshops varied, but included road agency staff, public transport providers, pedestrian and cycle groups and local traders. Indicative solutions were developed, and the likely safety benefits estimated. The Safe System Assessment Framework (SSAF) (Austroads 2016a) was used to assess the safety benefits, and more specifically to determine the Safe System alignment of existing locations as well as the concept designs for each of the case study sites. This approach allocates a rating to the key sources of risk (exposure, likelihood and severity) and to the key causes of fatal and serious injury outcomes (run-off-road, head-on, intersections, other - typically rear-end crashes, pedestrians, cyclists and motorcyclists). A total risk score is derived based on this assessment. Although subjective, the assessment provides an indicative level of risk for an infrastructure project. Relative risks for alternative designs can then be compared against current levels of risk.

An estimation of the severe crash reduction benefits for each option was also made using the method outlined in national guidelines (Austroads 2015b). This guidance caters well for simple road safety improvements, and involves an assessment of the baseline situation (i.e. the current situation) in terms of current crash numbers and the costs of these and an estimate of the likely benefits (crash reduction) from the suggested improvements. The process is based on generating a likely crash reduction based on findings from previous research for individual infrastructure treatments. Crash Modification Factors (CMFs) for each treatment were based on a previous review of relevant literature (Austroads 2017).

A second round of workshops was held to discuss the potential solutions and outcomes. Finally, a report was prepared that showcased a number of indicative design examples of how urban arterials could be designed or retrofitted to better achieve Safe System outcomes. Also included was information on the benefits from specific road safety interventions. This information was based on existing literature, including trials conducted in Australia and New Zealand as part of previous Austroads work. As well as these benefits, other key results included process-related guidance for road agencies and others on effective implementation of safety improvements on mixed use arterials. These results are presented in the following section.

\section{Results}

\section{Results for case study locations}

A large number of treatments were used across the six case study locations. These treatments varied for each of the routes based on local conditions and requirements identified during the workshops. However, there were come commonalities between routes. Key treatments included those that helped to manage vehicle speeds. Reduced design speed was considered in each case, and this typically involved lower speed limits (either on a full or parttime basis) supported by infrastructure, including safety platforms, gateway treatments, road narrowing, textured surfacing and additional measures. Other treatments to improve vulnerable road user safety were also considered including pedestrian crossing facilities, and cycle lanes and separated pathways.

In all cases, packages of treatments were seen as necessary to address the road safety issues. Table 1 provides a summary of the most common treatments, and also demonstrates the reliance on treatment packages at each location.

Based on the installation of these and other more minor treatments, it was estimated that fatal and serious injuries would be substantially reduced at the case study locations. Estimates of safety benefits were calculated based on application of the Safe System Assessment Framework 
Table 1. Packages of treatment options for each route

\begin{tabular}{|l|c|c|c|c|c|c|}
\hline & Grey St & $\begin{array}{c}\text { Glen Huntly } \\
\text { Rd }\end{array}$ & Unley Rd & Bondi Rd & Melrose Dr & York St \\
\hline Reduced speed environment & $\checkmark$ & $\checkmark$ & $\checkmark$ & $\checkmark$ & $\checkmark$ & $\checkmark$ \\
\hline Gateway & $\checkmark$ & $\checkmark$ & $\checkmark$ & $\checkmark$ & $\checkmark$ & $\checkmark$ \\
\hline Safety platform & $\checkmark$ & $\checkmark$ & $\checkmark$ & $\checkmark$ & $\checkmark$ & $\checkmark$ \\
\hline Raised pedestrian crossing & $\checkmark$ & & $\checkmark$ & $\checkmark$ & $\checkmark$ \\
\hline Roundabout & $\checkmark$ & $\checkmark$ & $\checkmark$ & $\checkmark$ & $\checkmark$ \\
\hline Narrowing & $\checkmark$ & $\checkmark$ & $\checkmark$ & $\checkmark$ & $\checkmark$ \\
\hline Colour or texture surface & $\checkmark$ & & $\checkmark$ & $\checkmark$ & $\checkmark$ \\
\hline Cycle path & $\checkmark$ & $\checkmark$ & $\checkmark$ & $\checkmark$ & & $\checkmark$ \\
\hline Access management & & & & $\checkmark$ & $\checkmark$ \\
\hline
\end{tabular}

Table 2. Expected fatal and serious injury risk reduction

\begin{tabular}{|l|c|c|c|}
\hline Route & Location & $\begin{array}{c}\text { Expected FSI risk } \\
\text { reduction - all road users }\end{array}$ & $\begin{array}{c}\text { Expected FSI risk } \\
\text { reduction - pedestrians and } \\
\text { cyclists }\end{array}$ \\
\hline Grey Street & Hamilton, New Zealand & $55 \%$ & $75 \%$ \\
\hline Glen Huntly Road & Melbourne, Victoria & $65 \%$ & $55 \%$ \\
\hline Unley Road & Adelaide, South Australia & $65 \%$ & $50 \%$ \\
\hline Bondi Road & Sydney, New South Wales & $40 \%$ & $35 \%$ \\
\hline Melrose Drive & Canberra, ACT & $40 \%$ & $35 \%$ \\
\hline York Street & Launceston, Tasmania & $55 \%$ & $50 \%$ \\
\hline
\end{tabular}

(SSAF; Austroads 2016a) as well as traditional analysis of crash reduction (based on Austroads guidance on the treatment of crash locations; Austroads 2015b). Table 2 provides the results from the SSAF assessment. Figures are rounded to the nearest $5 \%$.

Crash analysis revealed broadly consistent results with expected reductions in fatal and serious injury of between 40 and $75 \%$ for vehicle occupants, and between 50 and $70 \%$ for vulnerable road users.

\section{Results: individual treatments}

This section provides a summary of the most commonly used treatments across the routes, and the likely safety benefits of these. The safety benefits are based on an extensive review of existing literature which is documented in previous Austroads work (Austroads 2017; Austroads 2016b). A summary of the treatments, including a description of the treatment, the Crash Modification Factor (CMF) and an image is provided in Table 3. The CMF is a multiplier that is applied to the number of crashes in the 'before' period to indicate likely crash numbers in the 'after' period (once the treatment has been installed). For instance, if there are 10 crashes in the three year period before the treatment is installed, and the CMF is 0.6 , it could be expected that there would be 6 crashes in the after three year period $(10 \times 0.6=6)$. CMFs generally relate to the safety impact on all road users (i.e. not specific road user groups such as pedestrians) and are typically based on casualty crash reductions i.e. not fatal and serious crash reduction). Although it would be desirable to provide information for specific road user groups, and for impacts on fatal and serious injury outcomes, the evidence base typically does provide this detail.

\section{Results: Other key learnings}

As well as identifying viable safety solutions on mixed use arterial roads, the Austroads project highlighted a number of 'process' issues that need to be addressed when implementing safety improvements in these environment types. This section highlights some of the key learnings relating to implementation of safety improvements in mixed use environments. 
Table 3: Example mixed use arterial treatments

\begin{tabular}{|c|c|c|c|}
\hline Treatment & Brief description & CMF & Image \\
\hline $\begin{array}{l}\text { Raised } \\
\text { intersections }\end{array}$ & $\begin{array}{l}\text { Either the entire intersection is raised, acting as a type } \\
\text { of speed platform, or raised sections can be placed in } \\
\text { advance of the intersection (sometimes referred to as } \\
\text { raised stop bars). }\end{array}$ & 0.60 & \\
\hline Roundabouts & $\begin{array}{l}\text { Intersection control measure implemented in order to } \\
\text { reduce speeds and reduce road user conflict points. }\end{array}$ & 0.25 & \\
\hline $\begin{array}{l}\text { Reduced speed } \\
\text { limit }\end{array}$ & $\begin{array}{l}\text { Involves managing posted speed limits, revising them } \\
\text { towards Safe System levels. }\end{array}$ & 0.75 & \\
\hline Lane narrowing & $\begin{array}{l}\text { Narrowing lane through perceptual and physical measures, } \\
\text { e.g. kerb extensions, wide medians or shoulders. }\end{array}$ & 0.70 & \\
\hline Road diet & $\begin{array}{l}\text { Road narrowing measure typically involving the } \\
\text { conversion of a four-lane road (two each way) into a } \\
\text { road with only one lane in each direction, and a central } \\
\text { two-way right-turn lane. }\end{array}$ & 0.65 & \\
\hline $\begin{array}{l}\text { Humps/ } \\
\text { platforms }\end{array}$ & $\begin{array}{l}\text { Vertical deflection treatments used to control speed, with } \\
\text { various forms of speed humps available for different road } \\
\text { types. }\end{array}$ & 0.60 & \\
\hline Wombat crossings & $\begin{array}{l}\text { Similar profile and speed reduction effect as flat-top speed } \\
\text { humps but differ by giving priority to pedestrians rather } \\
\text { than motorists. }\end{array}$ & 0.60 & \\
\hline $\begin{array}{l}\text { Gateway } \\
\text { treatments }\end{array}$ & $\begin{array}{l}\text { Use of signs with other techniques to create a threshold } \\
\text { or gateway between high and low-speed environments. }\end{array}$ & $\begin{array}{l}\text { Unknown } \\
\text { (up to } 0.60 \\
\text { for rural) }\end{array}$ & \\
\hline
\end{tabular}

Source: Austroads 2017 


\section{Functional Classification/Movement and Place}

A key finding from this study was that assignment of function for roads is critical in planning for safety on urban arterials. This assignment requires a clear understanding around the intended use of routes within the broader urban context. This includes the need to identify different road user groups as well as time of day, day of week and seasonal considerations. It also requires agreement from all of the key stakeholders, including governmental, political and public endorsement. Tools have been developed to assist in this engagement task, including the movement and place framework (Austroads 2016c). This framework can assist with identifying options that best meet and balance strategic objectives. This includes graphical representation of different scenarios to highlight the implications for different decisions relating to road use.

Until the function has been decided and agreed upon by stakeholders, it is difficult to firm up speed and infrastructure requirements. This was clearly demonstrated at a number of the case study locations. In those cases where there had been agreement around function (or at least where these discussions have been had) there was a greater ability to seek transformational solutions. Conversely, it was clear in other locations that there was no such agreement and that the priority for competing road user types had not been set. In these cases the capacity for substantial change was far more limited, and agreement only possible on minor improvement programs. A more detailed discussion on this important issue, including gaps in knowledge, is provided in Turner et al. (2018).

\section{Processes for Assessment of Risk}

Crash data formed a basis for the assessment of risk for most of the case study locations. This is a key source of information relating to safety performance. In some cases this source of information on its own is adequate to help assess risk. These cases exhibit substantial crash numbers and clear crash patterns. However, it is typically the case that additional information is required to determine the full extent of risk. This is because crash locations remain scattered. Crashes can occur at locations where no previous crashes have occurred, and so a complete reliance on crash data alone is not sufficient. In addition, many of the routes assessed were facing substantial changes in traffic use and roadside development. For example, some routes were experiencing increases in residential development. It could be expected that in future the number of vulnerable road users would increase, and therefore the risk profile is likely to change.

It is also important to recognise the need for assessment of systemic risk as opposed to relying on risk assessment at specific locations. Crash risk is at elevated levels for much of the route in these mixed use urban environments, especially for unprotected road users. It is therefore important that sustainable, holistic treatments be applied that deliver Safe System outcomes on a route basis.
For this project, the SSAF was used to assess risk in a proactive manner. As highlighted, this allows an assessment of potential risks for different road user groups, including pedestrians, cyclists and motorcyclists. As indicated previously, ratings within this tool are quantitative but subjective, but provide a broad indication of risk. Other tools exist to allow proactive assessment (e.g. the Australian National Risk Assessment Model or ANRAM). The outcome from these assessments is a better understanding of where potential fatal and serious injury risks lie on the network. This allows better targeting of interventions to address not only the types of crashes that may have occurred previously, but also those that are likely to happen in the future.

\section{Safety Benefits of Solutions and Residual Risk}

As identified above, reductions in risk of fatal or serious injury crashes were likely to be substantial for each of the case study locations. However, despite the comprehensive safety improvements suggested for each of the sites, and the significant improvements expected, it is clear that the maximum benefit that can be obtained from the provision of infrastructure alone in these types of environments is up to around a $60 \%$ reduction in fatal and serious injury, with an indicative maximum of $75 \%$ reduction for pedestrians and cyclists at one site. This still leaves substantial residual risk of fatal and serious injury crashes.

Consideration should be given to this residual risk. Where possible, more substantive interventions may be required. However, it is clear that combinations of speed management and supporting infrastructure solutions alone will not typically lead to the complete elimination of death and serious injury, and this is consistent with Safe System thinking, where a broader systems approach across multiple pillars is required. Vehicle-based safety improvements are likely to provide substantial benefits into the future in these mixed use environments (e.g. pedestrian and cyclist warning, and braking systems), although it should be recognised that full implementation across the whole vehicle fleet is still some time off. Post-crash care improvements (e.g. increased community training in first aid, and faster access to specialist trauma care) may also contribute to reductions in fatal and serious injury outcomes.

\section{Impact on Traffic Operations}

Detailed modelling of the impact of treatments on traffic was outside the scope of the study. However, in most cases there is existing evidence to help understand the impact of different treatments on traffic operations. The impact on traffic operations from some of these interventions can be significant, however, this is often the intention. There may be a need to change the function of a road based on broader network objectives, and therefore change the priority for different road user groups. This may include the need to reduce the amount or type of motorised traffic entering the route, and/or the speed of traffic to give higher priority to vulnerable road users. In other cases, vulnerable road users may be redirected to alternative paths and greater priority 
given to the movement of motorised traffic. This highlights the importance of understanding vehicle mix/classification on routes and the surrounding network. In several of the case studies there was a demand to reduce traffic volumes along the route. The approach to meeting this demand included reductions in speed (e.g. lower speed limits supported by infrastructure such as safety platforms) and reduced traffic lanes (e.g. using a road diet). However, overseas and local experience has shown that such measures can be used while also maintaining current levels of traffic (Gordon 2011). Care should be taken so as not to displace traffic on to collector or local roads, but rather on to alternative routes with a more defined arterial traffic function.

\section{Synergies}

Although the focus of this project was on improving safety outcomes, there were other benefits that would derive from the designs. Synergistic benefits include a better environment to support active travel modes (walking and cycling), and this would have the dual benefit of reducing traffic as well as potential population health improvements. Other benefits from well-executed designs include increased social connection, improved liveability and greater vibrancy of the area. These in turn bring other social benefits including improved health and wellbeing and increased economic activity through support for local businesses. Although the evidence base is less well documented for these elements, there are likely benefits deriving from these areas. It would be useful that in future, information is collected to assess and quantify such benefits.

\section{Consultation}

As already indicated, a variety of stakeholders attended the workshops for each case study location. This included road agency staff (local government and state/territory) from planning, design, safety, and traffic management teams. In some cases, experts from other departments also attended (e.g. sustainable travel modes). There was also input from public transport agencies, pedestrian and cycle groups, and local traders. Road agency representation varied greatly between workshops. In some cases there was a strong representation from road safety and traffic management personnel, and less input from planners. At others, the workshops comprised predominantly planners. This seemed to matter less than the amount of groundwork and prior consultation that had been undertaken. It was very apparent that the most productive discussions were in locations where strategic planning had been undertaken, and there was a firm agreement on the form and function of the route. A number of locations had undertaken this prior to the workshops. This planning took the form of Masterplans, Network Operating Plans or Road Planning Framework. In others, this discussion had not been undertaken or no firm decision or agreement had been reached. In these cases there was much less consensus about the desired nature of the route, and therefore what infrastructure might be appropriate to meet the needs of all road users.
One positive by-product from this project was increased levels of engagement between key stakeholders. In many cases it was clear that the stakeholders had not recently met to address common issues. Discussion on case study locations provided a very useful opportunity to bring stakeholders together and address not only issues at the specific sites, but also broader transport-related issues.

\section{Conclusions and recommendations}

A significant proportion of fatal and serious injury crashes occur on urban arterial roads. Mixed use arterials (where there are different types of road users including motorised and non-motorised) are particularly high risk. This paper provides a synthesis of key safety solutions as well as issues that need to be considered when effectively addressing safety on urban mixed use arterial routes.

Given the mix of road users, a reduced speed environment was suggested for each case study locations, and this typically involved lower speed limits (either on a full or part-time basis) supported by infrastructure, including safety platforms, gateway treatments, road narrowing, textured surfacing and additional measures. Other treatments were also seen as necessary to improve vulnerable road user safety. Solutions included road narrowing, pedestrian crossing facilities, and cycle lanes and separated pathways. In each case, packages of treatments were suggested to provide comprehensive, route-based improvements. Individual treatments can bring about significant safety benefits (as indicated in Table 3), but greater benefits are likely, particularly over routes, when compatible combinations are used. It is recommended that greater use be made of these packages of treatments to help achieve significant safety improvements on mixed use arterials. One difficulty when applying packages of treatments is understanding the combined benefits of the treatments. Sometimes the different treatments act independently and address different crash risks while in other situations the treatments may act together to give a greater overall benefit. Some advice on how to calculate crash reductions for multiple treatments is provided in Austroads (2015b).

Although the proposed designs were not constructed as part of the Austroads project, estimates were made regarding the likely safety benefits. These were substantial, typically producing an estimated $60 \%$ reduction in fatal and serious injury crashes. However, it is clear that despite the significant improvements, the reductions fall short of Safe System objectives to completely eliminate death and serious injury. In many cases the benefits were variable for different road user groups, with vulnerable road users the most difficult group to treat. More substantive and innovative infrastructure solutions are required, as well as contributions from other Safe System pillars (particularly improved vehicle technologies).

In terms of implementation, a key recommendation is that formal assessment of routes be undertaken to determine and agree desired function by key governmental, political and public stakeholders. Without agreement on function, it is very difficult to make substantive safety improvements. 
However, once function is agreed, the appropriate design can be achieved more easily, and conflicts between safety and mobility are removed (see Turner et al. 2018 for a detailed discussion on this).

Related to this issue of functional definition is the need for greater consultation, and a community-based strategic approach to defining urban road hierarchies. Greater community dialog and agreement is required to facilitate the changes required to improve not only safety on these road networks, but also issues such as social connection, liveability, and population health and wellbeing. Road agencies are encouraged to share good practice around successful community engagement strategies, as well as on effective infrastructure improvements.

There are a number of limitations to this study. The information provided on treatment effectiveness (FSI reductions) for each of the locations is based on an estimate, and not from evaluation of actual crash reductions. A Safe System Assessment was undertaken which by its nature is a subjective measure of risk reduction. This was supported by information on likely crash reduction for different individual treatments, which are combined to produce an overall estimate for each location. Errors can occur in deriving estimates for individual treatments, as well as when combining these treatments for each route. There is a scarcity of information on the impact of packages of treatments, and it is recommended that future evaluations be undertaken and information disseminated. In addition, the packages of treatments were included in concept designs, and have yet to be implemented. Further learning from this implementation phase is required to validate some of the conclusions from this study.

\section{Acknowledgements}

The authors would like to acknowledge the involvement of participants at workshops for each of the six case studies. Input by representatives of various Austroads Task Forces in the direction of the project and production of this report is also greatly appreciated.

\section{References}

Austroads (2015a), Road fatalities and serious injuries in Australia and New Zealand 2001-10, AP-R478-15, Austroads, Sydney, NSW.

Austroads (2015b), Guide to road safety: part 8: treatment of crash locations, $2^{\text {nd }}$ edn, AGRS08-15, Austroads, Sydney, NSW.

Austroads (2016a), Safe system assessment framework, AP-R50916, Austroads, Sydney, NSW.

Austroads (2016b), Achieving safe system speeds on urban arterial roads: compendium of good practice, AP-R514-16, Austroads, Sydney, NSW.

Austroads (2016c), Guide to traffic management: part 4: network management, $4^{\text {th }}$ edn, AGTM04-16, Austroads, Sydney, NSW.

Austroads (2017), Safe System Infrastructure on Mixed Use Arterials, Austroads Sydney, Australia.

Gordon, G (2011), Mixed priority routes: results update and cost review, Department for Transport, London, UK

Jurewicz, C \& Bennett, P (2008), 'Casualty crash rates for Australian jurisdictions', Australasian road safety research policing education conference, Adelaide, South Australia, Department for Transport, Walkerville, SA, $24 \mathrm{pp}$.

Stephan, K. L. (2015). 'A multidisciplinary investigation of the influence of the built urban environment on driver behaviour and traffic crash risk', PhD thesis, Monash University, retrieved from https://doi.org/10.4225/03/58b78d6fea3f1

Turner, B, Steinmetz, L, Han, C \& Espada, I, (2018), Linking mobility and safety - Building on the mixed use arterials project. 28th ARRB International Conference - Next Generation Connectivity, Brisbane, Queensland, Australia. 


\title{
For whom didn't it click? A study of the non-use of seat belts in motor vehicle fatalities in New Zealand
}

\author{
Lily Hirsch ${ }^{1}$, Hamish Mackie ${ }^{1}$, Richard Scott $^{1}$, John de Pont ${ }^{2}$, Simon Douglas ${ }^{3}$, and Dylan Thomsen ${ }^{3}$ \\ ${ }^{1}$ Mackie Research, Auckland, New Zealand \\ ${ }^{2}$ TERNZ, Auckland, New Zealand \\ ${ }^{3}$ AA Research Foundation, Wellington, New Zealand
}

Corresponding Author: Lily Hirsch, PO Box 106525, Auckland City, Auckland, 1143, New Zealand, lily@mackieresearch.co.nz, +6493947040

\section{Key Findings}

- Seat belts substantially reduce the likelihood of injury or death in a crash

- In New Zealand, between 2006-2016, vehicle occupant fatalities where a seat belt was not worn accounted for 19-30\% of the total road fatalities

- The research identified five occupant profiles for people who did not wear a seat belt and died on New Zealand's roads

- The development of profiles can lead to better-targeted safety initiatives

\begin{abstract}
There is an increased risk of death or serious injury for occupants who did not wear a seat belt in a crash. In New Zealand, between 2006 and 2016, the non-use of seat belts accounted for 19-30\% of the overall motor vehicle road deaths, and this figure shows no sign of decreasing. It is important to better understand the contextual factors associated with crashes where seat belts are not worn, so that more relevant and effective road safety interventions can be designed and implemented. The aim of this research was to determine the profiles for seat belt non-users who were killed in motor vehicle crashes in New Zealand between 2011 and 2015. An in-depth analysis of 200 fatalities where seat belts were not worn (186 crash cases) was carried out following a Safe System framework, using NZ Police reports. Following this, a Multiple Correspondence Analysis (MCA) developed five profiles of vehicle occupants who were killed in crashes where seat belts were not worn. While the stereotypical 'young risky' males were an important group, a range of other people and contexts emerged: 'driving for work'; 'elderly and retired'; 'overseas passengers'; and 'people driving in rural settings'. This has implications for tailored road safety interventions, as a variety of motivations and influences are likely to be at play, depending on the people involved.
\end{abstract}

\section{Keywords}

Seat belt non-use, crash analysis, Safe System, profile development

\section{Introduction}

It has been well documented that in a crash, occupants who wear seat belts are less likely to experience serious injury or fatal outcomes (Fildes et al., 2003; de Pont, 2016; Han, 2017). Seat belts protect vehicle occupants from crash forces by retaining them in their seat during a crash, limiting their movement, and managing the energy transmitted (World Health Organisation, 2009; Road Safety Observatory, 2013). For front seat drivers and passengers, seat belt use reduces fatal and non-fatal crash injuries by between 40-60\% (Høye, 2016; World Health Organisation, 2016). Likewise, for rear seat passengers, seat belt use reduces fatality risk by between 25-75\% (World Health Organisation, 2016), and also dramatically reduces fatality risk for front occupants (Bose et al., 2013; Høye 2016).

In New Zealand, wearing a seat belt has been mandatory for vehicle occupants since 1989. Surveys of vehicle occupants generally show a high rate of compliance with these laws. In
2014 , seat belt usage rates in the front seats were $97.1 \%$ and $92 \%$ for people seated in the rear. However, in 2016, front seat usage rates dropped to $96.5 \%$ (Ministry of Transport, 2014; Ministry of Transport, 2016). These wearing rates may not be representative of the entire New Zealand population, however they are the most comprehensive rates available.

Between 2006 and 2016, fatalities where people were not wearing a seat belt annually accounted for $19-30 \%$ of the overall motor vehicle occupant road deaths. Over this period, the proportion of these fatalities has fluctuated but in 2015 and 2016 seat belt non-use fatalities were at their highest, accounting for $29-30 \%$ of all motor vehicle road deaths (New Zealand Transport Agency, 2017). Note that these figures were produced from a database query. The number is likely to be an under-estimate of the true figures as there are were several "unknown" entries under the "seat belt wearing' option. 
Many variables associated with the non-use of seat belts, both in New Zealand and internationally are well understood. For example: males are more likely to die in crashes whilst not wearing a seat belt than women (Palamara et al., 2009; Romano \& Voas, 2011); drivers aged 75 and older are most likely to wear a seat belt (Romano \& Voas, 2011), whilst drivers in their late teens and early 20s are least likely to wear a seat belt (Eluru \& Bhat, 2007; Alver et al., 2014); and seat belt usage can be understood as an equity issue, with usage rates being lower among people with fewer academic qualifications (Begg \& Langley, 2000; Demirer, Durat \& Haşimoğlu, 2012), and lower among people from marginalised and minority ethnic backgrounds (Raftery \& Wundersitz, 2011; Shin et al., 1999).

Whilst there is some understanding of 'why' people do not wear seat belts, mostly this information is understood as individual variables only. For example: there is a link between seat belt enforcement laws and wearing rates (Shults et al., 2016; Bhat et al., 2012); for some people, the discomfort of wearing, or the difficulty of fastening a seat belt may result in non-use particularly by those aged over 75 years, people who are obese, and people who experience arthritis (Fong et al., 2016; Begg \& Langley, 2012). Finally, the influence and attitudes of other people in the vehicle and a person's perceptions of the riskiness of a journey can affect the 'decision policy' to wear or not to wear a seat belt (Alattar et al., 2016).

The way in which factors associated with the non-use of seatbelts interrelate is less well understood. This is an important gap in the research as the complexity of humans means that the isolated study of one variable will result in a full picture. Therefore, understanding this interrelationship of variables will give a fuller picture of the 'profiles' of people who did not wear seat belts and who were killed in road crashes. This clearer understanding of 'who' does not wear seat belts can lead to better and more informed research to establish 'why' particular user groups do not wear seat belts.

\section{Aim}

In the New Zealand context, the fact that these potentially preventable deaths are not decreasing is an issue worthy of investigation. The aim of this research was to understand common contextual factors associated with seat belt nonuse fatalities for people aged fifteen years and over in New Zealand, and in doing so develop profiles of seat belt nonuser types. This may lead to the design and implementation of more relevant and effective road safety interventions.

\section{Methods}

The goal for the analysis was to understand the context relating to fatalities where seat belts had not been worn. To achieve this, the method was divided into two parts: 1) a crash analysis of seat belt non-use fatalities in New Zealand using a Safe System framework; and 2) the development of occupant profiles through MCA.

\section{Data}

In New Zealand, between 2011-2015 there were 290 crash cases where at least one fatally injured vehicle occupant was not wearing a seat belt (New Zealand Transport Agency, 2017). Data from New Zealand's Crash Analysis System (CAS) database in the form of Traffic Crash Reports (TCRs) and Serious Crash Unit (SCU) reports produced by NZ Police were retrieved. Traffic crash reports are completed by police officers at the scene of all road crashes. They record the details of where, when, how and why the crash happened. For fatal crashes, the Serious Crash Unit conducts an in-depth investigation of the crash case to ensure all causative factors are identified. These reports include witness statements, blood analyses, photographs, and details of the condition of the road and vehicle. Although serious injury cases are relevant to this field of research, they were excluded from this study because the detail provided in serious injury crash reports (TCR reports only) was not sufficient.

\section{Empirical Analysis}

Criteria were developed which excluded 76 crash cases. The criteria were: crashes involving a bus, tractor, or vehicles where seat belts are not required; cases where people travelled out of the vehicle i.e. the tray of a ute; crashes not occurring on a public road; and unrestrained, or incorrectly restrained children aged under 15 years. Of the remaining crash list, each fatality was assigned a randomly generated number using the MS Excel RAND function. These were then sorted from the smallest to largest number and the first 200 fatalities (186 crashes) were analysed for this study.

The TCR and SCU reports were coded into 53 nominal and 10 continuous variables by a single analyst following a Safe System framework which acknowledged that fatal crashes happen when a range of system failures occur (Larsson \& Tingvall, 2013; New Zealand Government \& National Road Safety Committee, 2016). Each fatality case was examined using variables relating to the four Safe System Pillars: Speed; Roads and Roadsides; Vehicles; and Users (New Zealand Government, \& National Road Safety Committee, 2016). As the aim of the research was ultimately to understand occupant behaviour in relation to seat belt use, the user pillar was investigated in-depth, whereas the other pillars were more superficially explored. To ensure coding rigour, ten 'test' cases were initially coded by the analyst, then separately by the first author. There was a strong level of agreement, which is understandable given that the exercise mostly involved identifying data, rather than subjective coding.

\section{Statistical Analysis}

Whilst the involvement of many individual factors in seat belt non-use crashes are well known, the combination and pattern in which these factors present are less well understood. In the R statistics programme and FactomineR add-in package (Husson et al., 2014; Das et al., 2018), a Multiple Correspondence Analysis (MCA) was conducted 
Table 1. Variables for the Multiple Correspondence Analysis

\begin{tabular}{|c|c|}
\hline Variable & Categories \\
\hline Time & Evening; Middle of day; Middle of night; Morning \\
\hline Vehicle age (years) & $1-7 ; 8-14 ; 15-21 ; 22+$ \\
\hline Intended trip duration & Long; Short; Unknown \\
\hline Crash location & Urban; rural \\
\hline Journey purpose & $\begin{array}{l}\text { Driving after drinking (pub) driving after drinking (party); evading police; joy ride; } \\
\text { possible suicide; recreation; tourism; utility trip; driving for work; unknown }\end{array}$ \\
\hline Previous driving offences & Yes/ no/ unknown \\
\hline Kilometers over the speed limit & $\begin{array}{l}0 \mathrm{~km} / \mathrm{h} ; 10 \mathrm{~km} / \mathrm{h} ; 20 \mathrm{~km} / \mathrm{h} ; 30 \mathrm{~km} / \mathrm{h} ; 40 \mathrm{~km} / \mathrm{h} ; 50 \mathrm{~km} / \mathrm{h} ; 60 \mathrm{~km} / \mathrm{h} ; 70 \mathrm{~km} / \mathrm{h} ; 80 \mathrm{~km} / \mathrm{h} \text {; } \\
90 \mathrm{~km} / \mathrm{h} \text {; unknown }\end{array}$ \\
\hline Location in vehicle & Driver; passenger \\
\hline Drugs present & Yes/ no/ unknown \\
\hline $\begin{array}{l}\text { Evidence victim was a habitual } \\
\text { seat belt non-user }\end{array}$ & Yes/ no/ suspected \\
\hline Heightened emotional state & Yes/ no \\
\hline Vehicle type & 4WD/SUV; car; rental; ute; van; truck \\
\hline $\mathrm{WoF} / \mathrm{CoF}^{1}$ & Yes; No \\
\hline Victim age (bands) & $16-25 ; 26-35 ; 36-45 ; 46-55 ; 56-65 ; 66-75 ; 76+$ \\
\hline Victim gender & Male; female \\
\hline Occupation & $\begin{array}{l}\text { Technicians and trades workers; community and personal service workers; sales } \\
\text { workers; machinery operators and drivers; labourers; beneficiary; retired; student; } \\
\text { unemployed; unknown }\end{array}$ \\
\hline Victim ethnicity & Pākehā²; Māori; Asian; Pasifika \\
\hline Driver's licence type & $\begin{array}{l}\text { Disqualified/ suspended/ forbidden; expired; unlicenced; full; lerner; restricted; } \\
\text { overseas }\end{array}$ \\
\hline Alcohol present & Yes/ no \\
\hline Evidence of fatigue & Yes/ no/ unknown \\
\hline $\begin{array}{l}\text { Medical condition or event } \\
\text { leading to the crash }\end{array}$ & Yes/ no/ unknown \\
\hline
\end{tabular}

${ }^{1}$ A regular vehicle check in New Zealand to ensure that the vehicle meets specific safety standards. Warrant of Fitness (WoF) or Certificate of Fitness (CoF).

${ }^{2}$ New Zealanders of European descent.

on 21 of the variables coded from the 200 fatality cases (Table 1). MCA is an extension of correspondence analysis (CA) because of its applicability to explore the association between a large set of categorical variables rather than ordinal data. Through its proximity mapping, MCA helps to reveal the main features from a multi-dimensional dataset (Das et al., 2018), analyse the correlations between the category variables, and develop new composite variables which are combinations of the category variables and are independent of each other. The MCA analysis was used as pre-processor for a Euclidean cluster analysis which identified groups of individuals close to each other in terms of composite variables. The aim was to detect and represent the underlying relationships between variables and thereby identify clusters or 'profiles' of individual fatality cases with similar characteristics.
Most of the variables in the database were nominal categorical variables, for example, the vehicle type can be "car", "truck", "van" etc. Some variables such as victim age, vehicle age, and $\mathrm{km} / \mathrm{h}$ travelling over the speed limit were continuous numerical variables and these were converted into category variables as shown in Table 1.

Finally, a probability sampling method through the generation of a random number applied to each fatality case was conducted. The random numbers were sorted from smallest to largest and the first 10 cases were selected. A manual 'sensemaking' check was conducted to validate that each case was best suited to the cluster or 'profile' derived through the MCA. This process returned full agreement and no further checking was conducted. 


\section{Results}

\section{Empirical Results}

\section{User factors}

The empirical analysis identified that fatally injured seat belt non-users were predominantly male, representing $75 \%$ of victims (Figure 1). For both males and females, those aged 15-24 were more strongly associated with seat belt non-use fatalities than people aged 25 years or over. For women, the age group 15-19 was overrepresented in fatality cases with 13 cases, or $26.5 \%$ of all female cases in the study. In 12 of these cases the deceased was a passenger in a vehicle and in 10 of these cases the driver was a young male (average age 21.5 years).

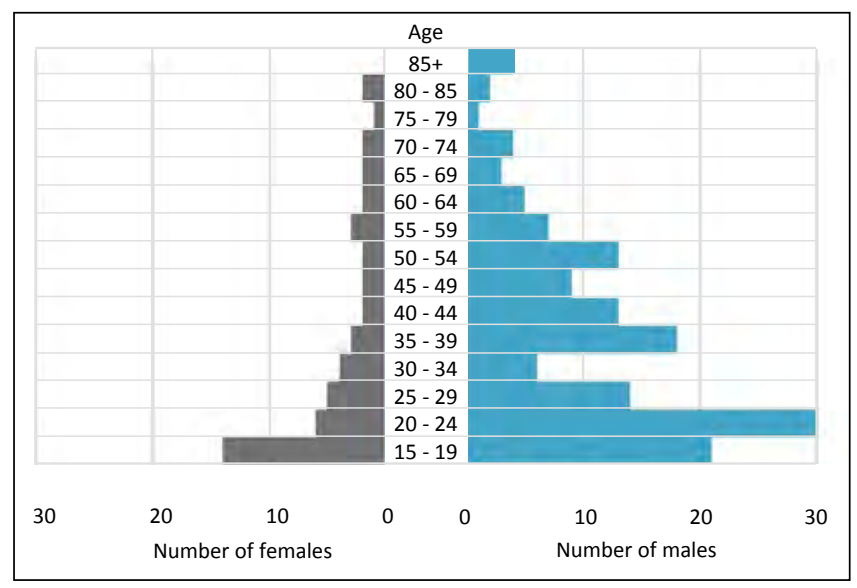

Figure 1. Age and gender profile of seat belt non-use victims

A summary of how the key variables coded under the User Pillar, were associated with fatalities and crashes is presented in Table 2.

Of those fatality cases where alcohol was involved $(n=107$ fatalities, $n=95$ crashes), in $95 \%$ of the crash cases the driver's blood alcohol content was over the legal driving limit of 50mg per $100 \mathrm{ml}$. In $38 \%(\mathrm{n}=36)$ of alcohol-involved crash cases, the driver's blood alcohol was more than $200 \mathrm{mg}$ per $100 \mathrm{ml}$. Alcohol-involved fatalities were typified with the journey purpose being driving home from a party or the pub $(n=64)$, and utility trips $(n=26)$.

Through interviews and witness statements, the Police reports identified that in 4 cases the victim usually wore a seat belt but had not worn it on that occasion. In 31 cases the fatally injured victims were described as habitual non-wearers of seat belts and 9 victims were described as part-time non-users of seat belts. Some witness statements elaborated on the reasons for the habitual or part-time non-use which included: frequent stops; short trip duration; difficult to fasten; more people in the vehicle than seat belts; physical discomfort; others were not wearing them.

\section{Time of day}

Two thirds $(n=122)$ of the crashes occurred during dusk or after dark, with the modal time occurring between $11 \mathrm{pm}$ and $2 \mathrm{am}(24.7 \%, \mathrm{n}=46)$. These late-night crashes were more associated with multiple fatality outcomes. This pattern is counter to normal travel patterns which have a peak demand in the morning and afternoon. Only $4.3 \%(n=8)$ of the crashes happened during the regular commuting hours of 8-9am and 5-6pm.

\section{Roads and Roadsides and Speed Environment factors}

A summary of the location of crashes, and the surface condition of the road at the time of the crash is presented in Table 3.

In New Zealand, speed limits are default $50 \mathrm{~km} / \mathrm{h}$ in urban areas and $100 \mathrm{~km} / \mathrm{h}$ on rural or open roads unless stated otherwise. Therefore, it is logical that these speed limits were represented in $88 \%$ of crash cases. Vehicles in areas with a posted speed limit of $100 \mathrm{~km} / \mathrm{h}$ were involved in 137 crash cases and 150 fatalities. Fewer cases were reported in $50 \mathrm{~km} / \mathrm{h}$ zones, with 27 crash cases and 28 fatalities.

\section{Vehicle factors}

A summary of vehicle factors recorded from the crash reports is presented in Table 4.

\section{Statistical Results}

The MCA analysis revealed five profiles of people who did not wear seat belts and who were fatally injured in crashes: 'young and risky'; 'driving for work'; 'elderly and retired'; 'overseas passengers'; and 'people driving in rural settings'. Every one of the 200 victims was ascribed to one and only one profile. Because the profiles show the best fit of the occupant groups, they are not equally populated. The five profiles have been retrospectively named based on the pattern of variables that they represent.

\section{Young and risky}

This profile comprised $28 \%(n=56)$ of the study's sample. Within this profile, 46 victims were male, 39 were aged between 15-25 years, and 14 were aged between 26 and 40 years. People whose ethnic background was Māori or Pasifika represented 35 fatalities, with the remaining being Pākehā. In 18 of the fatalities the driver was either unlicensed, had their licence suspended, or held an illegal licence, and in 24 cases the driver was reported to have had previous driving offences. Vehicles associated with these crashes were predominated by older vehicles of more than 14 years of age $(n=46)$.

The behavioural characteristics of members of this profile leading up to the crash were associated with inherently risky behaviours. These included: high speeds - in 41 cases, vehicle speed prior to the crash was more than $20 \mathrm{~km} / \mathrm{h}$ over the speed limit; alcohol involvement - for 32 fatalities, alcohol readings were more than $100 \mathrm{mg}$ per $100 \mathrm{ml}$ of 
Table 2. User Pillar empirical resuls for dichotomous and polychotomous variables by fatality and crash cases

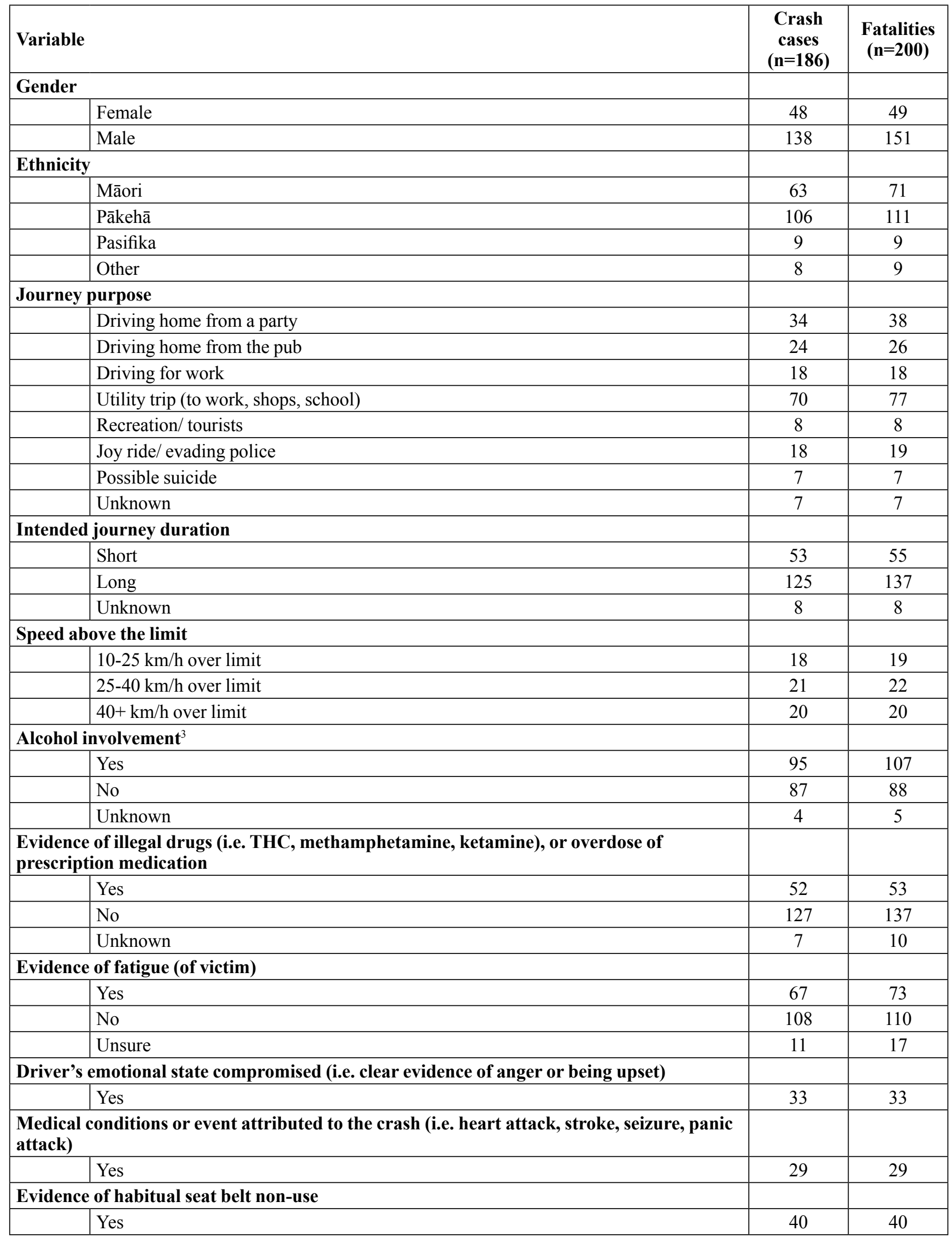

${ }^{3}$ In fatal crashes, there can sometimes be a delay of hours or days before the victims are found, or before blood is taken for testing, so in some cases, the degree of alcohol-involvement may be uncertain. 
Table 3. Roads and Roadsides Pillar empirical results for dichotomous and polychotomous variables by fatality and crash cases

\begin{tabular}{|l|l|l|l|}
\hline \multicolumn{2}{|l|}{ Variable } & $\begin{array}{l}\text { Crash } \\
\text { cases } \\
(\mathbf{n = 1 8 6})\end{array}$ & $\begin{array}{l}\text { Fatalities } \\
(\mathbf{n = 2 0 0})\end{array}$ \\
\hline \multicolumn{2}{|l|}{ Road surface condition } & & \\
\hline & Dry & 132 & 139 \\
\hline & Wet & 50 & 54 \\
\hline & Icy & 3 & 6 \\
\hline & Unknown & 1 & 1 \\
\hline Location & & Rural roads & \\
\hline & Urban roads & 152 & 165 \\
\hline & Mid-block & 34 & 35 \\
\hline & Intersection & 169 & 183 \\
\hline
\end{tabular}

${ }^{4}$ For the purposes of this research, the definitions of 'urban' and 'rural' were based on images from the crash location. An urban area was classified as having a high density of buildings, and urban motorways were also included. A rural area included farmland, forest, and/or a low density of buildings. Speed was not used to identify a rural versus urban location as the measurement is too crude (complicating factors can include urban motorways and temporary speed restrictions on rural roads).

blood alcohol; drug involvement - in 18 cases THC and/ or methamphetamine were identified in the victim's system; and a risky journey purpose - such as 18 cases of 'driving home from a party or the pub', and 19 cases of 'evading police' or 'joy ride'. In addition, in 23 cases there was evidence of unbalanced emotional state including suicidal tendencies and anger.

\section{Driving for work}

This category comprised $10 \%(n=20)$ of the total sample used in this study, 19 of whom were male. They were typified by their journey purpose which was driving a vehicle for work. Trucks and vans were the predominant vehicles, and the majority $(n=18)$ of drivers were travelling within the speed limit and had their full license $(n=16)$.

\section{Elderly and retired}

A total of $6 \%(n=12)$ of the sample used in this study formed this category. Two were aged between 66 and 75 years and ten were aged 76 years or over. All occupants were retired, none were speeding, eleven had a full license, and ten were Pākehā. Medical conditions which were acknowledged in the SCU reports as likely contributing factors to the crash were identified in eleven cases. These included seizures, strokes, and suicidal tendencies.
Table 4. Vehicle Pillar empirical results for dichotomous and polychotomous variables by fatality and crash cases

\begin{tabular}{|c|c|c|}
\hline Variable & $\begin{array}{c}\text { Crash } \\
\text { cases } \\
(n=186)\end{array}$ & $\begin{array}{c}\text { Fatalities } \\
(n=200)\end{array}$ \\
\hline \multicolumn{3}{|l|}{ Vehicle Age } \\
\hline 14 or under & 56 & 58 \\
\hline 15 or over & 130 & 142 \\
\hline \multicolumn{3}{|l|}{ Vehicle Type } \\
\hline Passenger sedan & 114 & 121 \\
\hline $4 \times 4 / \operatorname{van} / \mathrm{SUV}$ & 62 & 69 \\
\hline Truck & 10 & 10 \\
\hline \multicolumn{3}{|l|}{$\begin{array}{l}\text { Current Warrant or } \\
\text { Certificate of Fitness? }\end{array}$} \\
\hline Yes & 143 & 153 \\
\hline No & 43 & 47 \\
\hline \multicolumn{3}{|l|}{ Did the vehicle roll? } \\
\hline Yes & 84 & 90 \\
\hline No & 102 & 110 \\
\hline \multicolumn{3}{|l|}{ Vehicle safety systems } \\
\hline Front airbags present & 65 & 69 \\
\hline Side airbags present & 14 & 14 \\
\hline $\begin{array}{l}\text { Seat belt reminder } \\
\text { present }\end{array}$ & 17 & 17 \\
\hline
\end{tabular}

\section{Overseas passengers}

This was a reasonably small group, but an important group when considering the safety outcomes of tourists in New Zealand. The group comprised $4.5 \%(n=7)$ of the study's sample and consisted of people who were visiting New Zealand. Six of the group were female and four were of Asian descent. All members of this cohort were passengers in vehicles where a long journey had been planned and many were asleep across the rear seats when the crash occurred.

\section{People driving in rural settings}

This large group comprising $52.5 \%(n=105)$ of the sample all crashed in rural settings. Most $(n=83)$ had been planning a long trip and all vehicles were light vehicles such as passenger sedans $(n=56)$ and 4-wheel drives, vans, or utes $(n=49)$. The presence of drugs and alcohol was $10 \%$ higher in this cohort than the overall sample, with 70 cases involving alcohol, and 29 cases involving illegal, or abused prescription drugs. 


\section{Discussion}

This research furthered the understanding of seat belt nonuse crashes in the New Zealand context by identifying how patterns of factors were associated with different crash types and the formation of the five profiles. Whilst some authors have previously identified the 'young and risky' category (Begg \& Langley, 2000; Shults et al., 2016), other seat belt non-use profiles have not previously been described.

With regards to individual crash factors, this research reiterated findings from the USA (Alattar et al., 2016; McCartt \& Northrup, 2004; Steinhardt \& Watson, 2007) and Australia (Raftery \& Wundersitz, 2011; Steinhardt et al., 2007) that most crashes occur in the evening and early morning. In addition, crashes on rural roads were more commonly associated with seat belt non-use fatalities than urban roads. This may partly be due to the typically higher speed environment and the decreased chance of survivability in high-speed crashes (Bédard et al., 2002; Elvik 2012), but also reflects USA and Australian literature which suggests that seat belt wearing rates may be lower in rural settings (Knight, Harris, \& Iverson, 2008; Raftery \& Wundersitz, 2011; Steinhardt et al., 2007).

This study showed a significant disparity between fatal outcomes between men and women - with far fewer women being represented. Whilst this research did not describe seat belt usage rates, it did examine non-use outcomes. Evidence that women are more likely to wear seat belts than men has been demonstrated in New Zealand (Fergusson et al., 2003), USA (Eluru \& Bhat, 2007; Reagan et al., 2013), the United Kingdom (Richards et al., 2008), and Turkey (Alver, Demirel, \& Mutlu, 2014). In addition, there is a common theme that those not wearing seat belts in fatal crashes are more likely to be male (Palamara et al., 2009; Raftery \& Wundersitz, 2011; Romano \& Voas, 2011).

An association between age and seat belt use is a common theme throughout the literature, with drivers in their late teens and early 20 s being least likely to wear seat belts (Alver et al., 2014; Eluru et al., 2007; Romano et al., 2011). This trend is compounded for young males (Alattar et al., 2016; McCartt et al., 2004; Raftery \& Wundersitz, 2011). These patterns were reiterated by this study, but were associated for all vehicle occupants, not just drivers. Women in the age group 15-19 were overrepresented in this study's fatality cases $(n=13)$, although in 10 of these cases the deceased was a passenger in a vehicle driven by a young male who fit the criteria for the 'young and risky' profile (note, driver survivors were not included in the analysis). The non-use of a seat belt in these crashes may in part be due to peer pressure (Jaccard et al., 2005).

Māori were overrepresented in seat belt non-use fatalities (35\%), compared to their proportion of the New Zealand population (15\%). Conversely, Pākehā were underrepresented $(54 \%)$ compared to their proportion of the population (74\%) (Statistics New Zealand, 2013). This raises questions about underlying socioeconomic and colonialisation issues. Indeed, the association between lower seat belt-wearing rates and people from disadvantaged ethnic backgrounds has been described for Indigenous Australians (Raftery \& Wundersitz, 2011) and in the USA for people from African American and Hispanic backgrounds (Shin et al., 1999; Shults et al., 2016).

The literature reinforces that for many people the use of seat belts may be governed by numerous factors, known as a 'decision policy' (Alattar et al., 2016). Evidence of these factors were illustrated in this research, including: the influence of the behaviour and choices of others (Han, 2017; McCartt \& Northrup, 2004; Jaccard et al., 2005); perceptions of the journey's risk (Begg \& Langley, 2000); and the planned number, speed, and duration of trips (Reagan et al., 2013; Alattar et al., 2016). Kawsnicka et al. discuss that "habitual behaviours are likely to dominate when resources are limited" (2016, p.287) and for part-time seat belt users who do not have ingrained habitual behaviours regarding seat belt use, wearing a seat belt may be more influenced by external factors than those who habitually use them. The results of this study suggest that fatigue, which was present in $36.5 \%$ of fatality cases may have been a contributing factor to some victims', particularly passengers, lack of seat belt use. This was particularly evident for passengers sleeping across the rear seats. In addition, it is likely that alcohol consumption, which is a known limiter of cognitive resources may have played a part in the decision of some of the $53.5 \%$ of fatality cases to wear a seat belt prior to the crash. Indeed, the high rate of alcohol involvement in nonseat belt crashes is an international issue (Begg \& Langley, 2000; Raftery et al., 2011; Romano et al., 2011; Bogstrand et al., 2015; Shults et al., 2016).

This research provides a part of the wholistic understanding of seat belt non-users in New Zealand. To that end, only seat belt non-use fatality cases were examined and therefore we were unable to draw comparisons between the profiles identified from this research and profiles of belted occupants who died in crashes. Further research to allow for comparison of these crash types would be beneficial when drawing broader conclusions. In addition, although developing an in-depth understanding of serious injury cases would have been beneficial to better inform the profiles, the analysis was limited by the available data. Another methodological limitation was that only people aged 15 years and over were examined, as the funding scope excluded unrestrained or incorrectly restrained children. With regards to the findings, the profile 'people driving in rural settings' contained just over half of the fatality cases and the MCA was unable to meaningfully split it into smaller categories. The individuals in this profile exhibited the least homogenous behavioural attributes and it may be that the MCA method was limited by the number of variables entered $(n=21)$. However, it might simply be that some crash circumstances may not fit neatly into particular categories. Certainly, the patterns of factors in the other four profiles were strongly aligned. Finally, this research was designed to understand 'who' died on New Zealand's roads whilst not wearing a seat belt, not 'why'. Future research, particularly through qualitative interviews with seat belt non-use crash survivors, as well as non-crash-involved people who fit the profiles from this research would be valuable. 


\section{Conclusion}

This research provides a deeper understanding into the contexts behind fatal crashes where seat belts were not worn in New Zealand. It shows that a broad range of people and situations are represented in these crashes, and highlights that for many victims, the non-use of a seat belt may be the only risky aspect of their otherwise normal journey.

Compared with the generally high rate of seat belt wearing in New Zealand, the number of fatalities for seat belt nonusers as a proportion of all vehicle occupant fatalities (at least one quarter) is high. Merely getting vehicle occupants to wear their seat belt may not reduce their likelihood of crashing, but it should reduce their fatality rate substantially (Høye, 2016). These findings suggest that the issue of seat belt non-use will not be solved by focusing on seat belts alone, rather it is part of a broader Safe System issue.

The next step towards meaningful road safety initiatives to improve seat belt compliance is to understand why the profiles identified in this research do not wear seat belts. The data presented in this paper pertain only to people who did not wear a seat belt and died. A fatal crash is a relatively unusual driving outcome and it is therefore likely that there is a broader cohort of people who may fit the occupant profiles who are alive. There are a range of possibilities about why people do not wear seat belts, and if the mechanisms are more clearly defined for various contexts, then road safety initiatives can be better targeted to address these and have a greater likelihood of success. For some profiles, a general focus on risky driving is needed, or even support from outside of the transport system. For others, cultural norms and a focus on positive habits may be more relevant.

\section{Acknowledgements}

This work was financially supported by the AA Research Foundation. No conflicts of interest have been identified.

\section{References}

Alattar, L., Yates, J. F., Eby, D. W., LeBlanc, D. J., \& Molnar, L. J. (2016). Understanding and reducing inconsistency in seatbelt-use decisions: Findings from a cardinal decision issue perspective. Risk Analysis, 36(1), 83-97. DOI: 10.1111/risa.12419

Alver, Y., Demirel, M. C., \& Mutlu, M. M. (2014). Interaction between socio-demographic characteristics: Traffic rule violations and traffic crash history for young drivers. Accident Analysis \& Prevention, 72, 95-104. DOI: 10.1016/j.aap.2014.06.015

Alattar, L., Yates, J. F., Eby, D. W., Le Blanc, D. J., Molnar, L. J. (2016). Understanding and reducing inconsistency in seatbelt-use decisions: Findings from a cardinal decision issue perspective. Risk Analysis. 36(1): 83-97. DOI: 10.1111/risa.12419

Bédard, M., Guyatt, G. H., Stones, M. J., \& Hirdes, J. P. (2002). The independent contribution of driver, crash, and vehicle characteristics to driver fatalities. Accident Analysis \& Prevention, 34(6), 717-727. DOI: 10.1016/S00014575(01)00072-0

Begg, D. J., \& Langley, J. D. (2000). Seat-belt use and related behaviors among young adults. Journal of Safety Research, 31(4), 211-220. DOI: 10.1016/S0022-4375(00)00038-4

Bhat, G., Beck, L., Bergen, G., \& Kresnow, M.-J. (2012). Predictors of rear seat belt use among US adults. Journal of Safety Research, 53, 103-106.

Bogstrand, S. T., Larsson, M., Holtan, A., Staff, T., Vindenes, V., \& Gjerde, H. (2015). Associations between driving under the influence of alcohol or drugs, speeding and seatbelt use among fatally injured car drivers in Norway. Accident Analysis \& Prevention, 78, 14-19. DOI: 10.1016/j. app.2014.12.025

Bose, D., C. Arregui-Dalmases, D. Sanchez-Molina, J. VelazquezAmeijide and J. Crandall (2013). "Increased risk of driver fatality due to unrestrained rear-seat passengers in severe frontal crashes." Accident Analysis \& Prevention 53(1): 100-104. DOI: 10.1016/j.aap.2012.11.031

Chliaoutakis, J. E., Gnardellis, C., Drakou, I., Darviri, C., \& Sboukis, V. (2000). Modelling the factors related to the seatbelt use by the young drivers of Athens. Accident Analysis \& Prevention, 32(6), 815-825. DOI: 10.1016/S0014575(00)00006-3

de Pont, J. (2016). Why do people die in road crashes?, Ministry of Transport.

Eluru, N., \& Bhat, C. R. (2007). A joint econometric analysis of seat belt use and crash-related injury severity. Accident Analysis \& Prevention, 39(5), 1037-1049. DOI: 10.1016/j. aap.2007.02.001

Das, S., Avelar, R., Dixon, K., \& Sun, X. (2018). Investigation on the wrong way driving crash patterns using multiple correspondence analysis. Accident Analysis \& Prevention, 111, 43-55. DOI: 10.1016/j.aap.2017.11.016

Demirer, A., Durat, M., Haşimoğlu, C. (2012). Investigation of seat belt use among the drivers of different education levels. Safety Science, 50(4), 1005-1008. DOI: 10.1016/j. ssci.2011.12.013

Elvik, R. (2012). Speed limits, enforcement, and health consequences. Annual Review of Public Health, 33, 225238. DOI: 10.1146/annurev-publhealth-031811-124634

Fergusson, D., Swain-Campbell, N., \& Horwood, J. (2003). Risky driving behaviour in young people: Prevalence, personal characteristics and traffic accidents. Australian and New Zealand Journal of Public Health, 27(3), 337-342. DOI: 10.1375/acri.36.3.354

Fildes, B., M. Fitzharris, S. Koppel, P. Vulcan and C. Brooks (2003). Benefits of seat belt reminder systems. Annual Proceedings/Association for the Advancement of Automotive Medicine (Vol. 47).

Fildes, B., Stevenson, M., Hoque, S., \& Hammid, A. (2016). Restraint use in the Eastern Province of the Kingdom of Saudi Arabia. Traffic Injury Prevention, 17(5), 488-494. DOI: $10.1080 / 15389588.2015 .1103849$ 
Fong, C. K., Keay, L., Coxon, K., Clarke, E., Brown, J. (2016). Seat belt use and fit among drivers aged 75 years and older in their own vehicles. Traffic Injury Prevention, 17(2): 142150. DOI: $10.1080 / 15389588.2015 .1052420$

Hatamabadi, H., Vafaee, R., Haddadi, M., Abdalvand, A., Esnaashari, H., \& Soori, H. (2012). Epidemiologic study of road traffic injuries by road user type characteristics and road environment in Iran: A community-based approach. Traffic Injury Prevention, 13(1), 61-64.

Han, G.-M. (2017). Non-seatbelt use and associated factors among passengers. International Journal of Injury Control and Safety Promotion 24(2): 251-255

Høye, A. (2016). How would increasing seat belt use affect the number of killed or seriously injured light vehicle occupants? Accident Analysis \& Prevention, 88, 175-186. DOI: $10.1016 /$ j.app.2015.12.022

Husson, F., Josse, J., Le, S., Mazet, J. FactoMineR: Multivariate Exploratory Data Analysis and Data Mining with R. R package version 1.25. http://CRAN.R project.org/ package=FactoMineR. Accessed June 3, 2019.

Jaccard, J., H. Blanton and T. Dodge (2005). Peer influences on risk behaviour: An analysis of the effects of a close friend. Developmental Psychology 41(1): 135-147. DOI: 10.1037/0012-1649.41.1.135

Knight, P. J., Harris, M. F., \& Iverson, D. (2008). Early driving experience and risk perception in young rural people. Paper presented at the Australasian Road Safety Research, Policing and Education Conference, Adelaide, Australia.

Kawsnicka, D., Dombrowski, S. U., White, M., \& Sniehotta, F. (2016) Theoretical explanations for maintenance of behaviour change: A systematic review of behaviour theories. Health Psychology Review 10(3): 277-296. DOI:10 $.1080 / 17437199.2016 .1151372$

Larsson, P., \& Tingvall, C. (2013). The Safe System Approach - A Road Safety Strategy Based on Human Factors Principles. In D. Harris (Ed.), Engineering Psychology and Cognitive Ergonomics. Applications and Services (Vol. 8020, pp. 1928): Springer Berlin Heidelberg.

McCartt, A. T., \& Northrup, V. S. (2004). Factors related to seat belt use among fatally injured teenage drivers. Journal of Safety Research, 35(1), 29-38. DOI: 10.1016/j. jsr.2003.09.016

Ministry of Transport. (2014). Front seat safety belt use by adults: Results of a national survey 2014. Wellington, New Zealand:

Ministry of Transport. (2016). 2016 adult front seat occupants. Retrieved from https://www.transport.govt.nz/resources/ road-safety-resources/roadsafetysurveys/safetybeltstatisticsa ndchildrestraintsurveys/2016-adult-front-seat-occupants/

New Zealand Government, \& National Road Safety Committee. (2016). Safer Journeys Action Plan 2016-2020. Retrieved from https://www.saferjourneys.govt.nz/action-plans/20162020-action-plan/
New Zealand Transport Agency (2017, March 27). Seat-belt non-use fatality search 2011-2015. Retrieved from Crash Analysis System database

Palamara, P., Oxley, J., Langford, J., Thompson, C., \& Chapman, A.-M. (2009). An investigation of the factors associated with the non-use of a seat belt through the analysis of linked Western Australian crash, death and hospitalisation data. Paper presented at the Australasian Road Safety Research, Policing and Education Conference, Sydney, Australia.

Raftery, S., \& Wundersitz, L. (2011). No restraint? Understanding differences in seat belt use between fatal crashes and observational surveys. Journal of Safety Research, 31(4), 211-220.

Reagan, I. J., McClafferty, J. A., Berlin, S. P., \& Hankey, J. M. (2013). Using naturalistic driving data to identify variables associated with infrequent, occasional, and consistent seat belt use. Accident Analysis \& Prevention, 50, 600-607. DOI: 10.1016/j.app.2012.06.008

Richards, D. C., Hutchins, R., Cookson, R. E., Massie, P., \& Cuerden, R. W. (2008). Who doesn't wear seat belts? Paper presented at the International conference: Expert Symposium on Accident Research, Hannover, Germany.

Road Safety Observatory (2013). Seat belts review. UK

Romano, E., \& Voas, R. B. (2011). Drug and alcohol involvement in four types of fatal crashes. Journal of Studies on Alcohol and Drugs, 72(4), 567-576. DOI: 10.15288/ jsand.2011.72.567

Routley, V., Ozanne-Smith, J., Li, D., Hu, X., Wang, P., \& Qin, Y. (2007). Pattern of seat belt wearing in Nanjing, China. Injury Prevention, 13(6), 388-393. DOI: 10.1136/ ip.2007.015701

Shin, D., Hong, L., \& Waldron, I. (1999). Possible causes of socioeconomic and ethnic differences in seat belt use among high school students. Accident Analysis \& Prevention, 31(5), 485-496. DOI: 10.1016/S0001-4575(99)00004-4

Shults, R. A., Haegerich, T. M., Bhat, G., \& Zhang, X. (2016). Teens and seat belt use: What makes them click? Journal of Safety Research, 57, 19-25. DOI: 10.1016/j.jsr.2016.03.003

Statistics New Zealand. (2013). 2013 Census - Major ethnic groups in New Zealand.

Steinhardt, D. A., \& Watson, B. C. (2007). Night time seatbelt non-use in serious crashes: A comparison of contributing factors in rural and urban areas of the United States and Queensland. Paper presented at the Australasian Road Safety Research, Policing \& Education Conference, Melbourne, Australia.

Traynor, T. (2005). The impact of driver alcohol use on crash severity: A crash specific analysis. Transportation Research Part E: Logistics and Transportation Review, 41(5), 421437. DOI: 10.1016/j.tre.2005.03.005

World Health Organisation (2009). The need for seat-belts and child restraints, World Health Organisation.

World Health Organisation. (2016). "Road Traffic Injuries." Retrieved from http://www.who.int/mediacentre/factsheets/ fs358/en/ 


\title{
The frequency and nature of aggressive acts on Australian roads
}

\author{
Amanda Stephens ${ }^{1}$ and Michael Fitzharris ${ }^{1}$ \\ ${ }^{1}$ Monash University Accident Research Centre, Clayton, Victoria, Australia \\ Corresponding Author: Amanda Stephens, 21 Alliance Way, Clayton Campus 3800,Amanda.stephens@monash.edu \\ +61399051191 .
}

\section{Key Findings}

- Self reported aggressive driving behaviour and engagement in other risk-taking behaviours were reported by a representative sample of drivers in Australia;

- Aggression was relatively common, particularly among younger males;

- $\quad$ One third of male drivers aged 26-39 reported having chased another driver when angry;

- $\quad$ Associations were found between aggression, speeding, mobile phone use, drink-driving and crashes.

\section{Abstract}

To understand the current prevalence of aggressive acts on Australian roads, a large cross-sectional survey was conducted inviting drivers from all Australian jurisdictions to participate. A stratified sampling procedure was undertaken to ensure the age and gender distributions were representative of each jurisdiction. Participants were asked to report the frequency of aggressive driving behaviours as well as speeding, drink-driving and mobile phone usage while driving. Recent crash history was also obtained. The sample consisted of 2,916 drivers (males $=45 \%$ ) with an average age of $42( \pm 16)$ years. Minor aggressive behaviours such as expressing annoyance to other drivers and sounding the horn in anger were reported by the majority of the sample (60\% and $70 \%$ respectively). More extreme behaviour such as chasing another driver when angry was less common, however still reported by $18 \%$ of the overall sample. Aggressive driving behaviours were more common in younger, male drivers with $36 \%$ of drivers aged 22 to 39 reporting extreme aggression. Associations were found between aggressive driving with crash involvement and other forms of risky driving behaviour. The results show that aggressive driving is a problem on Australian roads. Further research is warranted to explore where aggressive driving fits within an overall risky driving pattern of behaviour, what attitudes drivers hold toward aggressive driving, and how to target the reduction of these behaviours.

\section{Keywords}

Aggressive driving, Tailgating, Speeding, Risky driving behaviour

\section{Introduction}

Driver aggression poses a problem to road safety as it manifests in deliberate behaviours that increase the crash risk for the perpetrator and other road users (Tasca, 2000). While aggression can range on a continuum from mild acts of aggressive expression to criminal acts of violence or 'road rage', common aggressive driving behaviours of particular concern include excessive speeding, tailgating (Deffenbacher, Lynch, Oetting, \& Swaim, 2002) and dangerous lane changing (Shinar \& Compton, 2004). Most researchers agree that aggressive driving behaviours are distinct from other aberrant behaviours in that they are usually motivated by negative emotions such as anger, irritation and frustration (Björklund, 2008; Deffenbacher, Richards, \& Lynch, 2004; Parker, Lajunen, \& Summala, 2002) and are dependent upon the current driving environment (Shinar, 1998).

The reporting of aggressive driving within road agency statistics is limited and tends to be captured through other offence categories. For instance, in the absence of a specific all-encompassing aggressive driving offence, in Australia, drivers can be charged for some forms of aggressive behaviours depending upon their level of severity (such as tailgating, dangerous driving, culpable driving). Consequently, the affective motivation is not captured and hence aggressive driving is not clearly represented in offence data or crash statistics. Given this, it is hard to understand the prevalence of aggression, yet this understanding is fundamental to targeting strategies aimed at reducing these behaviours. This is particularly so, given the intentional nature of the behaviours and the likelihood that that i) there might be certain drivers who are more aggressive than others and ii) aggressive driving may be emblematic of broader driving issues.

Based on survey data, aggressive driving behaviours appear to be common on the roads. In a global poll of drivers from 23 Countries $(\mathrm{N}=13,673 ; 2003)$, approximately half of 
the drivers surveyed in the US (66\%), Europe (48\%) and Australia (51\%) had been subjected to aggression from other drivers in the past year. Further, $68 \%, 51 \%$ and $60 \%$ respectively reported being an aggressive driver at least once during that time period (EOS Gallup Europe, 2003). A 2004 study by insurer AAMI in Australia showed that $93 \%$ of those surveyed $(\mathrm{N}=1,880)$ had been subjected to aggression from other motorists during their driving lifetime, while $43 \%$ had perpetrated aggressive driving in retaliation to the behaviour of others (AAMI, 2004). More recent, yet smaller and more localised studies, also show that most drivers report being aggressive at some time while driving. Data from drivers in the British Isles show that $72 \%$ reported being a victim of aggressive driving and $62 \%$ reported being an aggressor (Stephens \& Sullman, 2014). Similarly, data from drivers in Malaysia show the majority of drivers surveyed had been victims of aggressive driving $(66 \%)$ and also been an aggressive driver (55\%; Sullman, Stephens \& Yong, 2014). Taken together, these studies indicate that drivers are likely to either experience or witness aggression while driving and the majority are also likely to be aggressive at some point.

Aggressive driving (or behaviours that can also be classified as aggressive but for which the intent is not known) has been associated with crash risk. As noted above, crash data however tend to not include the intention of the driver and therefore aggressive-type behaviours (ie speeding, tailgating and failing to give way) are used as a proxy for aggressive driving. When done and defined as potentially aggressive driving, this has been identified as a major contributing factor to crash involvement (American Automobile Association, 2009). Although examining aggressive-type behaviours is likely to overestimate the contribution of aggression to crashes, the findings are largely supported by other methodologies. Questionnaire studies have shown strong associations between aggressive expressions of anger while driving and self-reported crash involvement (Deffenbacher, Lynch, Filetti, Dahlen, \& Oetting, 2003; Stephens \& Sullman, 2015; Wickens, Mann, Ialomiteanu, \& Stoduto, 2016). Simulator studies also confirm direct effects of aggressive behaviours on driving performance (Ellison $\square$ Potter, Bell, \& Deffenbacher, 2001). It is clear that reducing the incidents of aggressive behaviour will have both a direct and indirect benefit to road safety.

However, reducing the incidents of aggressive driving relies on understanding both who is aggressive and the frequency of these aggressive behaviours. This is because aggressive behaviour is the result of a complex interaction between the person and the situation (Anderson \& Bushman, 2002). Aggression results from a combination of how a driver is feeling and the assessments made of the driving situation and outcomes for the aggressive action. Current data are lacking on the prevalence of aggression on Australian roads. Further, there is limited understanding of the "perpetrator" and the context in which these behaviours are exhibited. Data from outside of Australia show that aggressive driving decreases with age (Paleti, Eluru, \& Bhat, 2010; Roberts \& Indermaur, 2005) and is more prevalent in males (Shinar \& Compton, 2004; Vanlaar, Simpson, Mayhew, \& Robertson,
2008). Research has also indicated that aggressive drivers are also likely to commit other traffic infringement offenses (Vanlaar et al., 2008) and engage in other dangerous behaviours, such as failure to wear a seat belt (Eluru \& Bhat, 2007). This suggests that aggressive driving sits within a constellation of other poorer road behaviours. Given the above, it can be postulated that, in Australia, aggressive driving is common, dangerous and especially evident in younger and thereby less experienced drivers. Further, the question of whether this behaviour is emblematic of the driving culture or the broader societal culture is interesting, but to date unexplored other than in recent media.

The aim of this paper was to explore self-reported aggressive driving behaviours of a representative sample of Australian drivers and to understand who is likely to be an aggressive driver. A further aim was to explore the associations these behaviours have with crash involvement as well as other dangerous behaviours, such as speeding, drink-driving and illegal mobile phone use. The latter will provide understanding of where aggressive driving sits within a broader range of aberrant behaviours.

\section{Methods}

\section{Participants and Procedure}

Data were taken from a large National Survey of drivers in Australia designed to understand driving behaviours and attitudes towards road safety. The survey was developed by the Victorian Transport Accident Commission in collaboration with Monash University Accident Research Centre and conducted by Ipsos Social Research Institute. Participants were recruited through the Ipsos online panel of members. A stratified sampling procedure was incorporated using targets based on the age and gender distributions of the Australian adult population as recorded in the 2011 census (ABS, 2011). The survey was distributed in two phases (see Figure 1 and Stephens \& Fitzharris; 2016) for more details) with attitudinal data, self-reported speeding behaviour and crash involvement being recorded in Phase 1 , and self-reported aggressive driving and drink-driving obtained in Phase 2. Although separating the research across two phases leads to a marked reduction in participants, it avoids potential common method biases related to reporting aggression and crash involvement at the same time-point.

The final sample contained 2,916 participants (see Figure 2 for sampling distribution) all of whom reported driving a car within the last year. Overall, $55 \%$ of the sample were female and their age ranged from 16 to 75 years $(M=42.72$ \pm 16.45 ). Recent Australian census data shows broadly similar age and gender distributions for Australian residents (Australian Bureau of Statistics, 2014). 


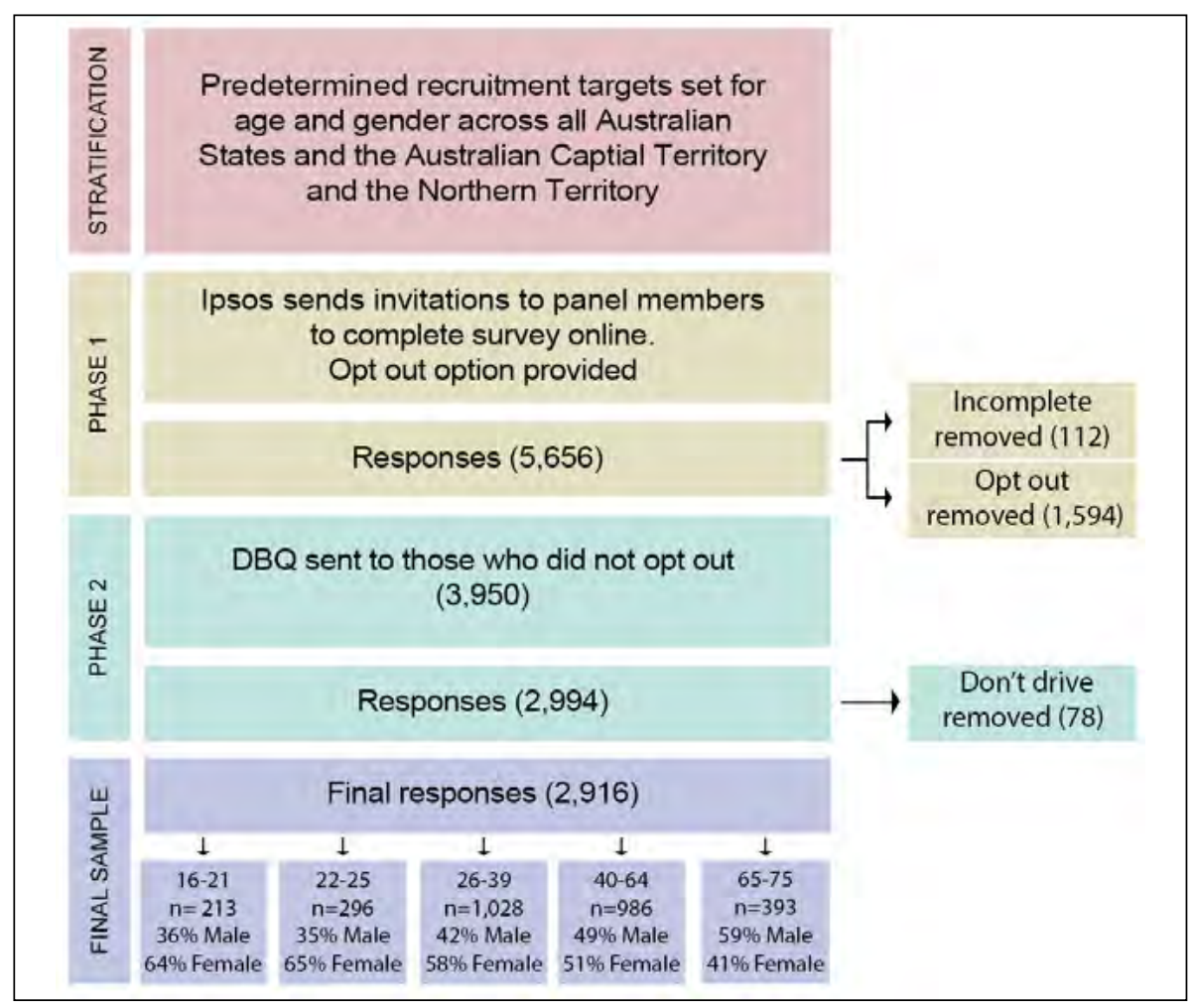

Figure 1. Two-phased sampling procedure

\section{Materials}

\section{Aggressive driving}

Four aggressive driving behaviours were examined, via the following survey questions:

Thinking about your driving/riding in the last 2 years, how often would you say you...?

- Use your horn to indicate your annoyance to another road user;

- Get angry at a certain type of driver and express your anger any way you can;

- Become angry at another driver and chase them with the intention of showing them how angry you are;

- Drive so close to the car in front that it would be difficult to stop in an emergency.

These four items are taken from the Driver Behaviour Questionnaire (DBQ: Reason et al., 1990). Although the time windows differed between crash and DBQ items, all drivers reported driving a car within the past 12 months, suggesting DBQ frequencies are a reflection of the previous year and therefore align with crash information.

For each item, a 6-point likert response was required, ranging from 1 (never) to 6 (almost always). However, to avoid cases with thin cells, responses were later recoded into never ( 1 on the likert scale), infrequently ( 2 on the likert scale representing hardly ever), occasionally ( 3 and 4 representing occasionally and quite often) and frequently ( 5 and 6 being frequently and nearly all the time responses).

\section{Other dangerous driving behaviours}

The following behaviours were also assessed:

Drink-driving: "Have you driven or ridden a vehicle over the last 3 months when you think you may have been over the legal Blood Alcohol Concentration (BAC)?" and yes / no responses were provided.

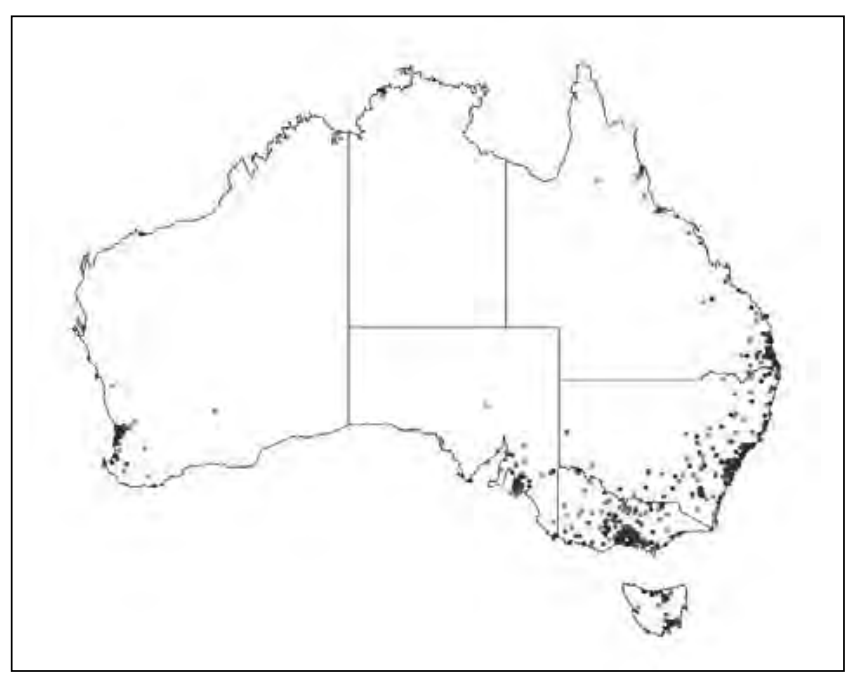

Figure 2. Sampling distribution across Australia 
Mobile phone use while driving: "How often do you use a hand-held mobile phone for texts or calls while driving?" Responses were on an 8 -point scale (daily to never).

Speeding: Speeding was assessed with a question: "What speed do you normally drive or ride in ..." repeated across four speed zones of 40, 50,60 and $100 \mathrm{~km} / \mathrm{h}$ ) - In a $40 \mathrm{~km}$ zone. For each one, drivers selected either, below or at the speed limit, up to $5 \mathrm{~km} / \mathrm{h}$ over, 6 to $10 \mathrm{~km} / \mathrm{h}$ over or 11 or more $\mathrm{km} / \mathrm{h}$ over.

For analysis, the dangerous driving behaviours were recoded as binary variables (yes / no).

\section{Demographic information}

Information was also obtained regarding age, gender and mileage. Postcode data were obtained and used to identify urban or rural residence as well as a proxy for socioeconomic status following the classifications published by the Australian Bureau of Statistics (ABS; 2011), SocioEconomic Indexes for Areas (SEIFA), Australia, 2011. Each postcode has a percentile for the Index of Relative Socioeconomic Advantage and Disadvantage (IRSAD) with lower scores representing disadvantaged $(0-50)$ and higher scores representing advantaged areas $(51-100)$. These were then classified into quartiles (disadvantaged $0-25$; moderately disadvantaged $26-50$; moderately advantaged $51-75$ and advantaged $76-100)$.

\section{Data analysis}

Data were analysed with SPSS v. 22 and Stata v.14. Chisquare tests were used to explore relationships between aggressive driving, age and gender. Effect sizes were measured with Phi $(\varphi)$ for 2 x 2 tables and Cramer's V $\left(\varphi_{c}\right)$ for larger tables. Values of $0.10 ; 0.30$ and 0.50 represent small, medium and large effects respectively (Cohen, 1992). Post hoc tests were performed with adjusted standardised residuals and for tables larger than $2 \times 2$, a conservative significance level was set at $.01( \pm 2.58)$ to account for multiple comparisons. In situations where more than $20 \%$ of the cells in the chi-square analysis had an expected count less than 5, and therefore an assumption of the Pearson chisquare test was violated, the Fisher's exact test $p$ value is reported instead.

Logistic regression was conducted to explore associations between demographic variables (age, gender, SEIFA score, rural or urban residence) with engagement in aggression (yes / no). Initial univariate models with inclusion criteria set at $\mathrm{p}<.25$ were conducted and exclusion was set at .05 for subsequent multivariate models (Hosmer, Lemeshow \& Sturdivant, 2013). Both a main effects model and interaction model were tested and model evaluation and diagnostics were conducted. There was no evidence of collinearity. Adjusted odds ratios were calculated for each independent variable at a 95\% confidence interval (Hosmer, et al., 2013).

\section{Results}

\section{Driving frequency and mileage}

Over half of the participants reported driving daily (58\%) and a further $28 \%$ drove more than twice a week. Fivepercent of the sample drove infrequently (either at least once a month, $2 \%$, every couple of months $1 \%$ or rarely, $2 \%$ ). Therefore, the majority of the sample (93\%) were frequent drivers, driving at least once a week but most driving daily.

Participants reported an average weekly mileage of $281 \mathrm{kms}$ ( \pm 426; range 1 to 9,000 , median $=200)$ and annual mileage of $15,766 \mathrm{kms}( \pm 18,657$; range 5 to 250,000 ; median $=$ 10,000).

\section{Frequency of aggressive behaviours}

Table 1 shows the self-reported frequency of the four aggressive behaviours. As expected, the most frequently reported behaviour was sounding the horn to indicate annoyance. Almost $71 \%$ of the sample reported doing this behaviour at least once in the past two years and 30.9\% of the sample reported doing this occasionally. Tailgating also emerged as behaviour reported at least once by almost half of the respondents $(44.8 \%)$, however if done, this was mostly infrequent $(31.6 \%)$. Further, more than half of the sample $(59.3 \%)$ reported expressing annoyance at other drivers "any way they can" with one quarter doing this occasionally to often $(23.7 \%)$ or frequently $(2.2 \%)$. Most concerning, however is that $17.7 \%$ of the sample reported chasing another driver with the intention of expressing their anger at least once across the two-year period.

\section{Aggressive behaviours across gender and age}

Figure 3 shows the relationships between gender and selfreported frequency of aggressive behaviours across five age groups. No significant differences were found for using

Table 1. Frequency of aggressive driving behaviours across the total sample $(\mathrm{N}=2,916)$

\begin{tabular}{|l|l|l|l|l|}
\cline { 2 - 5 } \multicolumn{1}{c|}{} & Never $\mathbf{( \% )}$ & $\begin{array}{l}\text { Infrequently } \\
\mathbf{( \% )}\end{array}$ & Occasionally (\%) & Frequently $(\mathbf{\%})$ \\
\hline Use your horn to indicate annoyance & 28.8 & 38.2 & 30.9 & 2.1 \\
\hline $\begin{array}{l}\text { Get angry at a certain type of driver and } \\
\text { indicate your annoyance anyway you can }\end{array}$ & 40.7 & 33.4 & 23.7 & 2.2 \\
\hline Chase another driver when angry & 82.3 & 11.4 & 5.4 & 0.9 \\
\hline Follow another driver too closely & 56.2 & 31.6 & 11.2 & 1.0 \\
\hline
\end{tabular}



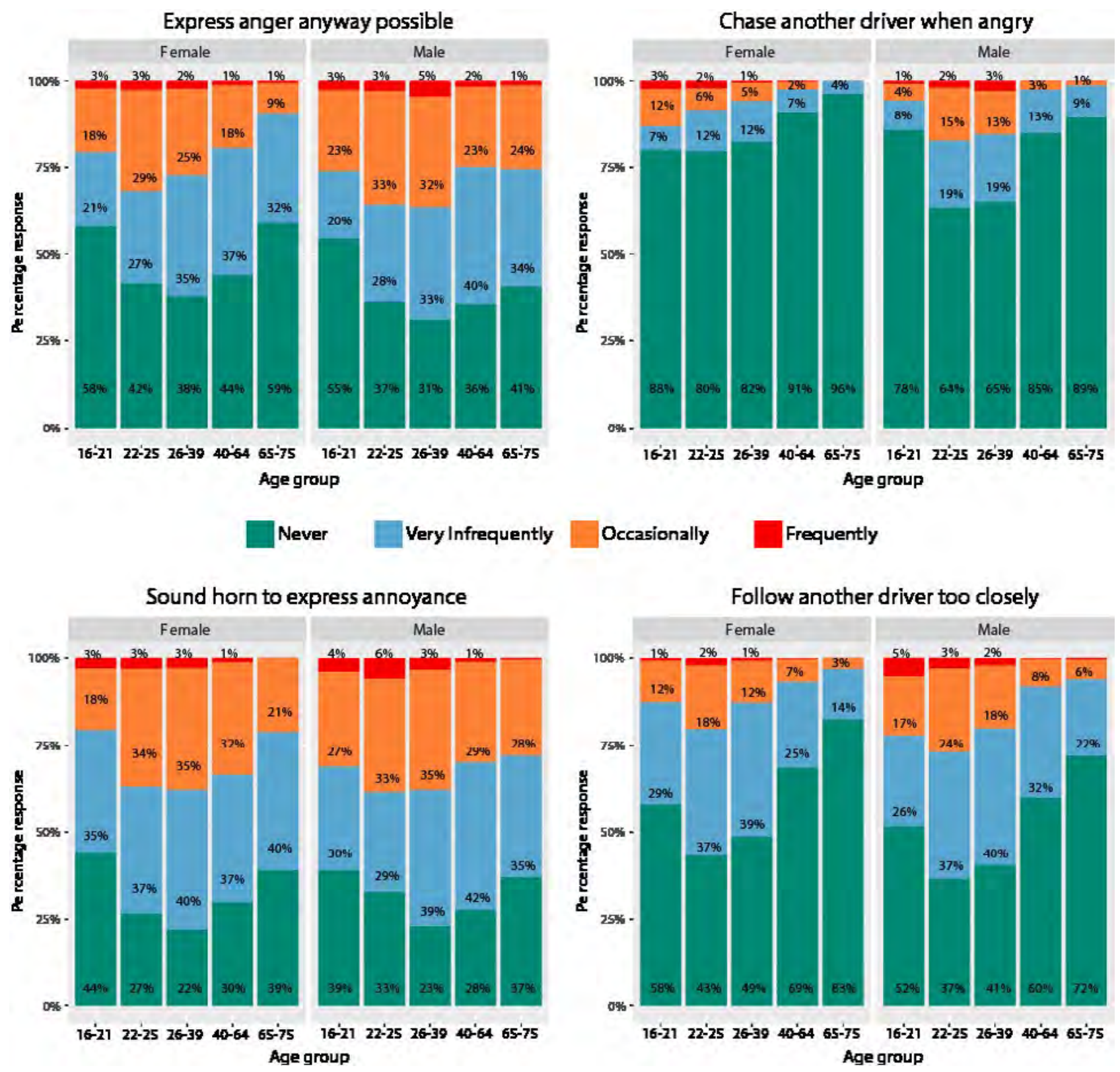

Figure 3. Relationships between gender and aggressive driving behaviours across age groups

the horn to indicate annoyance ( $\mathrm{ps}>.05$ ), indicating that males and females across all age groups do this behaviour with similar frequency. Overall, females were less likely to engage in any of the three other aggressive types of behaviours, and this was indicated by a significantly higher percentage of females in the never categories relative to males. No gender differences in self-reported aggression were observed for drivers aged 16 to 21 years, which may reflect the licencing conditions of this cohort.

Most notably in Figure 3 is that $36 \%$ of males aged 22 to 25 years and $35 \%$ of males aged 26 to 39 years reported chasing another driver when angry at least once over the past two years, when compared to $19 \%$ and $18 \%$ of similarly aged females. These gender differences were significant at the .01 level (by Fisher's exact tests). Further, 15\% and 13\% of males in these age groups did this behaviour occasionally, while $2 \%$ to $3 \%$ respectively, reported frequently chasing other drivers when angry.

Males also reported expressing anger toward certain types of drivers more frequently than females, although this relationship was not evident across all age groups. In particular, $32 \%$ of males aged 26 to 39 reported occasionally doing this behaviour compared to $25 \%$ of females in this age group and this difference was significant $\left(\chi^{2}(3)=11.52\right.$, $\left.\mathrm{p}<.001, \varphi_{\mathrm{c}=} .11\right)$. For drivers aged 65 to 75 years, $24 \%$ of male drivers expressed anger towards certain types of road users occasionally, while only $9 \%$ of similarly aged females reported occasionally expressing anger anyway possible $\left(\chi^{2}\right.$ $\left.(3)=22.68, \mathrm{p}<.001, \varphi_{\mathrm{c}=} .09\right)$. 
Table 2. Associations between driver characteristics and aggressive driving

\begin{tabular}{|c|c|c|c|c|c|c|c|}
\hline & $\begin{array}{c}\text { Aggression } \\
\text { Yes }\end{array}$ & OR & $95 \% \mathrm{CI}$ & p-value & $\begin{array}{l}\text { Adjusted } \\
\text { OR }\end{array}$ & $95 \% \mathrm{CI}$ & p-value \\
\hline \multicolumn{8}{|l|}{ Age group } \\
\hline $16-21$ & $74 \%$ & \multicolumn{2}{|c|}{ Referent (1.0) } & & \multicolumn{2}{|c|}{ Referent (1.0) } & \\
\hline $22-25$ & $86 \%$ & 2.17 & 1.38 .3 .40 & .001 & 2.18 & $1.39,3.42$ & .001 \\
\hline $26-39$ & $88 \%$ & 2.56 & $1.79,3.67$ & $<.001$ & 2.57 & $1.79,3.69$ & $<.001$ \\
\hline $40-59$ & $84 \%$ & 1.88 & $1.32,2.67$ & $<.001$ & 1.92 & $1.35,2.73$ & $<.001$ \\
\hline $60-75$ & $77 \%$ & 1.14 & $0.77,1.67$ & 0.51 & 1.18 & $0.80,1.73$ & 0.41 \\
\hline \multicolumn{8}{|l|}{ Gender } \\
\hline Males & $85 \%$ & \multicolumn{2}{|c|}{ Referent (1.0) } & & & & \\
\hline Females & $83 \%$ & 0.88 & $0.72,1.07$ & 0.21 & & & \\
\hline \multicolumn{8}{|l|}{ SEIFA score (IRSAD) } \\
\hline Disadvantaged $0-25$ & $80 \%$ & \multicolumn{2}{|c|}{ Referent (1.0) } & & & & \\
\hline $\begin{array}{l}\text { Moderately } \\
\text { disadvantaged } \\
26-50\end{array}$ & $82 \%$ & 1.15 & $0.87,1.54$ & 0.32 & & & \\
\hline $\begin{array}{l}\text { Moderately } \\
\text { advantaged } \\
51-75\end{array}$ & $87 \%$ & 1.71 & $1.27,2.32$ & $<.001$ & & & \\
\hline $\begin{array}{l}\text { Advantaged } \\
76-100\end{array}$ & $86 \%$ & 1.50 & $1.13,1.98$ & .005 & & & \\
\hline \multicolumn{8}{|l|}{ Residence } \\
\hline Urban & $85 \%$ & \multicolumn{2}{|c|}{ Referent (1.0) } & & & & \\
\hline Rural & $81 \%$ & 0.73 & $0.59,0.89$ & .003 & 0.74 & $0.60,0.92$ & .006 \\
\hline \multicolumn{8}{|l|}{ Mileage (kms) } \\
\hline Low $(0-9,000)$ & $84 \%$ & \multicolumn{2}{|c|}{ Referent (1.0) } & & & & \\
\hline $\begin{array}{l}\text { Medium }(9,001- \\
15,000)\end{array}$ & $87 \%$ & 1.32 & $0.99,1.77$ & 0.06 & & & \\
\hline $\operatorname{High}(15,001+)$ & $88 \%$ & 1.39 & $1.01,1.90$ & 0.04 & & & \\
\hline
\end{tabular}

Further, a greater percentage of male drivers aged 26 to 39 $(18 \%)$ reported occasionally tailgating when compared to female drivers of the same age $\left(12 \% ; \chi^{2}(3)=13.00, p<.01\right.$, $\left.\varphi_{c=} .11\right)$. Therefore showing that male drivers particularly those aged 26 to 39 more frequently engage in aggressive type behaviours when compared to similar aged females.

\section{Driver factors associated with aggressive behaviours}

Table 2 shows the associations between age, gender, SEIFA scores, residence (rural v. urban) and mileage (low, medium and high) with self-reported aggressive driving. A combined outcome variable was created for those who reported any of the five aggressive behaviours (yes group) and those who had not (no group).

As can be seen in Table 2, when adjusting for age, the odds of aggressive driving decreased for those in rural areas, with drivers in these areas having $26 \%$ lower odds of aggression compared to drivers in urban areas, where arguably there is more exposure to other drivers and situations conducive to expressing aggression. Further, as expected, the odds of aggressive driving increased with age. Relative to young drivers aged 16 to 21 , the odds of aggressive driving were approximately twofold for drivers aged 22 to 25 years (ORadjusted: 2.18 ; 95\% CI: 1.39,3.42); 26 to 39 years (ORadjusted: $2.57 ; 95 \% \mathrm{CI}: 1.79,3.69)$ and 40 to 59 years (ORadjusted: 1.92; 95\%CI: 1.35,2.73). 


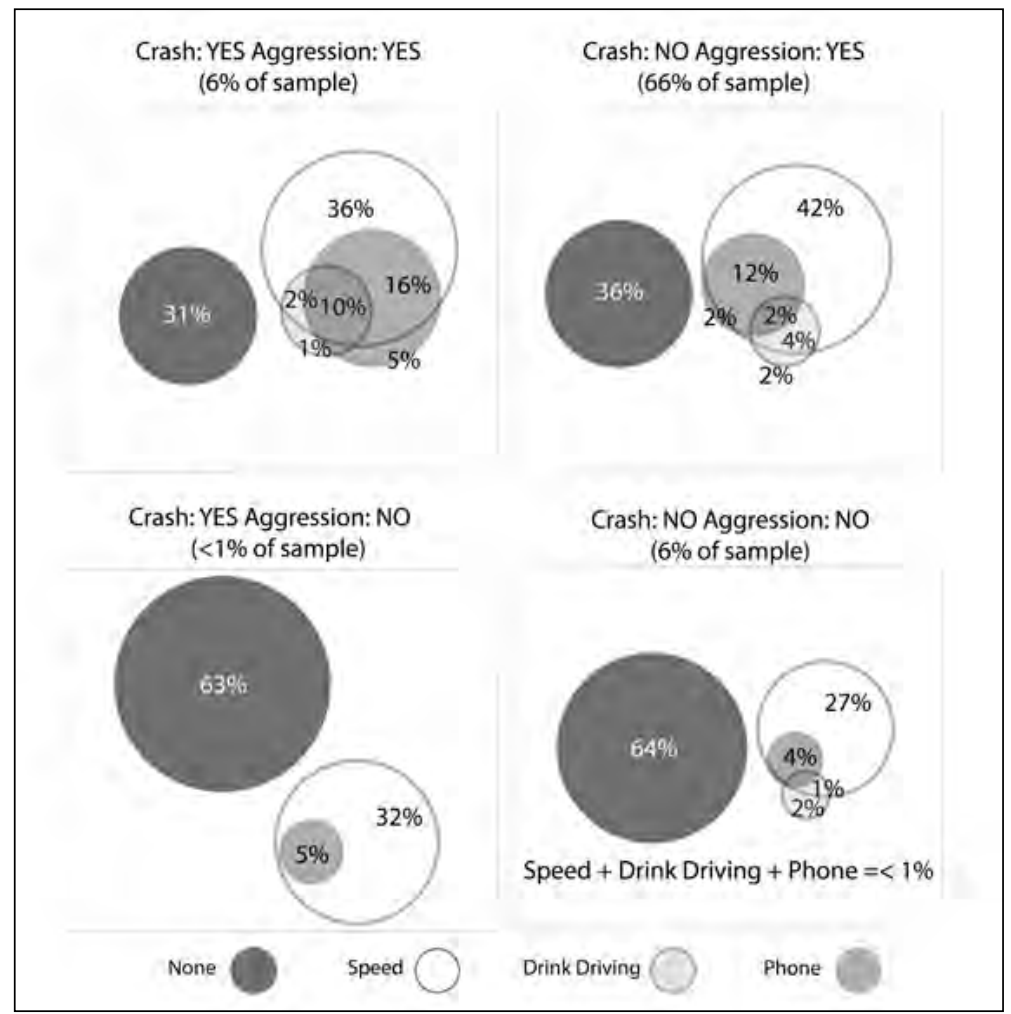

Figure 4. Relationships between speeding, drink-driving and use of a hand-held mobile phone while driving across crashes and self-reported aggression

\section{Aggressive behaviours and their association with other dangerous driving behaviours}

Table 3 shows the relationships between the dichotomised aggressive driving variable and responses with hand-held mobile phone use while driving, drink-driving, speeding behaviour and crashes. Significant relationships were found between all variables and aggressive driving. In comparison to drivers who did not report any aggressive type behaviours, drivers who reported expressing aggression were more likely to report:
a. $\quad$ using a hand-held mobile phone while driving $(18 \%$ cf. $5 \%$;
b. having driven when over the legal BAC limit in the past three months ( $9 \%$ cf. $4 \%$ ); and
c. normally driving in excess of the posted speed limit (60\% cf. $33 \%)$.

Table 3. Associations between aggressive driving and other dangerous behaviours

\begin{tabular}{|c|c|c|c|c|}
\hline & & Total & \multicolumn{2}{|c|}{ Aggressive driving } \\
\hline & & & Yes & No \\
\hline \multirow{2}{*}{$\begin{array}{l}\text { Hand-held mobile use while driving } \\
\chi^{2}(1)=49.45, p<.001, \varphi_{=} .13\end{array}$} & Yes & $16.2 \%$ & $18.3 \%$ & $5.2 \%$ \\
\hline & No & $83.8 \%$ & $81.7 \%$ & $94.8 \%$ \\
\hline \multirow{2}{*}{$\begin{array}{l}\text { Drink-drive in the past three months } \\
\chi^{2}(1)=12.97, p<.001, \varphi_{=} .07\end{array}$} & Yes & $7.8 \%$ & $8.6 \%$ & $3.7 \%$ \\
\hline & No & $92.2 \%$ & $91.4 \%$ & $96.3 \%$ \\
\hline \multirow{2}{*}{$\begin{array}{l}\text { Exceed the speed limit } \\
\chi^{2}(1)=119.79, p<.001, \varphi_{=} .20\end{array}$} & Yes & $56 \%$ & $60.4 \%$ & $32.9 \%$ \\
\hline & No & $44 \%$ & $39.6 \%$ & $67.1 \%$ \\
\hline \multirow{2}{*}{$\begin{array}{l}\text { Crash involvement in previous } 12 \text { months } \\
\chi^{2}(1)=5.49, p=.02, \varphi_{=} .04\end{array}$} & Yes & $6.6 \%$ & $7.0 \%$ & $4.1 \%$ \\
\hline & No & $93.4 \%$ & $93.0 \%$ & $95.9 \%$ \\
\hline
\end{tabular}


A relationship was also observed for aggressive driving and crash involvement, with $7 \%$ of drivers who reported aggressive behaviours also reporting crash involvement in the previous 12 months. This is compared to only $4 \%$ of drivers not reporting aggressive type behaviours. Although while statistically significant $(\mathrm{p}=.02)$, this was considered as a small effect using Cohen's statistics reported in the Method section.

Figure 3 shows the relationships between drink-driving, hand-held mobile phone use and speeding separated across crash involvement and aggressive behaviours. Aggressive drivers were more likely to also engage in other dangerous behaviours compared to drivers reporting no aggression and this is demonstrated by a higher percentage of drivers who engaged in all three behaviours $(10 \%$ for those who had crashed and $3 \%$ for those who had not crashed) as well as a lower percentage of drivers who reported engaging in none of the three behaviours $(31 \%$ for those who had crashed and $36 \%$ for those who had not crashed). In comparison, a higher percentage of drivers who reported no aggression did not report any of the three dangerous behaviours $(63 \%$ and $64 \%$ ).

\section{Discussion}

This paper presents self-reported aggressive driving from a representative sample of drivers in Australia. The results show that aggressive driving is relatively common with approximately 60 to $70 \%$ of the sample reporting minor aggressive acts such as sounding the horn in anger and using other unspecified mechanisms to express anger. More concerning, almost half of the drivers sampled reported following another driver too closely while almost one fifth of drivers reported chasing another driver when angry. Previous, albeit now dated research, has shown that approximately $60 \%$ of drivers in Australia report acts of aggression while driving (EOS Gallup Europe, 2003). The results broadly align with these findings and show a trend for more frequent minor aggressive acts from the majority of the sample yet some extreme dangerous acts of aggression from a subset of this group.

Self-reported engagement in aggression was found to differ across driver age and gender. With the exception of sounding the horn when angry, males reported significantly more aggressive driving behaviours than females. This was exacerbated for younger drivers. In particular, over one third (35-36\%) of male drivers aged 22 to 39 years reported having chased another driver when angry with the intention of showing them their anger. In comparison, 18 to $19 \%$ of female drivers in this age range reported chasing another driver when angry. Although considerably lower than the male cohort, this is still an alarmingly high proportion of drivers to report this behaviour.

Interestingly, although male drivers reported more extreme aggression, traditionally females drivers tend to report higher propensities to become angry while driving (Deffenbacher, Stephens \& Sullman, 2016). Hence, there may not always be a direct link between anger and aggression on the roads. While data in this regard are lacking from an Australian sample, there is convincing evidence to suggest that this dichotomy may result from other driver characteristics, including gender roles (Sullman, Stephens, \& Hill, 2016), aggressive tendencies (Lajunen \& Parker, 2001) or risk taking propensities (Yagil, 1998). Indeed, in the current sample, the profile of more aggressive drivers was the same as those found to engage in other risky driving behaviours. These include, more frequent speeding behaviour (Stephens, Nieuwesteeg, Page-Smith \& Fitzharris), drink-driving ( Stephens, Bishop, Liu \& Fitzharris, 2017) and hand-held mobile phone usage while driving (Lansdown, 2012).

It was also found that SEIFA scores were associated with aggressive driving. Those in moderately advantaged or advantaged areas had higher odds of being aggressive than those in disadvantaged areas. This finding might provide evidence of additional factors that mediate the relationships between anger and aggression. This might be due to specific attitudes, type of vehicles driven or main areas driven in, levels of stress, etc. This is worthy of further investigation especially with the use of alternative SIEFA measures, including the index of education and occupation (IEO) and the index of economic resources (IER). These would provide additional understanding of potential underpinning factors for aggression.

The results from the current study also highlight the relationships between speeding behaviour, drink-driving, using a hand-held phone and crash involvement. Of those who reported aggressive driving, $7 \%$ also reported a crash. This is compared to only $4 \%$ of those who did not report aggressive driving. Further, a higher percentage of drivers who reported crash involvement and aggression also reported speeding, drink-driving and driving while using a hand-held mobile phone when compared to those who reported crash involvement and no aggression. Further, not one of the non-aggressive drivers who had been involved in a crash reported speeding or drink-driving; again highlighting that aggressive driving may be part of a broader pattern of dangerous driving behaviours.

A trend in road safety is to silo behaviours and only examine for example, aggression, speeding, drink-driving or mobile phone usage. However, the data reported in this paper suggest the risk profiles of drivers who engage in these behaviours may be broadly similar. Therefore, interventions for aggressive driving may lie in the published literature regarding motivations and attitudes toward other types of risky behaviour. For example, drivers who drink and drive and also those who speed tend to do this when they perceive they can get away with it and if they have friends and family who also engage in these behaviours (Stephens et al., 2017). This speaks to the social acceptability of these behaviours and the perceived enforcement for failure to comply with road safety rules. Indeed, research using the theory of planned behaviour (Ajzen, 1991) on DBQ items for aggressive driving, has shown that attitudes and beliefs regarding aggression and its outcomes predict intentions to aggress (Parker, Lajunen \& Stradling, 1998). While, drinkdriving, speeding and mobile phone use are all identifiable illegal behaviours, aggressive driving may appear less so for drivers. This is because charges for aggressive driving can 
be covered by a number of different traffic offenses targeting specific behaviours, rather than aggressive intent. Further, at least in Australia, unlike speeding, drink-driving and mobile phone usage, aggressive driving has not been the subject of extensive road safety media campaigns and therefore less may be known about enforcement consequences. More research is clearly needed to understand where aggressive driving fits within an overall risky driving pattern of behaviour, what attitudes drivers hold toward aggressive driving and how to target the reduction of these.

While the results show that aggressive driving is also a current problem on Australian roads, the findings are based on self-reported behaviours. Self-reports can be criticised for socially desirable responses (e.g. Paulhus, 1991). However, research has shown strong correlations between self-reported anger tendencies and anger provoked during simulated driving (Stephens \& Groeger, 2009). More recent research has also shown the scores on the DBQ factors are related to how drivers drive both in simulated and onroad driving (Helman \& Reed, 2015). Given the items for aggressive driving used for this study were from the DBQ, we can be confident that the self-reports reflect aggression while driving in the current sample.

An additional limitation of the current study is that the definition aggression itself was limited to only a small number of aggressive type behaviours. Further, the timeperiods were different across reports of aggression and other illegal driving behaviours. A recent cognitive debrief of the DBQ (Social Research Centre, 2014) has shown that drivers tend to report driving styles, rather than frequencies across specific time frames. Therefore, the different time frames given to participants for different activities, while not ideal, are unlikely to reduce the strength of the actual relationships.

The current findings provide avenues for additional research. Additional research ought to explore various types of aggressive behaviours to gain further understanding of the prevalence of aggression per kilometre travelled. It is likely that aggressive behaviours are reciprocal on the road and hence it is important understand the prevalence and impacts of both perpetrated and received aggression, its context, and the consequences these have on subsequent driver behaviour. Further research could also explore more comprehensively the factors that influence whether a driver engages in aggression, considering this as a fluid process that changes according to the driver's current personal circumstance and the driving situation. Naturalistic driving studies might provide a rich data source to address this question. In addition, a research focus on the driver, their broader circumstances and current attitudes towards aggression will also be important. This would allow understanding of whether aggression is part of a broader problem outside of driving and what attitudes could be targeted for its reduction. International research using the TPB has shown that attitudes toward aggressive driving are associated with more frequent engagement (Parker et al., 1998). This has yet to be explored in Australia.

\section{Conclusions and Practical Implications}

The frequency of engagement in a number of self-reported aggressive acts was obtained from a representative sample of drivers in Australia. The results showed that aggression was relatively common, particularly among younger male drivers. One third of male drivers aged 26 to 39 reported having chased another driver when angry. Further, associations were found between self-reported aggression with other dangerous behaviours such as speeding, illegal mobile phone use and drink driving as well as with crashes. This suggests that aggression may be part of a broader problem related to aberrant behaviours on the roads.

While further research is warranted to understand the motivations of aggressive behaviours, the findings suggest a pattern of behaviour which may result from a social acceptability of aggression coupled with positive reinforcement towards aggressive outcomes. Law enforcement, with specific regulations or enforcement programs targeting aggressive driving, is likely to be an effective strategy for changing these attitudes.

\section{Acknowledgements}

The authors wish to thank Michael Nieuwesteeg and Jodi Page-Smith of the Transport Accident Commission (TAC) Victoria and Julie Young, Research Manager Ipsos Social Research Institute for providing the survey data.

Funding: This research did not receive any specific grant from funding agencies in the public, commercial, or not-forprofit sectors.

\section{References}

AAMI. (2004). AAMI Crash Index: Tenth annual road safety report.

Ajzen, I. (1991). The theory of planned behavior. Organizational behavior and human decision processes, 50(2), 179-211.

American Automobile Association. (2009). Aggressive Driving Research update 2009 AAA foundation for traffic safety.

Anderson, C.A. \& Bushman, B.J. (2002). Human aggression. Annual Review of Psychology, 53, 27-51

Australian Bureau of Statistics. (2014). Australian Demographic Statistics, Jun 2014. (3101.0).

Björklund, G. M. (2008). Driver irritation and aggressive behaviour. Accident Analysis \& Prevention, 40(3), 10691077.

Deffenbacher, J., Richards, T., \& Lynch, R. (2004). Anger, aggression, and risky behavior in high anger drivers. Focus on aggression research. Hauppage, NY: Nova Science Publishers.

Deffenbacher, J. L., Lynch, R. S., Filetti, L. B., Dahlen, E. R., \& Oetting, E. R. (2003). Anger, aggression, risky behavior, and crash-related outcomes in three groups of drivers. Behaviour research and therapy, 41(3), 333-349. 
Deffenbacher, J. L., Lynch, R. S., Oetting, E. R., \& Swaim, R. C. (2002). The Driving Anger Expression Inventory: A measure of how people express their anger on the road. Behaviour research and therapy, 40(6), 717-737.

Deffenbacher, J. L., Stephens, A. N., \& Sullman, M. J. M. (2016). Driving anger as a psychological construct: Twenty years of research using the Driving Anger Scale. Transportation Research Part F: Traffic Psychology and Behaviour, 42, Part 2, 236-247. doi: http://dx.doi.org/10.1016/j. trf.2015.10.021

Ellison-Potter, P., Bell, P., \& Deffenbacher, J. (2001). The effects of trait driving anger, anonymity, and aggressive stimuli on aggressive driving behavior. Journal of Applied Social Psychology, 31(2), 431-443.

EOS Gallup Europe. (2003). Aggressive behaviour behind the wheel.

Helman, S., \& Reed, N., (2015). Validation of the driver behaviour questionnaire using behavioural data from an instrumented vehicle and high-fidelity driving simulator. Accident Analysis \& Prevention, 75, 245-251

Lajunen, T., \& Parker, D. (2001). Are aggressive people aggressive drivers? A study of the relationship between selfreported general aggressiveness, driver anger and aggressive driving. Accident Analysis \& Prevention, 33(2), 243-255. doi: http://dx.doi.org/10.1016/S0001-4575(00)00039-7

Lansdown, T. C. (2012). Individual differences and propensity to engage with in-vehicle distractions - A self-report survey. Transportation Research Part F: Traffic Psychology and Behaviour, 15(1), 1-8. doi: http://dx.doi.org/10.1016/j. trf.2011.09.001

Paleti, R., Eluru, N., \& Bhat, C. R. (2010). Examining the influence of aggressive driving behavior on driver injury severity in traffic crashes. Accident Analysis \& Prevention, 42(6), 1839-1854.

Parker, D., Lajunen, T., \& Stradling, S. (1998). Attitudinal predictors of interpersonally aggressive violations on the road. Transportation Research Part F: Traffic Psychology and Behaviour, 1(1), 11-24.

Parker, D., Lajunen, T., \& Summala, H. (2002). Anger and aggression among drivers in three European countries. Accident Analysis \& Prevention, 34(2), 229-235.

Paulhus, D.L., (1991). Measurement and control of response bias. In Measures of Personality and Social Psychological Attitudes, Robinson, J.P., Shaver, P.R., \& Wrightsman, L.S (Eds). Academic Press: San Diego. Pp 17-59.

Roberts, L., \& Indermaur, D. (2005). Boys and road rage: drivingrelated violence and aggression in Western Australia. Australian \& New Zealand Journal of Criminology, 38(3), 361-380.
Shinar, D., \& Compton, R. (2004). Aggressive driving: an observational study of driver, vehicle, and situational variables. Accident Analysis \& Prevention, 36(3), 429-437.

Stephens, A. N., Bishop, C. A., Liu, S., \& Fitzharris, M. (2017). Alcohol consumption patterns and attitudes toward drinkdrive behaviours and road safety enforcement strategies. Accident Analysis \& Prevention, 98, 241-251. doi: http:// dx.doi.org/10.1016/j.aap.2016.10.011

Stephens, A.N., \& Groeger, J.A. (2009) Situational specifity of trait influences on drivers' evalations and driving behaviour. Transportation Research Part F, 12, 29-39.

Stephens, A. N., \& Fitzharris, M. (2016). Validation of the Driving Behaviour Questionnaire in a representative sample of drivers in Australia. Accident Anal Prev, 86, 186-198. doi: 10.1016/j.aap.2015.10.030

Stephens, A. N., \& Sullman, M. J. (2014). Development of a short form of the driving anger expression inventory. Accident Analysis \& Prevention, 72, 169-176.

Stephens, A. N., \& Sullman, M. J. (2015). Trait Predictors of Aggression and Crash-Related Behaviors Across Drivers from the United Kingdom and the Irish Republic. Risk analysis.

Sullman, M. J. M., Stephens, A. N., \& Hill, T. (2016). Gender Roles and the Expression of Driving Anger Among Ukrainian Drivers. Risk Analysis, n/a-n/a. doi: 10.1111/ risa. 12592

Tasca, L. (2000). A review of the literature on aggressive driving research: Citeseer.

The Social Research Centre. (2014). Cognitive testing of the driver behaviour questionnaire for the TAC: Results and recommendations. March, 2014.

Vanlaar, W., Simpson, H., Mayhew, D., \& Robertson, R. (2008). Aggressive driving: A survey of attitudes, opinions and behaviors. Journal of safety research, 39(4), 375-381.

Wickens, C. M., Mann, R. E., Ialomiteanu, A. R., \& Stoduto, G. (2016). Do driver anger and aggression contribute to the odds of a crash? A population-level analysis. Transportation research part F: traffic psychology and behaviour.

Yagil, D. (1998). Gender and age-related differences in attitudes toward traffic laws and traffic violations. Transportation Research Part F: Traffic Psychology and Behaviour, 1(2), 123-135. doi: http://dx.doi.org/10.1016/S13698478(98)00010-2 


\title{
The crash performance of seagull intersections and intersections with left turn slip lanes
}

\author{
Shane Turner ${ }^{1}$, Fergus Tate ${ }^{2}$, Graham Wood ${ }^{3}$ \\ ${ }_{1}$ Technical Director/Safety System Specialist, Abley, Christchurch, New Zealand \\ ${ }^{2}$ Transportation Manager, WSP, Wellington, New Zealand \\ ${ }^{3}$ Consultant Statistician, Dunedin, New Zealand
}

Corresponding Author: Dr Shane Turner, Abley NZ, 137 Victoria Street, Christchurch Central, Christchurch 8013, New Zealand shane.turner@abley.com. +64 27 495-5048

This peer-reviewed paper was first presented as an Extended Abstract and Oral Presentation at the 2018 Australasian Road Safety Conference (ARSC2018) held in Sydney, NSW, Australia and first published in the ARSC2018 Proceedings in the form of an Extended Abstract. It was expanded into a 'Full Paper' and underwent further peer-review by three independent experts in the field. It is being reproduced here with the kind permission of the authors and is now only available in this edition of the JACRS.

\section{Key Findings}

- $\quad$ Larger rural and urban seagull intersections, especially those on four-lane roads and those with wide medians, have higher crash rates (per vehicle) than smaller seagull intersections;

- $\quad$ Distraction to the left of side-roads resulting from road features, such as parking and movement from nearby accesses/side-roads and the operation of right turn bays does increase right turn out versus through vehicle crashes at T-intersections;

- The design of left turn slip lanes, especially where this restricts visibility to through vehicles, does increase the risk of right turn out versus through vehicle crashes at rural seagull intersections.

\begin{abstract}
Alternative intersection layouts may reduce traffic delays and/or improve road safety. Two alternatives are reviewed in this research: 'priority-controlled Seagull intersections' and 'priority-controlled intersections with a Left Turn Slip Lane'. Seagull intersections are used to reduce traffic delays. Some do experience high crash rates, however. Left Turn Slip Lanes allow turning traffic to move clear of the through traffic before decelerating, thereby reducing the risk of rear-end crashes. Although there is debate about the safety problems that occur at Seagull intersections and Left Turn Slip Lanes there has been very little research to quantify the safety impact of different layouts. In this study, crash prediction models have been developed to quantify the effect of various Seagull intersection and Left Turn Slip Lane designs on the key crash types that occur at priority intersections. The analysis showed that seagulls are not safe on 4-lane roads, that roadway features like kerb-side parking and nearby intersections can increase crash rates and that left turners in LTSLs can restrict visibility and create safety problems.
\end{abstract}

\section{Introduction}

The majority of urban and rural intersections in New Zealand have priority control (Stop or Give-Way) or no formal control. National crash data (2011 to 2015) indicates that $64 \%$ of rural and $43 \%$ of urban intersection all-injury crashes occur at three leg priority intersections. The serious injury and fatal crash proportion is also $64 \%$ for rural intersections but $52 \%$ for urban intersections.

Despite the high proportion of crashes and the high severity of these crashes only a small proportion of the research literature focusses on crashes at priority intersections, compared with the number of studies that have been undertaken of for signalized intersections, roundabouts and road links, especially in urban areas. In New Zealand this leads to a gap in the crash prediction models that are available to the road safety industry, especially for urban areas.
With a focus on the safe system philosophy, it is important we have better tools (crash prediction models) to look at the safety of priority-controlled intersections, where over 50\% of serious injuries and fatalities occur.

The challenge with priority controlled intersections is that there are so many intersections to consider for safety improvement. Generally, the focus needs to be on the higher volume intersections, where high right turning volumes and high through volumes at peak times result in fewer gaps and increased risk taking.

A common treatment at high volume priority rural intersections (where the speed limit is $80 \mathrm{~km} / \mathrm{h}$ or greater) is Left Turn Slip Lanes (LTSL) which seeks to reduce rear-end crashes by removing slower moving turning traffic from the through traffic. There are however concerns that some designs may increase the risk of crashes involving through and right turn out vehicles (JA crashes), due to left turners masking following through vehicles. 


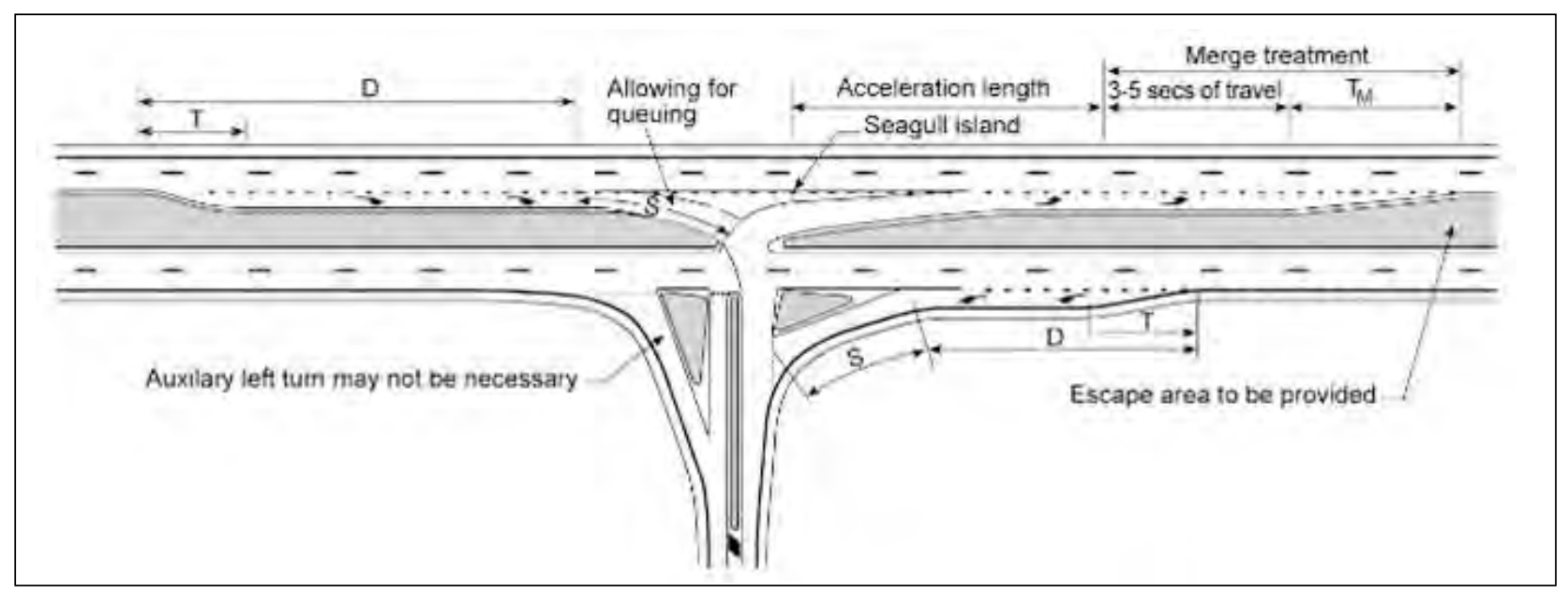

Figure 1: Typical Seagull Intersection Layout with Raised Islands

Another treatment type, which is less common, is the 'Seagull' layout, where drivers can break their right turn movement into two stages (see Figure 1, which also includes one type of LTSL). In the first stage drivers cross over to a painted or solid median area. In the second stage they merge with through traffic on the main road via a merge lane and taper. While in theory these layouts should be safer, the experience is that some have high numbers of JA (right turn out crashes) and LB (right turn against or right turn versus opposing through vehicle) crashes (see Figure 3).

In New Zealand seagull intersections are mostly priority controlled but can also operate with traffic signals. At priority-controlled seagulls both through movements are free-flowing, with sideroad traffic having to give-way when crossing to the median. The signalised seagulls typically involve three signal phases allowing the through movement in only one direction (top of the tee) to flow continuously. On the side with the side-road the through traffic is stopped to allow traffic to move from the side-road into the central median and then merge with through traffic via the acceleration lane.

This project focuses on priority-controlled seagull intersections, as they typically have a higher number of crashes than signalised seagulls. Crash prediction models have been developed for standard priority three leg intersection layouts (see Figure 2), with and without Left Turn Slip Lanes, and Seagull layouts. The first section of the paper looks at the limited research available on the safety performance of Seagull intersections and the safety issues associated with LTSL. The paper then presents the data collected and the crash prediction models produced in this research, followed by a discussion of the research findings.

\section{Literature Review}

The literature review focused on research of prioritycontrolled Seagull intersections and standard priority intersections with and without LTSLs (particularly from the main road into a side-road). Across New Zealand there are a variety of existing types of Seagull intersection and general priority tee-junctions. Priority controlled Seagull intersections (see Figure 1) have three key characteristics, 1) a seagull shaped 'splitter' island between through and right turning traffic on the main road, 2) a merge lane with acceleration taper for traffic turning right out of the side road and 3 ) at least one bypass lane for main road traffic traveling straight through from left to right.

Many of the higher volume standard priority intersections have some characteristics that are similar to Seagull intersections, such as left turn slip lanes and also areas in the median where drivers can wait and merge with through traffic, especially when the road has a central median island. However, unless they have all three characteristics specified they are not considered Seagull intersections.

Figure 1 also shows two LTSLs into and out of the sideroad. There are a variety of different LTSL layouts, from small painted islands up to large solid islands, with different deceleration lane lengths. The focus in this study was the LTSL from the main road into the side-road.

There is limited research available on Seagull layouts (called chanelised layouts in other parts of the world). Tang and Levett (2009) identified that two major crash types (right-near and right-through) were predominant in all crashes at Seagull intersections in New South Wales (refer to Figure 3 for equivalent crash types in New Zealand). The multivariate study of potential crash causing factors provided very little evidence on why these crashes were occurring. However, the study did show that young female drivers and older ( $\geq 67$ years old) male drivers were over-represented in the two main crash types. A potential explanation for the older age group demographic was the diminishing cognitive ability of older drivers, which may be causing them to misjudge appropriate gaps in the traffic.

Radalj et al. (2006) analysed the crash data and the design of 76 seagull intersections in Perth, Western Australia. The study identified that Seagull intersections, installed as per the recommended guidelines, did not result in any significant 


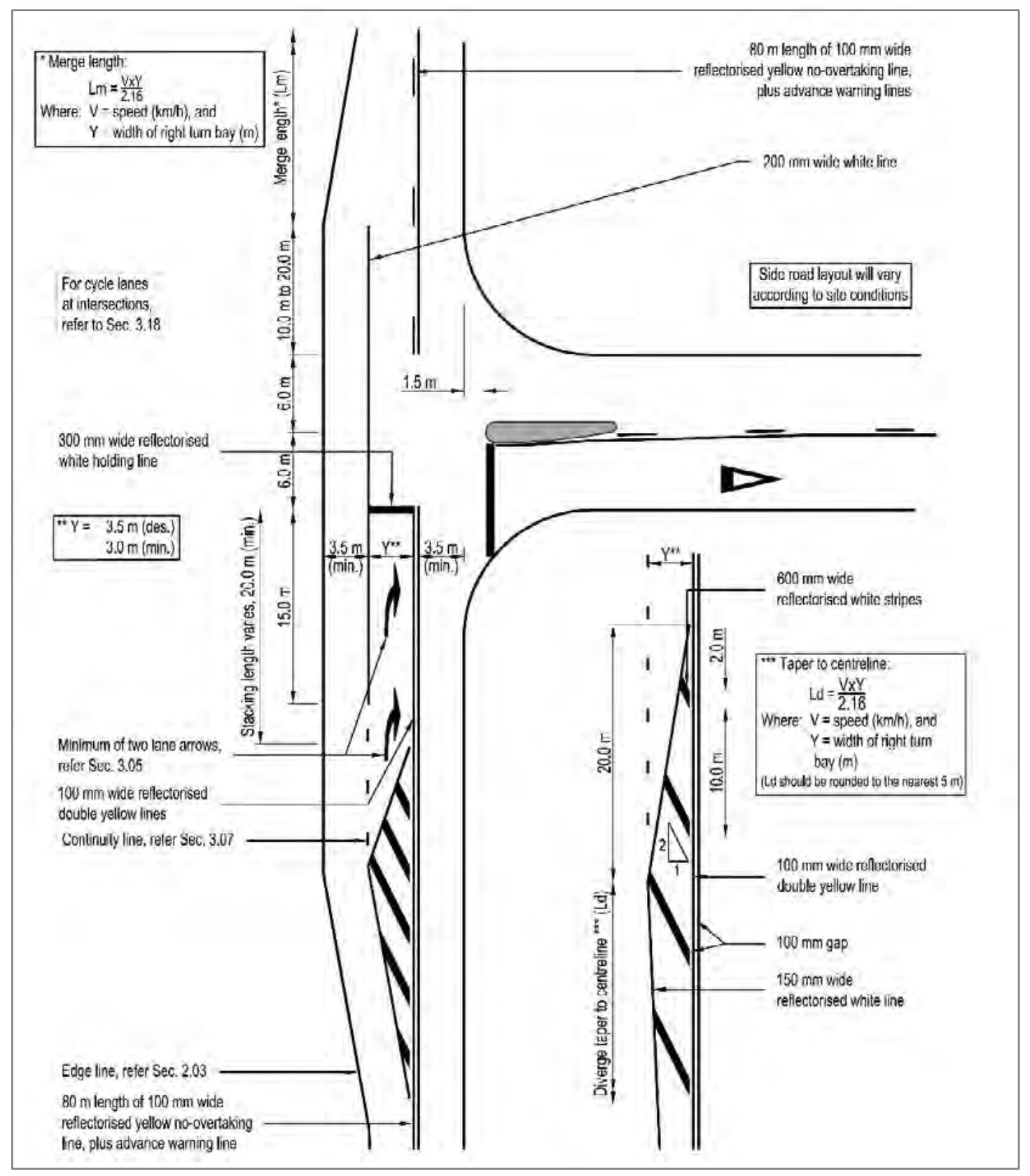

Figure 2: Standard Rural Priority Intersection (source: MOTSAM 2 Section 3 Figure 3.25)

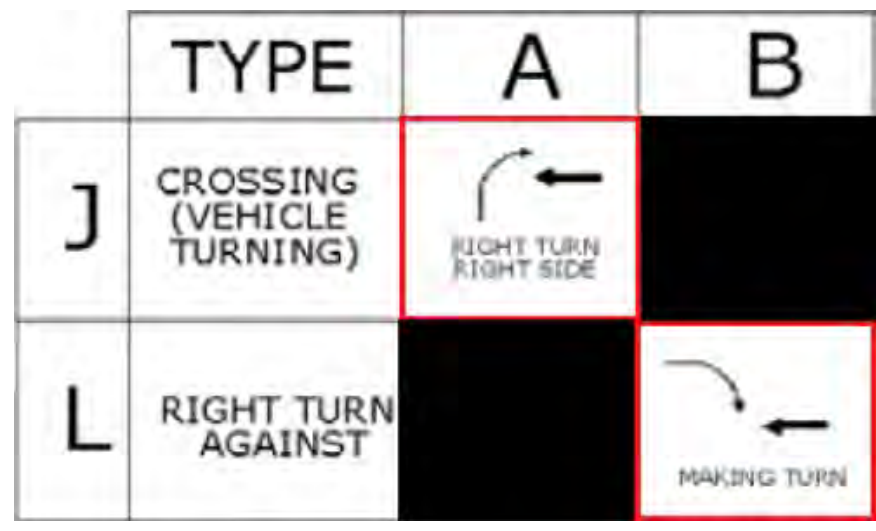

Figure 3: Common crash types at seagull intersections (NZ crash coding) 
(positive or negative) change in the type or number of crashes. However, where the intersection angle did not conform to the recommended guidance, the crash numbers and severity increased, especially the latter. The authors recommended that seagull islands should not be considered as an intersection safety treatment (as they had been in the past), as at best they tend to have a similar safety record to a standard T-intersection, and at worst can have a much worse safety record.

Both Summersgill et al. (1996) and Elvik et al. (2009) concluded that the effect of channelised passing lanes at T-intersections (Seagull intersections) is to increase the crash risk. In the case of Elvik, a $26 \%$ overall increase in all crashes is recorded, while the Summersgill study found a 50\% increase in 'JA' crashes. This research supports the concerns of most road safety specialists that Seagull intersections are less safe than traditional T-intersections, especially if poorly designed.

Harper, et al. (2011) researched the safety performance of three design variations of a Seagull intersection for the A1 Highway / Island Point Road intersection in New South Wales, Australia. After the Seagull intersection was constructed a number of 'right near' (JA) type crashes began to occur. The intersection was subsequently modified to include a short left turn splay that included a small raised concrete splitter island and priority control. However, this did not effectively address the 'right-near' crashes, and consequently right-through (LB) type crashes began to occur more frequently. A final modification increased separation between the left-turn deceleration lane and the straight through lane of the major road, after which the crashes reduced appreciably. The separation of the left turn lane from the through movement by a painted splitter island improved visibility for vehicles turning out of the sideroad. This design of LTSLs has safety benefits at Seagull and standard priority T-junctions, especially in higher speed areas.

There is more extensive safety research on LTSL. While the functions and use of these lanes are reasonably well documented (to reduce rear-end crashes), the overall safety benefits and dis-benefits have recently been questioned, particularly in rural/high speed areas. Elvik et al. (2009) identified from several studies that the provision of LTSL at T-intersections acts to increase the number of injury crashes by $12 \%$. The study reasoned that LTSL may create blind spots where a vehicle turning left can obscure through traffic coming from the right side of the side road. He also added that large scale intersection channelisation can complicate the road layout, and may increase driver error.

Masters research by Urlich (2014) considered the safety performance of LTSL facilities at rural intersections in New Zealand. The study focused on how LTSLs impact on the available sight distances for side road traffic to through vehicles and how this related to the crash rates. The analysis showed that the installation or modification of LTSLs (into side-roads) can increase injury crash rates. The key reason is that left turn vehicles do mask following through vehicles on a regular basis. This research indicates that careful consideration needs to be made on the design of LTSLs so that they do not compromise the safety of the intersection.

The previous research indicates that for both Seagull intersections and LTSLs there is evidence that crash rates can go up if intersections are not well designed. The experience in Perth (by Radalj) showed that Seagulls should not be considered a road safety treatment. Seagulls do reduce traffic delays and may be constructed to reduce delays. However it is important that they are well designed, especially in high speed areas where crash severity is often higher, to ensure a neutral road safety outcome. In terms of the design of LTSLs, there is some evidence that they can mask through vehicles and lead to increased crashes between right turn out and through vehicles. Especially in higher speed areas and where traffic volumes (left turn in and right turn out) are at higher levels, then the design should look to address visibility problems. Each of these matters was considered in this research study.

\section{Data Collection and Sample Size}

The current study utilised data that had previously been collected for standard three-arm urban and rural priority T-intersections (Turner 2001; Turner and Roozenberg 2007). In these studies data was collected for more than 190 priority T-intersections. The majority of these older sites did not have LTSLs and none had a Seagull layout. The ones with LTSLs were separated and combined with the new sites added to the dataset. The intention was to compare the safety performance of sites with LTSL and Seagulls with 'standard (unmodified)' priority intersections.

A further 69 new intersections that had Seagull treatments and LTSLs were selected across both islands of New Zealand, in multiple cities and rural areas. Given it is a relatively rare intersection type, most of the Seagull intersections for which turning volume data was already available, or could easily be collected nationally, were included in the dataset. Rural intersections with LTSLs were selected mainly in the Canterbury and Wellington regions. Table 1 shows the number of sites selected by type and location (urban or rural).

Table 1: Number of Seagull intersections and LTSL sites selected

\begin{tabular}{|l|l|l|l|}
\hline Intersection type & Urban & Rural & Total \\
\hline Seagull T-intersection & 17 & 14 & 31 \\
\hline T-intersection with LTSL & 4 & 34 & 38 \\
\hline
\end{tabular}

Approximately half of these sites are in the South Island (mainly in Canterbury and Christchurch City) and the other half are spread around a number of North Island cities (urban) and regions (rural). These new sites were combined with the 'old' sites from previous studies (Turner (2001) and Turner and Roozenberg (2007)). Table 2 shows the combined dataset.

We note that the 261 intersections described are necessarily a convenience sample, a mix of previously sampled and more 
Table 2: Total Number of Priority Sites by type and location (urban or rural)

\begin{tabular}{|l|l|l|l|}
\hline Intersection type & Urban & Rural & Total \\
\hline T-intersection (standard) & 92 & 93 & 185 \\
\hline T-intersection with LTSL & 10 & 37 & 47 \\
\hline Seagull T-intersection & 17 & 12 & 29 \\
\hline Total & 119 & 142 & 261 \\
\hline
\end{tabular}

recently obtained sites. The data has been collected from all around New Zealand with many of the data sites being from the Canterbury region as the researchers involved were based in Canterbury. However, the effect of the Canterbury earthquakes on traffic flows and the change to the give way rules (on 25 March 2012) have been ignored, with all sites combined for analysis on a national basis.

The results of the analysis should be seen as descriptive of these intersections and not the entire set of intersections of the given types (T, T with LTSLs and Seagull intersections) in New Zealand. No full sampling frame (listing all intersections of a given type) exists, necessitating the approach that has been taken, which is normally the case with this type of study. We are aware that there are regional differences in New Zealand and hence the models may not be accurate for all New Zealand regions.

A database was set up to store data for all 261 intersections. Where relevant, data from previous studies was extracted and imported into the database. Layout data was collected from Google maps and street-view, with checking on-site at most locations. Data included 1) turning traffic volumes (six movements), 2) crash data, 3) operating speed and/or speed limit (on through road) and 4) layout data. For standard T-intersections there were 25 layout variables. For LTSL and Seagulls this increased to 51 variables and 67 variables respectively.

Crash data was extracted from the New Zealand Crash Analysis System (CAS). A 50m square 'radius' was applied to each intersection for extracting the crash data. This system includes all crashes reported by the police. Only injury (minor and serious) and fatal crashes were included in the modelling. Non-injury or property damage only crashes were excluded due to highly variable reporting rates of this crash type across New Zealand. For approximately 20 sites from each of the rural and urban standard T-intersection datasets (from previous research) the crash data was collected for the same time period as the new intersections (along with recent traffic volumes). A five-year crash period of 2010-2014 was used for each intersection.

The speed limit was extracted from the crash listings for each intersection. For intersections with zero crashes (only in old datasets) the speed limit was extracted from these datasets. If neither of these approaches produced speed limits then a Google Earth search was done to check the speed limit signs leading up to the intersection. Urban speed limits ranged from $50 \mathrm{~km} / \mathrm{h}$ to $70 \mathrm{~km} / \mathrm{h}$, with the majority being $50 \mathrm{~km} / \mathrm{h}$. Rural speed limits ranged from $80 \mathrm{~km} / \mathrm{h}$ to $100 \mathrm{~km} / \mathrm{h}$, with the majority of sites having a speed limit of $100 \mathrm{~km} / \mathrm{h}$. There were some sites with 'rural' (high) speed limits within urban areas.

Previous research on rural intersections by Turner and Roozenburg (2007) shows that the actual approach speed on the main road was a better variable than the speed limit for the prediction model. Unlike on urban roads, the operating

\section{Table 3: Intersection layout variables}

\begin{tabular}{|l|l|}
\hline Category & Layout variables \\
\hline General & Road category, intersection types and region \\
\hline Right turn off main road & Right-turn bay, right-turn bay width, right-turn bay length and right-turn bay stacking \\
\hline Main road median(s) & Length and width \\
\hline Near side characteristics & Number of lanes and shoulder width \\
\hline $\begin{array}{l}\text { Features within wider intersection } \\
\text { and proximity }\end{array}$ & $\begin{array}{l}\text { Near side upstream and downstream, far side upstream and downstream eg. parking } \\
\text { and side-roads }\end{array}$ \\
\hline Far side characteristics & Number of lanes and shoulder width \\
\hline Side road details & Number of lanes, median island and median island width \\
\hline Curvature of main road & No curvature, moderate or sharp \\
\hline Gradient & Side road, main road left approach and main road right approach \\
\hline Street furniture & $\begin{array}{l}\text { Lighting, chevron sign, side road signs, main road speed limit sign and side road } \\
\text { speed limit sign }\end{array}$ \\
\hline Left-turn slip lane on main road & Type, profile, control and pedestrian crossing \\
\hline Left-turn slip lane off main road & $\begin{array}{l}\text { Type, profile, control, pedestrian crossing, offset distances from side road and main } \\
\text { road }\end{array}$ \\
\hline Splitter and median islands & Upstream splitter, upstream median, downstream splitter, downstream median \\
\hline Acceleration lane & Type, length and width \\
\hline
\end{tabular}


speed can be different from the speed limit because of the surrounding terrain and road alignment. In the models both operating speed and speed limit were tested for rural roads, and operating speed was found to be a better predictor variable.

The layout data included the general geometry of the intersections (e.g. whether on curve or grade), the layout of lanes (width and length), the island/median types (solid, painted and hit posts) and sizes, the number of traffic lanes, and the distance and type of the nearest upstream and downstream features (e.g. another side road, parking, bus bay). A summary of the layout variables collected is listed in Table 3.

\section{Crash Causal Factors}

\section{Expert Opinion of Crash Causal Factors}

A workshop involving experienced safety auditors and designers was held to discuss the key causal factors that they believe, based on their experience, impact on the safety of intersections with seagull layouts and LTSLs. This work was undertaken to help identify some of the variables that needed to be considered in the modelling. Note that a number of these factors are picked up and addressed in the design process or safety audits and hence some cannot be tested in crash modelling due to few sites having these faults. Indeed the fact that many are picked up before construction is a good thing. The concerns raised (in no particular order) include:

1. Visibility to the end of the merge. If the merge lane is too long for traffic turning right from the side road then it can appear as a separate traffic lane further upstream of the intersection. If it is too short or on a curve then vehicles may be cautious about entering the through lane.

2. Length of the upstream splitter island. By making the upstream splitter island longer, drivers waiting in the side road to turn right will be able to determine whether vehicles approaching from the left are in the bypass lane or are moving into the right-turn bay (and hence have priority). The main concern here is that the drivers are having to focus too much on the left and not enough on vehicles approaching from the right.

3. The seagull intersection island. Drivers in the side road need to be able to identify that there is a seagull intersection island in front of them and hence a seagull layout intersection. If the Seagull intersection island is painted, too low or over a crest in the road, motorists may not be able to judge that they can turn right without giving way to bypass traffic, causing driver frustration in vehicles behind them.

4. Main road curvature. When intersections are lo- cated at a curve in the main road, there can be issues with reliably assessing which lane drivers are in. They may for example appear to be in the bypass lane but instead are coming into the right-turn bay. The same can occur in terms of judging if a vehicle is turning into a LTSL or going straight through.

\section{Speed environment (speed limit and operating} speed). The speed of approaching vehicles can be difficult to judge when the speed limit is high. Higher speeds are also more likely to cause serious injury and fatal crashes than lower-speed intersections. High speed in combination with a poorly designed intersection or one on a curve is undesirable.

6. Length of the acceleration lane. Seagull intersections with a deficient taper can catch drivers out when they are merging with traffic. In addition merging from the right is a fairly uncommon movement in New Zealand as most merges are from the left to the right.

7. Presence of central medians and splitter islands. In rural areas median and splitter islands can come as a surprise to drivers when they occur over only a short section of roadway. Some drivers can also become confused about how to negotiate the intersection islands when turning in and out of side roads. This distraction can be enough to take the focus off giving way to traffic (e.g. research by Harper, 2011).

8. Double or single lane. Having two rather than one lane for through traffic can impact on speeds and also increase the distance to the safety of the median or side road.

9. Available sight distance. Sight distance is important if drivers are to avoid collision with vehicles they must give way to. The lack of readability of an intersection layout can lead to indecision and driver error. At Seagull intersections and priority intersections with LTSLs, insufficient sight distance can be due to 1) the alignment and topography or 2) location and length of the LTSL. In particular dynamic queuing in a LTSL can temporarily restrict visibility of through traffic when turning right out of the side road.

\section{Crash Analysis}

An analysis of crashes at the rural intersections (Figure 4) shows that the proportion of 'JA' and 'LB' (see Figure 3 for crash codes) increase at sites with a LTSL and at Seagulls (note that most Seagulls have LTSLs). This is partly explained by higher traffic volumes at these enhanced intersections. Understanding whether this increase can be attributed to the increase in traffic volume or the layout (LTSL or Seagull) is a key question that we sought to address in this research study. 

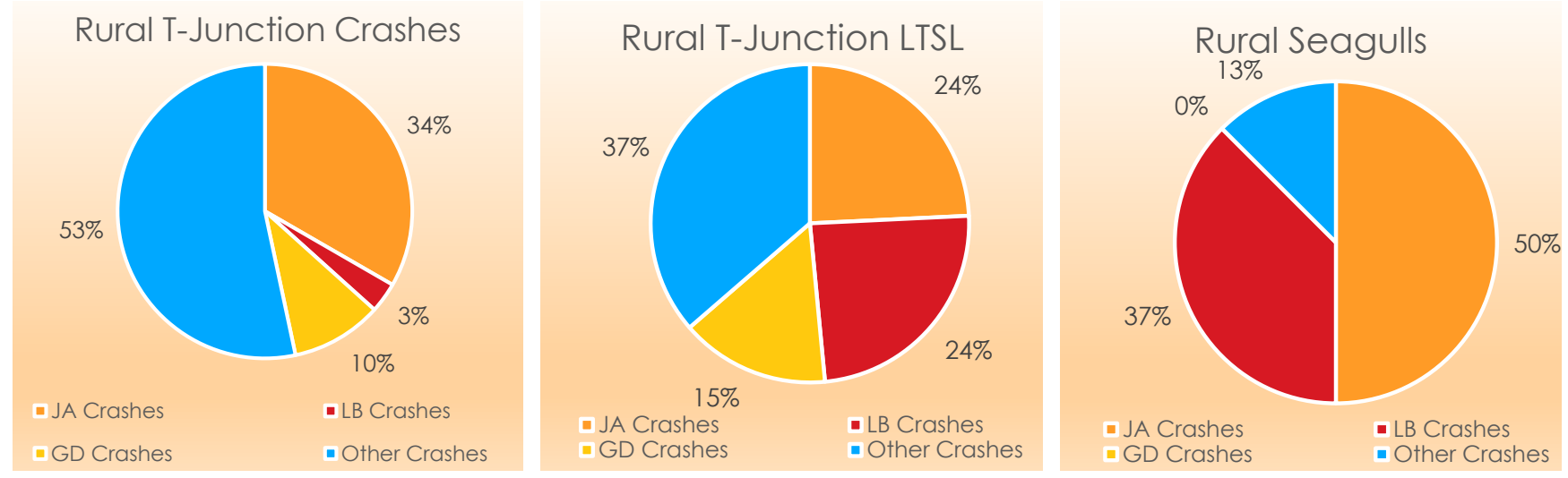

Figure 4: Key crash types at T-intersections

At urban intersections a comparison between standard and Seagull layouts indicates that the proportion of JA crashes increases from $24 \%$ to $34 \%$ and the proportion of LB crashes increases from $16 \%$ to $20 \%$. Again this may be due to higher average traffic volumes at Seagulls.

\section{Crash Prediction Modelling}

In this study generalised linear models (GLMs) were developed for the key crash types at standard priority T-intersections, T-intersections with LTSL and for seagull intersections. The same statistical methods were used to develop the original urban and rural priority T-intersection models (Turner 2001; Turner and Roozenberg 2007). While a number of other crash modelling methods have been used by researchers for crash analysis, GLMs, with either a Poisson or negative binomial error structure, still remain one of the most popular modelling methods internationally. Hence it is still relevant to use GLMs. The main change in the modelling from the previous studies is the addition of speed for the urban models and a design index for both the urban and rural models. The dataset of course also includes Seagull intersection layouts and intersections with LTSLs.

\section{Generalised Linear Models (GLMs)}

Generalised linear models were first introduced to road crash studies by Maycock and Hall (1984), and extensively developed in Hauer et al. (1989). These models were further developed and fitted using crash data and traffic counts for motor-vehicle crashes in New Zealand by Turner (1995).

The aim of the modelling exercise is to develop relationships between the number of crashes annually (the dependent variable), and traffic flows, speeds and road layout (the explanatory variables). Influential road layout variables are captured in a design index. For this study the generalised linear models are of the following form:

Equation $1 Y=\exp \left(\mathrm{b}_{0}\right) \mathrm{Q}_{1}{ }^{\mathrm{b} 1} \mathrm{Q}_{2}{ }^{\mathrm{b} 2}$ Speed ${ }^{\mathrm{b} 3}$ Design Index ${ }^{\mathrm{b} 4}$ where,

$Y$ is the annual number of crashes,

$\mathrm{Q}_{1}$ and $\mathrm{Q}_{2}$ are the average daily flow of vehicles in conflict for the crash type,

\begin{abstract}
'Speed' is either the main road speed limit (MRSL) or operating speed,
\end{abstract}

'Design Index' is a combination of road design features that impact on safety (more on this below),

$\mathrm{b}_{i}$ are the model coefficients, $i=0,1, \ldots, 4$.

The selected model error structure is either Poisson or negative binomial. The "Poisson" model is used where the variance in crash numbers is roughly equal to the mean over the majority of the explanatory variable range. Generally, however, the variance is higher than the mean and hence the "negative binomial" model is more commonly used. The negative binomial model is a mixture of Poisson distributions by a gamma distribution. The model is described using two parameters $k$ and $\mu$, where $k$ along with the coefficients $b_{0}, \ldots, b_{n}$ must be estimated from the data. A more detailed explanation of the models is given in Turner (1995) and Hauer et al. (1989).

The Akaiki information criterion (AIC) has been used to select the most appropriate model. It is defined as AIC $=2 \mathrm{n}-2 \ln (\mathrm{L})$, where $n$ is the number of parameters to be estimated and $L$ is the likelihood of the model fitted. It balances the number of parameters used against the likelihood of the model, using information theory. The AIC measures the relative quality of models; the model with the lowest AIC might still not be of much value so therefore this can be used as a guide only for intersection improvement.

The models were tested for goodness of fit using a grouping technique developed by Wood (2002). We have low mean values so intersections must be grouped and a $\mathrm{G}^{2}$ statistic formed; when the model fits, this follows a chi-square distribution with degrees of freedom approximately the number of groups minus the number of parameters in the model. If the model does not fit, the method indicates intersections with exceptional performance, either highly unsafe or highly safe.

\section{Intersection 'Design Index'}

The major new addition in all models (compared to previous models) is an intersection design index. In the past design variables have been added individually and often have 
Table 4: Summary of models developed

\begin{tabular}{|l|l|l|l|l|l|l|l|l|}
\hline \multicolumn{2}{|l|}{ Standard T-intersection } & \multicolumn{4}{l|}{ T-intersection - LTSL } & Seagull \\
\hline & JA & LB & & JA & LB & & JA & LB \\
\hline Rural (93) & TRJA & X & Rural (37) & TLRJA & TLRLB & Rural (12) & SRJA & SRLB \\
\hline Urban (92) & TUJA & TULB & Urban (10) & X & X & Urban (17) & SUJA & X \\
\hline
\end{tabular}

\# In model name abbreviations T is standard T-intersection, TL is T-intersection with LTSL, S is Seagull, R is rural, U is urban and JA and LB are crash types

Table 5: Crash Prediction Models- JA Crashes

\begin{tabular}{|l|c|c|c|c|c|c|c|}
\hline Model Names & bo & Q1 b1 & Q5 b2 & Speed b3 & DI b4 & GOF G $^{2}$ & Fit \\
\hline $\begin{array}{l}\text { Rural Standard T-Intersections } \\
\text { TRJA }\end{array}$ & -30.37 & 0.51 & 0.27 & 4.0 & 1.6 & 2.33 & Reasonable \\
\hline $\begin{array}{l}\text { Urban Standard } \\
\text { T-Intersections TUJA }\end{array}$ & -38.47 & 0.025 & 0.13 & 3.8 & 5.8 & 40.79 & Very Poor \\
\hline $\begin{array}{l}\text { Rural T-intersection with } \\
\text { LTSL TLRJA }\end{array}$ & -26.13 & 0.92 & 0.42 & 2.2 & 5.3 & $? ?$ & Excellent \\
\hline $\begin{array}{l}\text { Rural Seagull Intersection } \\
\text { SRJA }\end{array}$ & -21.00 & 1.11 & 0.23 & 1.9 & 2.8 & 3.96 & Moderate \\
\hline $\begin{array}{l}\text { Urban Seagulls Intersection } \\
\text { SUJA }\end{array}$ & -13.42 & 1.04 & 0.25 & - & 3.6 & 1.18 & Excellent \\
\hline
\end{tabular}

Speed - operating speed or speed limit, DI - Design Index, GOF - goodness-of-fit \& $\mathrm{G}^{2}$ - Deviance statistic

very low predictive power on their own. A "design index" which combined influential design variables was generally found to have significant predictive power. The research experimented with an 'expert' driven design index but found a data-driven one able to explain more.

The data-driven design index captures the way aspects of the geometry of the intersection influence safety, using the specific data gathered about each intersection. This was developed for each intersection type/location/crash type case (e.g. Seagull, urban, JA crashes). A partial model incorporating the conflicting flows and speed limit was fitted and the crash residuals examined - these are the variations in the crash rate not explained by the partial model. These residuals were plotted against up to 63 intersection variables (in the case of Seagulls) and those factors explaining some variation in the residual crash rate were noted. These were initially given equal weight and combined into a single design index. Improved models were obtained by upweighting the more important factors (by using weights proportional to the reciprocal of the $p$-values).

\section{Crash Prediction Modelling Results}

Crash prediction models have been built for all combinations of location (rural and urban), intersection type (T-intersections, T-intersection with LTSLs and Seagull intersections) and major crash type (JA and LB) for which adequate data is available. These cases are summarised in Table 4.
The number of intersections in each row of each subtable is shown (for example, there are 93 rural standard T-intersections). There were insufficient intersections or crashes for four of the combinations (those marked ' $\mathrm{X}$ '); in these cases models could not be fitted. For each of the remaining eight combinations a design index was developed, built using the geometric variables found to influence the safety of the combination. The key contributing variables change from case to case. The design index runs from low values when the intersection is safe to high values when it is unsafe. Table 5 and 6 show the crash models developed for both the JA and LB crash types. The tables also show the quality of the model fits. Some models have an excellent fit while others, especially some urban models, have a poor fit.

Table 7 shows the design elements that make up the design index (DI) for each model. For more detail on variables refer to Turner et al. (2018).

In some cases the addition of the design index was the key reason for achieving a well-fitting model. This is the case with the TLRJA model, which has a constant term, flows Q1 and Q5, Speed and the TLRJADI design index providing an excellent fit. The model with only constant term, or constant term with $\mathrm{Q}_{1}$, or constant term with both $\mathrm{Q}_{1}$ and $\mathrm{Q}_{5}$ fails to fit (the fitting algorithm does not converge). When speed is included as a fourth variable the model does fit, with AIC value of 22.14. When, in addition, the TLRJA design index TLRJADI is included, the model is improved, with a lower AIC value of 19.11 (the lower the AIC value, the better the fit). The design index in all cases considerably improves the model, reducing the AIC. 


\section{Summary of Findings and Future Research}

The previous research in this area, and an analysis of national crash data and crashes at the study intersections, identified that there were two main crash types at highvolume priority T-intersections: JA (right-turn crossing) and LB (right-turn-against) crashes. Of particular interest in this study has been the impact of LTSLs and Seagull layouts, at priority T-intersections, on JA and LB crashes.

As detailed in the literature review, road safety professionals are concerned that in some situations LTSLs may be increasing the risk of JA crashes. There are also concerns that Seagull layouts, especially poorly designed ones, also increase the crash risk. The impact of various design and layout variables on crash occurrence is also significant. Other important variables include the conflicting traffic volumes and speed.

The following sections outline the key findings of the research as they apply to urban and rural Seagulls and LTSLs in rural areas. These findings were identified in the literature review and through crash prediction modelling. Each of the models had an excellent fit to the data.

\section{Urban seagull intersections (SUJA)}

The key road safety findings at urban Seagulls are as follows - note that the human factors mentioned are one possible interpretation of why a variable was shown to be important:

Table 6: Crash Prediction Models- LB Crashes

\begin{tabular}{|l|c|c|c|c|c|c|c|}
\hline Model Names & bo & Q3 b1 & Q5 b2 & Speed b3 & DI b4 & GOF G' & Fit \\
\hline $\begin{array}{l}\text { Urban Standard T-Intersections } \\
\text { TULB }\end{array}$ & 1.21 & 0.40 & 0.21 & -4.5 & 3.1 & 17.31 & Very Poor \\
\hline $\begin{array}{l}\text { Rural T-intersection with LTSL } \\
\text { TLRLB }\end{array}$ & -21.17 & -0.034 & 0.35 & 2.4 & 4.8 & 2.27 & Excellent \\
\hline $\begin{array}{l}\text { Rural Seagull Intersection } \\
\text { SRLB }\end{array}$ & -8.5 & 1.0 & - & - & 1.5 & 1.93 & Excellent \\
\hline
\end{tabular}

$\mathrm{Q}_{1}$ - right turn from side-road, $\mathrm{Q}_{3}$ - right turn from main road \& $\mathrm{Q}_{5}$ through movement from right side of side-road

Table 7: Design Elements

\begin{tabular}{|c|c|c|}
\hline Models DI & $\begin{array}{l}\text { No. } \\
\text { Variables }\end{array}$ & Variables \\
\hline TRJA-DI & 6 & $\begin{array}{l}\text { Provision of right turn bay and width and length of this bay, main road median } \\
\text { width, presence of near-side upstream feature (e.g. parking, bus stops and side- } \\
\text { roads and visibility to right } 2 \mathrm{~m} \text { from limit line }\end{array}$ \\
\hline TUJA-DI & 10 & $\begin{array}{l}\text { Right turn bay taper length, main road median width and type (solid/painted), near } \\
\text { side number of lanes, distance to far-side upstream feature, number of lanes on } \\
\text { side-road approach and median width, gradient of main road, width of acceleration } \\
\text { lane and presence of car parking near intersection. }\end{array}$ \\
\hline TLRJA-DI & 4 & $\begin{array}{l}\text { Length of right turn bay, off-set of LTSL from side-road limit line, LTSL control } \\
\text { (none and give-way) and type of main road median. }\end{array}$ \\
\hline SRJA-DI & 7 & $\begin{array}{l}\text { Main road median width and type, number of near-side and far-side lanes, side road } \\
\text { signage (stop or give-way), width of separation between LTSL and through lane } \\
\text { and off-set of LTSL from side-road limit line. }\end{array}$ \\
\hline SUJA-DI & 9 & $\begin{array}{l}\text { Width of right turn bay, main road median type and width, near-side shoulder } \\
\text { width, distance to far-side upstream feature, LTSL into main road prevision and } \\
\text { type, length of seagull splitter island and length of acceleration lane. }\end{array}$ \\
\hline TULB-DI & 8 & $\begin{array}{l}\text { Distance to near-side upstream feature, presence and width of side-road median, } \\
\text { presence of street lighting and top of tee chevron board and main road median } \\
\text { island width and total road width. }\end{array}$ \\
\hline TLRLB-DI & 5 & $\begin{array}{l}\text { Width of right turn bay, width of side-road median and number approach lanes, } \\
\text { presence of top-of-tee chevron and type of LTSL }\end{array}$ \\
\hline SRLB-DI & 6 & $\begin{array}{l}\text { Right turn bay length, main road median width, number of near-side and far-side } \\
\text { lanes, type of LTSL and off-set of LTSL from side-road limit line. }\end{array}$ \\
\hline
\end{tabular}


1. Wider right-turn bays (on the main road) increase JA crashes (this may cause higher entry speeds into the right turn bay and distract drivers turning right out of the side-road)

2. Seagull intersection layouts with wider medians have more JA crashes (Radalj et al. 2006 found that poorly designed right-turn bays in wide medians - high angle - increased crashes and especially crash severity).

3. A greater nearside shoulder width increased JA crashes (this could be due to a greater crossing distance to the safety of the median).

4. Far-side upstream features impact on JA crashes (this may draw the attention of drivers turning right into the main road to the left, rather than looking to the right where they should be primarily focused).

5. Larger seagull islands (and typically larger intersections) increase JA crashes (most likely due to higher negotiation speeds).

6. The longer the Seagull acceleration lane is for drivers on the main road the more JA crashes are expected (may be due to higher intersection negotiating speeds).

\section{Rural T-intersections with LTSLs (TLRJA and TLRLB)}

The key road safety findings at rural intersections with LTSLs are as follows:

1. A shorter right-turn bay for turning into the side road increases JA crashes (this means that drivers drop into the right-turn bay later - this may draw the attention of the right-turn-out drivers to the left rather than to the right where they should be focused).

2. A greater number of side road traffic lanes reduces LB crashes (greater distance to safety of the side-road).

3. The presence and greater width of the side road median island increases LB crashes (may be associated with a slower right-turn movement around the median island, leaving the right turning vehicle exposed to a crash for longer).

4. The type of downstream median island impacts on the number of JA crashes. Wider painted and solid medians are safer (unclear why this is the case).

5. A give way control on a LTSL appears to reduce JA crashes (this could be due to lower speeds of leftturning vehicles or due to the safer design of the LTSL - generally give ways are placed on a high entry angle LTSL).

\section{Rural Seagull intersections (SRLB)}

The key road safety findings at rural Seagulls are as follows:

1. Longer right-turn bay increases LB crashes (may be a surrogate for high right-turn movement and create pressures on drivers to make the right turn into the side road).
2. Seagull intersections with wider main road medians have more LB and JA crashes (see comments on urban seagulls - SUJA).

3. The presence of two near-side lanes increases LB and JA crashes (this may be due to the wider distance to cross to a safe area).

4. The presence of two far-side through lanes increases LB and JA crashes (this is likely to be highly correlated to the number of near-side lanes, where the extra width is likely to increase crashes).

5. Intersections with stop controls have a higher risk of JA crashes than give way control (this is likely to be due to the reduced approach sight distance at stop controlled intersections).

6. The type of LTSL treatment impacts on LB crashes (this has been found in other studies - it might be that right-turn-out of side road drivers are expecting vehicles to turn left rather than travel straight through).

7. The more positive the offset between the side road limit line and the left-turn bay lane line, the higher the number of JA crashes (this is likely to be due to leftturning vehicles obscuring sight distance to through vehicles for drivers on the side road if the side road limit line is well set back from the main road).

\section{Goodness-of-fit and Analysis Tool}

Generally the rural crash models had a good fit to the crash data. Based on the good fit there is a level of confidence that these models are useful for estimating crashes in rural areas. In comparison the two models for standard urban T-intersections had a poor fit, despite a lot of variables being identified. Further work is required to develop better fitting models for urban priority intersections.

An Excel toolkit was developed to assess the safest form of control for a given combination of variables, including flows (see Turner et al. 2018 for more detail on this spreadsheet tool). There is considerable scope for a designer to improve safety by improving an intersection's design. Where this is not possible the designer can look at changing to a different layout, by adding a LTSL or a seagull layout. It is likely that the benefit of this will depend on the speed limit and the conflicting traffic volumes. Further work is required to test the toolkit and determine whether it is useful for designers to find ways of improving intersection design to provide crash reduction benefits. Hence we suggest caution in using the spreadsheet alone to change road designs.

\section{Future Research}

The focus of future research should be to:

1. Examine further the impact on crash rates of various LTSL types and combination of left-turn and through traffic volumes and speeds. The number of sites may need to be doubled from the existing sample size of 37 rural intersections to produce robust results. 
2. Explore alternative forms of the design indices that have been used for each of the eight models. This may improve the goodness of fit of the models, especially for urban models.

3. Study the effect of upstream and downstream features like car parking, bus shelters and side roads. The research could look at the type of features and the distance to features. It would also be useful for urban roads, in particular, to look at how road features (eg. parking) impact on approach speeds.

4. Develop better crash prediction models for JA and LB crashes at standard T-intersections, especially urban intersections. These models currently underestimate the number of crashes at medium and high-volume intersections, as most of the intersections had low traffic volumes.

\section{References}

Elvik, R., Høye, A., Vaa, T., \& Sørensen, M. 2009. The Handbook of Road Safety Measures (2nd ed.). Bingley: Emerald.

Harper, J., Smart, W., \& De Roos, M. 2009. Seagull intersection layout, island point road: a case study. Australasian Road Safety Research, Policing and Education Conference. Perth, WA.

E. Hauer, J.C.N. Ng, J. Lovell, 1989 Estimation of safety at signalized intersections, Transportation Res. Rec. 1185 pp48-61.

G. Maycock and R.D. Hall, 1984 Accidents at 4-arm roundabouts. Laboratory Report LR1120 Transport Research Laboratory, Crowthorne, Berks, UK.
Radalj, T., Raymond, R., Syeda, S., \& Johnston, D. 2006. Seagull island evaluation. Main Roads Western - Road Safety.

Summersgill, I., Kennedy, J., \& Baynes, D. 1996. Accidents at three-arm priority junctions on urban single-carriageway roads. Crowthorne, U.K: Department of Transport.

Tang, J., \& Levett, S. 2009. Safety performance of T-junctions on high speed rural roads: stage 1 - seagull T-junctions. Australasian Road Safety Research, Policing and Education Conference. Sydney, NSW.

Turner, S.A. 1995. Estimating Accidents in a Road Network. PhD Thesis, Department of Civil Engineering, University of Canterbury, NZ.

Turner, S. 2001. Accident Prediction Models. NZ Transport Agency Research Report 192,

Turner, S and Roozenburg, A. 2007. Crash Rates at Rural Intersections, Road Safety Trust Research Report, NZTA, Wellington, NZ

Turner, S., Easwarapadcham, U., Blewden, R., Bosher, S. and Wood, G. 2018. The crash performance of seagull intersections and left-turn slip lanes, NZ Transport Agency Research Report 644, Wellington, NZ (www.nzta.govt.nz/ resources/research/reports/644)

Urlich, C. 2014. Assessing the safety performance of left-turn facilities at rural T-junctions in New Zealand. University of Auckland Masters Project (788A and 788B). Auckland, NZ

Wood, G.R. 2002 Assessing goodness of fit for Poisson and negative binomial models with low mean, Communications in Statistics - Theory and Methods 31 (2002) 1977-2001. 


\title{
Road Traffic Fatalities in Malawi: The Role of Pedestrian Behaviour Factors
}

\author{
Gibson Mpokonyoka Ngwira ${ }^{1}$, Benjamin Bolaane ${ }^{2}$, and Bhagabat P. Parida ${ }^{3}$ \\ ${ }^{1}$ Directorate of Road Traffic and Safety Services, Lilongwe, Malawi \\ ${ }^{2}$ University of Botswana, Faculty of Engineering and Technology, Gaborone, Botswana \\ ${ }^{3}$ University of Botswana, Department of Civil Engineering, Gaborone, Botswana
}

Corresponding Author: Gibson Mpokonyoka Ngwira, Private Bag 257, Lilongwe, Malawi Email address: mpokonyoka@yahoo.co.uk Phone No.: +265999368944.

This peer-reviewed paper was first presented as an Extended Abstract and Oral Presentation at the 2018 Australasian Road Safety Conference (ARSC2018) held in Sydney, NSW, Australia and first published in the ARSC2018 Proceedings in the form of an Extended Abstract. It was expanded into a 'Full Paper' and underwent further peer-review by three independent experts in the field. It is being reproduced here with the kind permission of the authors and is now only available in this edition of the JACRS.

\section{Key Findings}

- The negative binomial regression model was found to be the best fitting model or the model that better agrees with the data.

- Pedestrian behaviour factors of walking on roads, crossing outside pedestrian crossings, crossing carelessly, and other forms of negligence demonstrated a positive relationship with road-related fatalities.

- Behaviour factors of being under the influence of alcohol demonstrated zero influence and crossing at pedestrian crossings exhibited a small negative influence.

- There was a $1 \%$ increase in the number of crash deaths for every additional fatal crash involving pedestrians walking on a road.

\begin{abstract}
Pedestrian behaviour is one of the major contributors to road fatalities. The negative binomial regression model was found to better agree with road fatality data, and this study used this model to assess the influence of pedestrian behaviour factors on road fatalities in Malawi. The data used in this analysis were crash reports of pedestrian behaviour factors and observed fatalities for the period 2000-2015 obtained from the national database, except for the 2013 data, which were disregarded because they appeared to be incomplete. Whereas pedestrian behaviour factors of walking on roads, crossing outside pedestrian crossings, and other negligent and careless behaviours were found to be positively correlated with road deaths, indicating that road-related fatalities increased with increasing input data, factors of being under the influence of alcohol and crossing at pedestrian crossings demonstrated negligible influence. The study also found that there was a $1 \%$ increase in the number of crash deaths for every additional fatal crash involving pedestrians walking on roads. Moreover, an additional $0.5 \%$ increase in the number of fatalities was recorded for every fatal crash involving a pedestrian behaviour factor of crossing outside the pedestrian crossing or other negligent behaviour. An increase of $0.3 \%$ in the number of the fatalities was seen for every extra fatal crash caused by crossing carelessly or factors other than pedestrian behaviour. Despite coefficient values being small in all variables, which is a major limitation of this study, enforcement can prioritise those variables that increase road-related fatalities or even couple them with other risk factors such as speed.
\end{abstract}

\section{Keywords}

Road Fatalities, Pedestrian Behaviour Factors, Count Data, Poisson Regression Models, Malawi

\section{Introduction}

Pedestrians are among the most vulnerable road users in almost all regions of the world, according to the World Health Organization (WHO), with Africa being the most severely affected (WHO, 2015). The recent WHO report on the global status of road safety indicates that pedestrians represented $39 \%$ of all crash deaths that occurred in Africa (WHO, 2015). Some reported studies have shown that the highest proportion of crash-related deaths reported in many African countries involve pedestrians. For example, an analysis of 2010 crash reports in Malawi showed that pedestrians accounted for $48 \%$ of all road deaths (Kuotha et al., 2016). An analysis of crash reports in Malawi for the period 2000-2015 also shows that the rate of road-related pedestrian fatalities remained high, at $47 \%$ (Table 1). Odero et al. (2003) reported that, in Kenya, pedestrians alone represented $42 \%$ of all crash victims killed between 1971 
Table 1. Distribution of road fatalities in Malawi by road user class (2000-2015)

\begin{tabular}{|l|l|l|}
\hline $\begin{array}{l}\text { Road user } \\
\text { category }\end{array}$ & Killed & Proportion (\%) \\
\hline Bicyclist & 1891 & 16.4 \\
\hline Driver & 1044 & 9 \\
\hline Motorcyclist & 163 & 1.4 \\
\hline Pedestrian & 5373 & 46.5 \\
\hline Passenger & 3092 & 26.7 \\
\hline Total & 11563 & 100 \\
\hline
\end{tabular}

Source: National crash database

and 1990. Similarly, pedestrians accounted for $55 \%$ of all road traffic deaths in Mozambique in the period 1993-2000 (Romão et al., 2003) and 46\% of all crash deaths reported in Ghana in the period 1994-1998 (Afukaar et al., 2003). Unlike in Malawi, in Ghana in 2016, road-related pedestrian fatalities were reported to have decreased to $22 \%$ (National Road Safety Commission, 2016); nevertheless, they remained high, being the second most common category of road-related deaths.

In addition to the high numbers of pedestrian deaths from exposure to road traffic (Odero, 1995; Khayesi, 1997, 1999; Said, 2000; Nantulya \& Muli-Musiime, 2001), they also belong to the most disadvantageous social-economic group, particularly in Africa (Nantulya \& Muli-Musiime, 2001). Road-related pedestrian fatalities in Africa are on the increase, and equivocal evidence points to contributions from pedestrian behaviour. For example, Ahmed (2016) showed that the probability of being involved in a fatal pedestrian crash increases with increasing road speed limit, increasing number of lanes, lack of designated crosswalks, and pedestrians crossing at mid-block sections, on rural roads, and in dark locations. Another study found that older pedestrians' road-crossing behaviour in complex traffic situations was less safe than that of their younger counterparts while, in less complex situations, older pedestrians' behaviour was more like that of younger pedestrians (Oxely et al., 1995). Poudel-Tandukar et al. (2007) found that there is no significant association between road behaviours such as 'looking both ways along the road before crossing' or 'playing in the road or sidewalks' and pedestrian injury. Further, Praveen et al. (2018) found that pedestrians with technological and social distractions were more prone to road traffic injuries. In observing the complexity of understanding the influence of pedestrian behaviour on fatalities, Mako and Szakoyi (2016) suggested that there should be a stronger contribution from human and engineering fields to realise more positive change in the safety of vulnerable road users. This study aims to assess the influence of pedestrian behaviour factors on road fatalities in Malawi. The study is a contribution towards addressing the growing problem of road traffic injuries through enhancing the understanding of the contributory factors towards pedestrian-related traffic fatalities. This study will help ensure that already scarce resources mainly in low-income countries (Lagarde, 2007) such as Malawi are properly targeted, thereby improving peoples' well-being.

\section{Methodology}

Archived crash data were analysed to establish the influence of pedestrian behaviour factors on road fatalities in Malawi. The following discusses mainly the data sources and methods used for collecting and analysing the data. The conceptual framework for the methodology used in this study is presented in Figure 1.

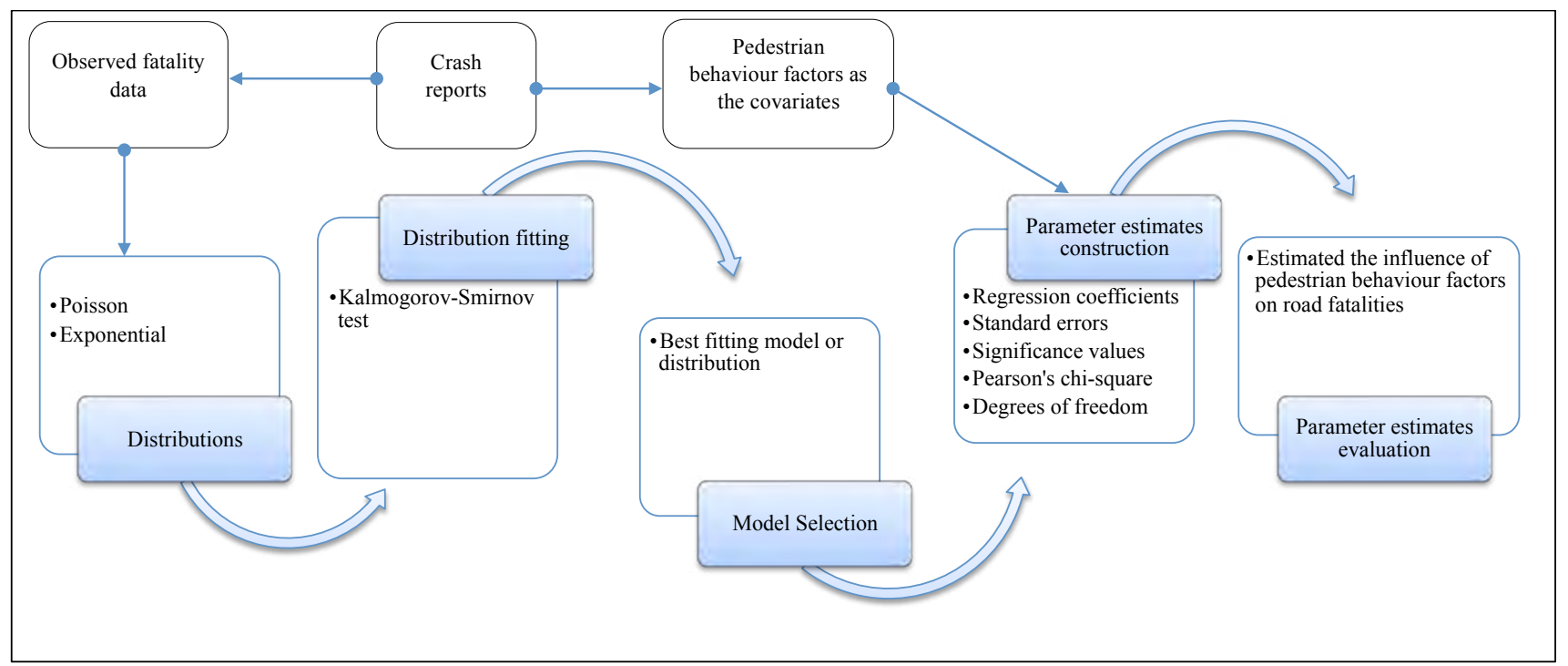

Figure 1. Process undertaken to assess the influence of pedestrian behaviour factors on road fatalities in Malawi 


\section{Data Sources and Type}

Police are the only source of crash data in Malawi and routinely collect data on road crashes, personal injuries (minor, serious, and fatal), and property damage. Accident report forms are used for recording crash details to provide consistency in reporting. Apart from the data being used for court prosecution and insurance compensation by police, they are also sent to the Malawi Directorate of Road Traffic $\&$ Safety Services (DRTSS) for processing, storage, and reporting to state authorities and the general public. In Malawi, a death is considered a result of a road accident if the victim dies instantly or within 30 days of the crash ('Road Traffic Act," 1997; WHO, 2013).

The data used in this analysis, which are crash reports for pedestrian behaviour factors and fatalities, are presented in Table 2. These data were obtained from the national database of annual crash reports kept and managed by DRTSS. They cover the period from 2000 to 2015, except for the 2013 data, which were disregarded because they appeared to be incomplete. The restructuring of DRTSS in 2013 affected data recording in that year. However, statistics and trends of the observed data (Table 2) show that data entry became normal again in 2014 and subsequent years.

\section{Model Identification}

Studies in the past have generally suggested the use of regression count models such as Poisson regression $(\mathrm{PR})$ and negative binomial regression (NBR) models (Cameron \& Trivedi, 1998; Wulu et al., 2002; Surhone et al., 2010; Sarani et al., 2012) and autoregressive (AR) and autoregressive integrated moving average (ARIMA) (Lana et al., 2018) time series models for estimating road traffic fatalities. Because crash deaths are data counts in positive integers and generally small in sample size, PR or NBR models have generally been favoured as powerful tools for making reliable predictions in road safety (Cameron \& Trivedi, 1998; Wulu et al., 2002; Surhone et al., 2010; Sarani et al., 2012. Further, as the intent of this study is to establish the influences of pedestrian behaviour factors on road traffic fatalities, PR models were deemed appropriate as they use multivariate data to establish the relationship between the influencing factors and outcome data (Sarani et al., 2012).

Apart from the fact that data must be count data, they should also meet the distribution assumption for purposes of using PR models for statistical analyses. To satisfy this assumption, the observed traffic fatality data (Table 2) were tested for Poisson and exponential distributions. These distributions were tested using the Kalmogorov-Smirnov $(\mathrm{K}-\mathrm{S})$ test. One of the advantages of the K-S test is that it

Table 2. Annual distribution of road crashes by pedestrian behaviour factors

\begin{tabular}{|c|c|c|c|c|c|c|c|c|}
\hline Year & BUI & $\begin{array}{c}\text { Crossing at } \\
\text { pedestrian } \\
\text { crossing }\end{array}$ & $\begin{array}{l}\text { Crossing } \\
\text { carelessly }\end{array}$ & $\begin{array}{c}\text { Crossing } \\
\text { outside } \\
\text { pedestrian } \\
\text { crossing }\end{array}$ & $\begin{array}{c}\text { Nothing } \\
\text { noted }\end{array}$ & $\begin{array}{l}\text { Walking } \\
\text { on road }\end{array}$ & Other & $\begin{array}{c}\text { Traffic } \\
\text { fatalities }\end{array}$ \\
\hline 2000 & 7 & 2 & 60 & 2 & 39 & 5 & 1 & 342 \\
\hline 2001 & 9 & 0 & 55 & 7 & 54 & 9 & 4 & 321 \\
\hline 2002 & 10 & 0 & 90 & 6 & 107 & 15 & 3 & 453 \\
\hline 2003 & 10 & 3 & 82 & 2 & 57 & 16 & 8 & 432 \\
\hline 2004 & 5 & 7 & 30 & 0 & 58 & 12 & 39 & 283 \\
\hline 2005 & 11 & 3 & 124 & 1 & 267 & 21 & 42 & 1027 \\
\hline 2006 & 8 & 2 & 124 & 0 & 218 & 25 & 17 & 930 \\
\hline 2007 & 15 & 1 & 118 & 1 & 257 & 9 & 18 & 841 \\
\hline 2008 & 23 & 3 & 103 & 1 & 308 & 22 & 28 & 942 \\
\hline 2009 & 17 & 6 & 64 & 2 & 200 & 19 & 52 & 863 \\
\hline 2010 & 15 & 5 & 88 & 0 & 324 & 20 & 22 & 976 \\
\hline 2011 & 11 & 5 & 75 & 3 & 230 & 15 & 28 & 784 \\
\hline 2012 & 17 & 8 & 102 & 3 & 144 & 9 & 143 & 880 \\
\hline 2013 & 4 & 2 & 28 & 1 & 126 & 11 & 20 & 416 \\
\hline 2014 & 14 & 0 & 42 & 1 & 378 & 13 & 17 & 1068 \\
\hline 2015 & 17 & 0 & 67 & 5 & 341 & 18 & 24 & 1068 \\
\hline
\end{tabular}

Source: National crash database 
does not depend on adequate sample size for the test results to be valid (Croarkin et al., 2002); hence, it is ideal for this study because the observed datasets are not long enough $(n=15)$. In this case, the distribution that showed better agreement with the data could be used for determining the influence of pedestrian behaviour factors on road traffic fatalities.

Mathematical structures for PR and NBR models recommended for estimating crash data are expressed in the following.

\section{Poisson regression model}

Suppose $Y$ is a discrete random variable such as crash deaths having independent response variables $y_{1}, y_{2}, \ldots, y_{n}$ that follow a Poisson distribution (Wulu et al., 2002). The density function of a PR model of a random count $Y$ given $x_{i}$ (Cameron \& Trivedi, 1998; Wulu et al., 2002; Surhone et al., 2010; Sarani et al., 2012) may be defined as follows:

$f\left(Y=y_{i} \mid x_{i}\right)=\frac{e^{-\mu_{i} \mu_{i} y_{i}}}{y_{i} !}, \quad y_{i}=0,1,2, \ldots$,

where $\mu_{i}$ is the mean incidence rate of events for an observation $i$ which are crash deaths; and $\mu_{i}$ is also the called exponential mean or linear parameter of the PR model. Therefore,

$$
\begin{aligned}
\mathrm{E}\left[y_{i} \mid x_{i}\right]= & \mu_{i}=\exp \left(\beta_{0}+X_{1}^{\prime} \beta_{i}\right)= \\
& \exp \left(\beta_{0}+\beta_{1} X_{1 i}+\beta_{2} X_{2 i}+\cdots+\beta_{n} X_{n i}\right)
\end{aligned}
$$

Taking the natural logarithm of the linear parameter $\left(\mu_{i}\right)$ gives

$$
\begin{aligned}
& \ln \mathrm{E}\left[y_{i} \mid x_{i}\right]=\ln \mu_{i}=\ln \left[\exp \left(\beta_{0}+X_{1}^{\prime} \beta_{i}\right)\right] \\
&=\ln \left[\exp \left(\beta_{0}+\beta_{1} X_{1 i}+\beta_{2} X_{2 i}+\cdots+\beta_{n} X_{n i}\right)\right] \\
& f\left(Y=y_{i} \mid x_{i}\right)=\beta_{0}+\beta_{1} X_{1 i}+\beta_{2} X_{2 i}+\cdots+\beta_{n} X_{n i}
\end{aligned}
$$

where $y_{i}=\mu_{i}$ is the incidence rate of events for an observation $i$ that follows a Poisson distribution, which are the crash deaths; $\beta=\beta_{1}, \beta_{2}, \ldots, \beta_{n}$ are the regression coefficients for the explanatory variables of pedestrian behaviour factors of walking on the road, crossing outside pedestrian crossings, other negligent behaviour, crossing carelessly, being under the influence (BUI) of alcohol, and crossing at pedestrian crossings estimated from a set of crash data; $X=X_{1 i}, X_{2 i}, \ldots, X_{n i}$ are a set of $n$ explanatory variables of the above-mentioned pedestrian behaviour factors; and $\beta_{0}$ is a constant (intercept).

Equation (3) is referred to as a PR model. The assumption is that the mean and variance are equal and this model describes a set of count data as equidispersed. Hence, PR models are ideal for handling equidispersion (Wulu et al., 2002).

\section{Negative binomial regression model}

The negative binomial distribution is a mixture of Poisson and gamma distributions (Surhone et al., 2010; Hilbe, 2011). Suppose $Y$ is a discrete random variable such as crash deaths having independent response variables $y_{1}, y_{2}, \ldots, y_{n}$ that follow a negative binomial distribution (Wulu et al., 2002). The density distribution of an NBR model of a discrete random count $Y$ given $\theta_{i}$ (Cameron $\&$ Trivedi, 1998) is as follows:

$$
f\left(Y=y_{i} \mid \theta_{i}\right)=\frac{\exp \left(-\theta_{i}\right)\left(\theta_{i}\right)^{y_{i}}}{y_{i} !}, y=0,1, \ldots,
$$

where $\theta_{i}=\mu_{i} v_{i}$

Suppose the parameter $\theta_{i}$ has a random intercept term and that the random term enters the conditional mean function multiplicatively (Cameron \& Trivedi, 1998), that is,

$$
\begin{aligned}
\theta_{i} & =\mu_{i} v_{i}=\exp \left(\beta_{0}+X_{\hat{1}}^{\prime} \beta_{i}+\varepsilon_{i}\right)=\text { linear parameter } \\
& =e^{X_{1}^{\prime} \beta_{i}} e^{\beta_{0}+\varepsilon_{i}}
\end{aligned}
$$

where $\exp \left(\beta_{10}+\varepsilon_{i}\right)$ is interpreted as a random intercept, $\mu_{i}=e^{\left(\beta_{0}+X_{i} \beta_{i}\right)}$ is the mean incidence rate of events for an observation $i$, which are crash deaths, and $v_{i}=e^{\varepsilon_{i}}$ is the NBR model error term.

Taking the natural logarithm of the linear parameter $\left(\theta_{i}=\mu_{i} v_{i}\right)$ gives

$$
\begin{aligned}
\ln \left(\theta_{i}=\mu_{i} v_{i}\right) & =\ln \left[\exp \left(\beta_{0}+X_{1}^{\prime} \beta_{i}+\varepsilon_{i}\right)\right] \\
& =\beta_{0}+X_{i}^{\prime} \beta_{i}+\varepsilon_{i},
\end{aligned}
$$

where

$$
X_{1}^{\prime} \beta_{i}=\beta_{1} X_{1 i}+\beta_{2} X_{2 i}+\cdots+\beta_{n} X_{n i}
$$

Therefore,

$f\left(Y=y_{i} \mid \mu_{i}, v_{i}\right)=\beta_{0}+\beta_{1} X_{1 i}+\beta_{2} X_{2 i}+\cdots+\beta_{n} X_{n i}+\varepsilon_{i}$,

where $y_{i}=\mu_{i}$ is the incidence rate of events for an observation $i$ that follows a negative binomial distribution, which are the crash deaths; $\beta=\beta_{1}, \beta_{2}, \ldots, \beta_{n}$ are the regression coefficients for the same explanatory variables as explained in the PR model; $X=X_{1 i}, X_{2 i}, \ldots, X_{n i}$ are a set of $n$ explanatory variables of the same pedestrian behaviour factors as described in the PR model; $\beta_{0}$ is a constant (intercept); and $\varepsilon$ is the NBR model error term.

Equation (6) is referred to as an NBR model. The assumption is that the variance is greater than the mean and this model describes a set of count data as overdispersed. Therefore, NBR models are ideal for handling overdispersion (Wulu et al., 2002).

The parameter estimates for these models (PR and NBR) can be constructed using these equations, i.e., Eq. (3) for the PR model and Eq. (6) for the NBR model. However, performing analyses using this approach (equations) could be too tedious and overwhelming; therefore, any appropriate statistical software can be used. 
For this study, the parameter estimates for the model (PR or NBR) that demonstrated better agreement with the observed fatality data were constructed using SPSS software. The constructed parameter estimates were mainly regression coefficients $(\beta)$, standard errors (SEs), twotailed significance $(\rho)$, Pearson's chi-square, and degree of freedom (DF). The regression coefficients were used for defining the level of influence of pedestrian behaviour factors on road fatalities, and Pearson's chi-square and DF were used for testing data characteristics.

\section{Results and Discussion}

To assess the influence of pedestrian behaviour factors on road fatalities in Malawi, data on crash reports as presented in Table 2 have been considered. The analyses were conducted in two stages:

i. A goodness-of-fit test was undertaken for different distributions to identify a best-fit distribution or a model that best agrees with the data to ensure that valid results or estimates are obtained.

ii. Unknown parameter estimates of the best-fit distribution or model identified in (i) were constructed. This will be the model to use for determining the influence of pedestrian behaviour factors on road traffic fatalities in Malawi.

\section{Goodness-of-Fit Test for Different Distributions}

The results of a series of K-S tests performed on the observed traffic fatalities are presented in Table 3. At a significance level of 0.05 , values of $p \leq 0.05$ rejected the null assumption that data followed a specified distribution and accepted the alternative hypothesis. The results show that the K-S tests rejected the supposition that data were Poisson distributed as the $p$ value $(p=0.000)$ was $<0.5$ and failed to reject the exponential assumption $(p=0.096)$. The exponential family also comprises distributions such as gamma, Poisson, and negative binomial. Studies recommend PR and NBR models as the ideal tools for analysing crash data and the Poisson distribution has been rejected (Table 3), demonstrating the appropriate use of the NBR model.

Table 3. Distribution fitness statistics

\begin{tabular}{|l|c|c|c|}
\hline \multirow{2}{*}{ Distribution } & \multicolumn{3}{|l|}{ K-S test } \\
\cline { 2 - 4 } & Statistic & $\boldsymbol{N}$ & $\begin{array}{c}\text { Significance } \\
\text { level }\end{array}$ \\
\hline Poisson & 2.322 & 15 & 0.000 \\
\hline Exponential & 1.231 & 15 & 0.096 \\
\hline
\end{tabular}

\section{Parameter Estimates}

Using SPSS software for count models, the NBR model was run to assess the influence of pedestrian behaviour factors (see Table 2) on road fatalities in Malawi and its parameter estimates are presented in Table 4 . The results of the Omnibus test show that the model was statistically better over its null model (without predictors), a statistically significant result, with $p=0.000<0.05$. Another way of stating this is to say that the model was not statistically different from its null model. The results further show that pedestrian behaviour factors of walking on the $\operatorname{road}(\beta=$ $0.009)$, crossing outside pedestrian crossings $(\beta=0.003)$, other negligent behaviours $(\beta=0.004)$, and crossing carelessly $(\beta=0.003)$ were positively correlated with road fatalities. This indicates that the rate of road-related fatalities increases with increasing input data of these variables, hence providing an important development in road safety. Despite this, the coefficient values in all variables were negligible, indicating that these behaviour factors had an insignificant influence on road fatalities, which is a major limitation of this study. However, with more input data in the future, the influence of these variables could intensify and become detrimental to road safety.

Because pedestrian behaviour factors have been demonstrated to make an insignificant contribution to the risk of road fatalities in the country, other factors rather than these variables must play a major role in the risk of roadrelated pedestrian fatalities observed in Table 1 and the total number of road fatalities. One such factor could be speed. This assumption is supported by much of the literature. As stated earlier, research has shown that the rate of fatal pedestrian crashes increases with increasing speed limit (Ahmed, 2016). Studies have also indicated that the large proportion of road traffic deaths for vulnerable road users mainly in African countries (Odero et al., 2003; Romão et al., 2003; Afukaar et al., 2003; WHO, 2015) is explained by the traffic mix (of pedestrians, bicyclists, motorcyclists, cars, trucks, and buses), which exposes road users with the least degree of protection to high-speed traffic (Tiwari et al., 1998; Peden et al., 2004; Lagarde, 2007).

Even though these variables have been shown to have an insignificant influence on road fatalities, these findings can still contribute to road safety. BUI was found to have no influence $(\beta=0.000)$ on road fatalities and crossing at pedestrian crossings was negatively correlated $(\beta=-0.008)$ (Table 4), supporting the literature. Because income is positively associated with alcohol-related deadly crashes (Peden et al., 2004; Vecino-Ortiz et al., 2014), it should not be surprising for this study to find that the factor of pedestrians BUI has no influence on road fatalities because pedestrians are generally economically underprivileged in developing countries (Nantulya \& Muli-Musiime, 2001). The numbers of fatal pedestrian crashes should also be minimal at pedestrian crossings because most pedestrian crossings, particularly in public built-up areas such as schools and markets, are mostly constructed with speed humps or rumble strips or a combination of both, which automatically forces drivers to reduce approaching speed and saves lives (Afukaar, 2003; Forjuoh, 2003).

Lastly, it can be seen that the value of Pearson's chi-square (0.152) divided by degrees of freedom (7) did not yield a value equal or close to 1.0 (being 0.0217) (Table 4). This suggests that the observed fatalities were not overdispersed and hence the NBR model performed the same as an 
Table 4. Parameter estimates

\begin{tabular}{|c|c|c|c|}
\hline \multirow[t]{2}{*}{ Variable } & \multicolumn{3}{|c|}{ Negative binomial regression } \\
\hline & $\boldsymbol{\beta}$ & $\begin{array}{l}\text { Standard } \\
\text { error }\end{array}$ & $\begin{array}{c}\text { Significance } \\
\text { level at } \\
95 \% \\
\text { confidence } \\
\text { interval } \\
\end{array}$ \\
\hline Intercept & 5.366 & 0.2238 & 0.000 \\
\hline BUI & 0.000 & 0.0133 & 0.981 \\
\hline $\begin{array}{l}\text { Crossing at } \\
\text { pedestrian crossing }\end{array}$ & -0.008 & 0.0342 & 0.826 \\
\hline Crossing carelessly & 0.003 & 0.0018 & 0.065 \\
\hline $\begin{array}{l}\text { Crossing outside } \\
\text { pedestrian crossing }\end{array}$ & 0.003 & 0.0282 & 0.912 \\
\hline Nothing noted & 0.003 & 0.0007 & 0.000 \\
\hline Walking on road & 0.009 & 0.0100 & 0.386 \\
\hline \multirow[t]{2}{*}{$\begin{array}{l}\text { Other form of } \\
\text { negligence }\end{array}$} & 0.004 & 0.0024 & 0.090 \\
\hline & \multicolumn{2}{|c|}{ Value } & Value/DF \\
\hline $\mathrm{DF}$ & \multicolumn{2}{|c|}{7} & \\
\hline $\begin{array}{l}\text { Pearson's chi- } \\
\text { square }\end{array}$ & \multicolumn{2}{|c|}{0.152} & 0.0217 \\
\hline Omnibus (p) & \multicolumn{3}{|c|}{0.000} \\
\hline
\end{tabular}

ordinary PR model could have done. The NBR model handles overdispersed data by offering an improvement in the parameter estimates of the PR model (Cameron \& Trivedi, 1998; Wulu et al., 2002; Lord \& Mannering, 2010).

\section{Percentage Change in Fatalities Resulting from Pedestrian Behaviours}

From the analysis of the data in Table 2, it was found that there was a $1 \%$ increase in the number of crash deaths for every additional fatal crash involving pedestrians walking on a road. Moreover, an additional $0.5 \%$ increase in the number fatalities was recorded for every fatal crash involving the pedestrian behaviour factor of crossing outside pedestrian crossings or other negligent behaviour. An increase of $0.3 \%$ in the number of fatalities was seen for every extra fatal crash caused by pedestrians crossing carelessly or factors other than pedestrian behaviours.

\section{Conclusions}

The study found that, between 2000 and 2015, there was a $1 \%$ increase in the number of crash deaths for every additional fatal crash involving pedestrians walking on the road. An additional $0.5 \%$ increase was recorded for every fatal crash involving the pedestrian behaviour factor of crossing outside pedestrian crossings or other negligent behaviour. Further, a $0.3 \%$ increase was noted for every extra fatal crash caused by pedestrians crossing carelessly or factors other than pedestrian behaviours.
An NBR model was developed to estimate the influence of pedestrian behaviour factors on road fatalities in Malawi, and these factors are listed in Table 2. Through their coefficient values, it was found that the covariates such as 'Being under the influence of alcohol,' even including other factors, possibly have minimal effect on road safety in Malawi, as the coefficients have very small values, but this was a major limitation of this study.

However, with the availability of more input data in the future, meaningful results may be obtained in assessing the key covariates. Because of the general concern over pedestrian fatalities, it is important that these covariates be considered when conducting public awareness campaigns and law enforcement. DRTSS regularly conducts awareness campaigns to educate pedestrians about the safety benefits of observing traffic rules that govern their movements on roads. These campaigns should be maintained.

Another limitation of this study was the use of policerecorded data. These data are often underreported by gross margins (Liren, 1996; Jacobs et al., 2000; Gururaj et al., 2000; Mackay, 2003; Peden et al., 2004). Therefore, the findings of this study may not reflect the true influence of the covariates. Malawi needs to establish more data sources to be used for comparison with data reported by police.

\section{Acknowledgements}

We thank the Director of Road Traffic \& Safety Services for allowing us to use its data and other resources for this study. This study was part of programs being undertaken by the government of Malawi to improve road safety in the country.

\section{References}

Afukaar, F. K. (2003). Speed control in developing countries: issues, challenges and opportunities in reducing road traffic injuries. INJURY CONTROL AND SAFETY PROMOTION, 10(1-2), 77-81.

Afukaar, F. K., Antwi, P., \& Ofosu-Amaah, S. (2003). Pattern of road traffic injuries in Ghana: implications for control. INJURY CONTROL AND SAFETY PROMOTION, 10(1/2), 69-76.

Ahmed, M. S. (2016, October 16-20, 2016). Pedestrian Safety and Road Crossing Behaviour: A Case Study of Abu Dhabi. Paper presented at the 2nd IRF Asia Regional Congress, Kuala Lumpur, Malaysia.

Cameron, A. C., \& Trivedi, P. K. (1998). Regression analysis of count data. Cambridge, UK: Cambridge university press.

Croarkin, C., Tobias, P., \& Zey, C. (2002). Engineering statistics handbook: NIST iTL.

Forjuoh, S. N. (2003). Traffic-related injury prevention interventions for low-income countries. INJURY CONTROL AND SAFETY PROMOTION, 10(1-2), 109-118.

Gururaj, G., Thomas, A. A., \& Reddi, M. (2000). Underreporting of road traffic injuries in Bangalore. Implications for road safety policies and programmes. Paper presented at the Proceedings of the 5th world conference on injury prevention and control. 
Hilbe, J. (2011). Negative Binomial Regression (2nd ed.). New York: Cambridge University Press.

Jacobs, G., Aeron-Thomas, A., \& Astrop, A. (2000). Estimating global road fatalities (Vol. 1-35). Crowthorne: U.K.: Transport Research Laboratory.

Khayesi, M. (1997). Livable streets for pedestrians in Nairobi: The challenge of road traffic accidents. World Transport Policy and Practice, 3(1), 4-7.

Khayesi, M. (1999). An analysis of the pattern of road traffic accidents in relation to selected social-economic dynamics and intervention measures in Kenya (Ph.D. dissertation), Kenyatta University.

Kuotha, W. S., Ngwira, G. M., \& Ngoma, I. (2016). Road Traffic Injuries in Malawi: Their Magnitude, Major Causes and Action for Intervention. Paper presented at the 3rd International Conference on Transportation in Africa (ICTA2016), Ramada Resort, Accra, Ghana.

Lagarde, E. (2007). Road traffic injury is an escalating burden in Africa and deserves proportionate research efforts. PLoS medicine, 4(6), 170.

Lana, I., Del Ser, J., Velez, M., \& Viahogogianni, E. I. (2018). Road traffic forecasting: recent advances and new challenges. IEEE Intelligent Transportation Systems Magazine, 10(2), 93-109.

Liren, D. (1996). Viewing china road traffic safety and the countermeasures in accordance with international comparison. Beijing research in traffic engineering. Paper presented at the Proceedings of the Second Conference in Asian Road Safety.

Lord, D., \& Mannering, F. (2010). The statistical analysis of crashfrequency data: a review and assessment of methodological alternatives. Transportation Research Part A: Policy and Practice, 44(5), 291-305.

Mackay, M. (2003). National differences in European mass accident data bases. Paper presented at the Proceedings: Contemporary Injury Severity and Outcome Issues, RCOBI Annual Conference, Lisbon, Portugal.

Mako, E., \& Szakoyi, P. (2016). Evaluation of human behaviour at pedestrian crossings. Transportation Research Procedia. Transportation Research Procedia, 14(2016), 2121-2128.

Nantulya, V. M., \& Muli-Musiime, F. (2001). Kenya: uncovering the social determinants of road traffic accidents. Challenging inequities in health: from ethics to action, 211-225.

National Road Safety Commission. (2016). Ghana 2016 National Road Traffic Crash Statistics Report. Kumasi: CSIR Building and Road Research Institute.

Odero, W. (1995). Road traffic accidents in Kenya: An epidemiological appraisal. East African Medical Journal, 75(5), 299-305.
Odero, W., Khayesi, M., \& Heda, P. M. (2003). Road traffic injuries in Kenya: Magnitude, causes and status of intervention. INJURY CONTROL AND SAFETY PROMOTION, 10(1-2), 53-61.

Oxely, J., B., F., Ihsen, E., Day, R., \& Charlton, J. (1995). An investigation of road crossing bahaviour of older pedestrians. Victoria, Australia: Monash University Accident Research Centre.

Peden, M., Scurfield, R., Sleet, D., Mohan, D., Hyder, A. A., Jarawan, E., \& Mathers, C. (2004). World report on road traffic injury prevention. Geneva, Switzerland: World Health Organisation (WHO).

Poudel-Tandukar, K., Nakaraha, S., Ichikawa, M., Poudel, K. C., \& Jimba, M. (2007). Risk perception, road behaviour, and pedestrian injury among adolescent students in Kathmandu, Nepal. Injury prevention, 13, 258-263.

Praveen, K. N., Nandini, C., Saranya, R., \& Sridevi, N. H. (2018). Impact of pedestrian crossing behaviour at intersections on road traffic accidents in Shivamogga, Karnataka: an observational study. International Journal of Community Medicine and Public Health, 5(6), 2437-2441.

Road Traffic Act, Road Traffic Directorate, Malawi (1997).

Romão, F., Nizamo, H., Mapasse, D., Rafico, M. M., José, J., Mataruca, S., . . Bicho, J. M. M. (2003). Road traffic injuries in Mozambique. INJURY CONTROL AND SAFETY PROMOTION, 10(1-2), 63-67.

Said, S. H. (2000). The care burden and severity profit of road trauma admissions at Kenyatta National Hospital. (M.Med.), University of Nairobi, Nairobi, Kenya.

Sarani, R., Rahim, S., Marjan, J. M., \& Wong, S. (2012). Predicting Malaysian Road Fatalities for Year 2020. Kuala Lumpur: Malaysian Institute of Road Safety Research (MIROS).

Surhone, L. M., Timpledon, M. T., \& Marseken, S. F. (2010). Ncss (Statistical Software): VDM Publishing.

Tiwari, G., Mohan, D., \& Fazio, J. (1998). Conflict analysis for prediction of fatal crash locations in mixed traffic streams. Accident Analysis \& Prevention, 30(2), 207-215.

Vecino-Ortiz, A. I., Bishai, D., Chandran, A., Bhalla, K., Bachani, A. M., Gupta, S., . . Hyder, A. A. (2014). Seatbelt wearing rates in middle income countries: A cross-country analysis. Accident Analysis \& Prevention, 71, 115-119.

WHO. (2013). WHO global status report on road safety 2013: supporting a decade of action. Geneva, Switzerland: World Health Organization.

WHO. (2015). Global status report on road safety 2015. Geneva, Switzerland: World Health Organization.

Wulu, J., Singh, K., Famoye, F., \& McGwin, G. (2002). Regression analysis of count data. Journal of the Indian Society of Agricultural Statistics, 55(2), 220-231. 


\title{
Road Safety Policy \& Practice Contemporary Guidance on Management of Road Safety Audits
}

Auttapone Karndacharuk ${ }^{1}$ and Paul Hillier ${ }^{2}$

${ }^{1}$ Transport for NSW, New South Wales, Australia

${ }^{2}$ Australian Road Research Board, New South Wales, Australia

Corresponding Author: Dr Aut Karndacharuk, 18 Lee Street Chippendale NSW 2008, aut.karndacharuk@transport.nsw. gov.au and +61429580107.

This peer-reviewed paper was first presented as an Extended Abstract and Oral Presentation at the 2018 Australasian Road Safety Conference (ARSC2018) held in Sydney, NSW, Australia and first published in the ARSC2018 Proceedings in the form of an Extended Abstract. It was expanded into a 'Full Paper' and underwent further peer-review by three independent experts in the field. It is being reproduced here with the kind permission of the authors and is now only available in this edition of the JACRS.

\section{Key Findings}

- $\quad$ Road safety audit remains one of main proactive techniques aiming to save lives and reduce severity

- New Austroads guide further incorporates Safe System thinking into road safety audit practice

- Focus on raising awareness of contemporary issues and techniques to promote effective audits

- Consistent with responsibility of road agencies to maximise alignment with Safe System principles

\begin{abstract}
Although there is good awareness of road safety audit as a proactive technique for identifying and mitigating road safety related risks throughout Australasia and internationally, local practices in procuring, managing and conducting audits can vary between jurisdictions. This paper provides an overview of recent policy developments and practical guidance in managing road safety audits in Australia and New Zealand
\end{abstract}

Based on the update (Austroads 2019) of Austroads Guide to Road Safety Part 6 (AGRS), the guidance aims at maximizing alignment with Safe System principles by integrating them into the audit process. This is achieved through improved awareness of practitioners new to the principles and concepts (especially project clients and project managers) and promoting the conduct of audits to realise their harm minimisation benefits.

\section{Keywords}

Road Safety Audit; Safe System; Safe System Assessment Framework; Road Safety Management; Risk assessment; Crash Risk

\section{Introduction}

There is a good level of awareness throughout Australia, New Zealand and internationally of road safety audit (RSA) as a proactive technique for identifying and treating roadsafety-related risks and hazards on roads with a view to their mitigation. However, local policies and practices in procuring, managing and conducting audits vary between jurisdictions at all level of government and between the public and private sectors, leading to sub-optimal road safety outcomes. A number of influences can be identified, including a lack of clarity in how and when audits and other tools fit within road safety management strategies and the understanding of pressing issues with regard to the procurement, commissioning and undertaking of audits.
As a peak organisation of Australasian road transport agencies, Austroads recognised these issues, and identified a need to revise the exiting guidance in the Guide to Road Safety (Austroads 2009) in order to provide practical and contemporary guidance for project managers and practitioners involving in RSA activities. ARRB was engaged by Austroads to scope and prepare a revision of the current Austroads guide as well as to facilitate the consultation process with road safety representatives from the Australian and New Zealand jurisdictions. 


\section{Project Objectives}

Previous Austroads guidance on the conduct of audits was published nearly a decade ago (Austroads 2009) and it has been recognised that practitioner awareness of and expertise in RSA and the road safety and operational context have changed since then.

The objectives of a project to update the Austroads guide were identified as follows:

- $\quad$ To raise the awareness of practitioners new to the principles and concepts (especially project clients and project managers) and promote the conduct of audits and other assessments to maximise their benefits

- To ensure that practitioners have an awareness of contemporary operating environments and contexts (e.g. the Safe System approach to road safety) and recent developments in road safety risk assessments.

The current 2009 document will be retained in its entirety, but retitled and relaunched as Part 6A: Implementation of Road Safety Audits. The content for a new guide will assume the title of Part 6: Managing Road Safety Audits (Austroads 2019).

\section{Methods and Approach}

As shown in Figure 1, the contemprary guidance documented in the revised guide (AGRS Part 6: Managing Road Safety Audits) and in this paper was established by an extensive review of jurisdictional practices and stakeholder engagement, including workshops with the Australian and New Zealand road transport authorities.

Both Australia and New Zealand have commitments to the adoption and implementation of the Safe System approach through the National Road Safety Strategy
2011-2020 (Australian Transport Council 2011) and Safer Journeys: New Zealand's Road Safety Strategy 2010 - 2020 (Ministry of Transport 2010), respectively. To honour this commitment, it is important for road safety policy and processes, including RSAs, to align well with Safe System principles.

\section{Management of Road Safety Audits}

This section provides a concise and practical illustration of how RSAs (and other tools) 'fit' within a policy framework and project cycles in a road safety strategy. It recognises the Safe System thinking as a major shift in road safety management, road transport management, road design and traffic management (Austroads 2017a, 2017b, 2017c). As RSAs are one of the most well-known and widespread road safety processes, integrating Safe System thinking into audits is a critical step in ensuring the design and implementation of forgiving road and roadside infrastructure with a safe and credible operating speed environment for any road transport network or initiative.

\section{RSA Practice in Road Safety Management}

RSA policy and practice play an important role in road safety management (RSM). RSM at a global level is one of the five pillars of the Global Plan for the Decade of Action for Road Safety (United Nations Road Safety Collaboration 2011), and is integrated into the ISO 39001 Road Traffic Safety Management System (Austroads 2015c, International Organization for Standardization 2012).

RSM places an emphasis on the 'production' of road safety, and just like other goods and services, safety can be produced. The process is viewed as a management system with three levels: institutional management functions, which produce interventions that in turn produce desired results. Day-to-day road safety debate often revolves

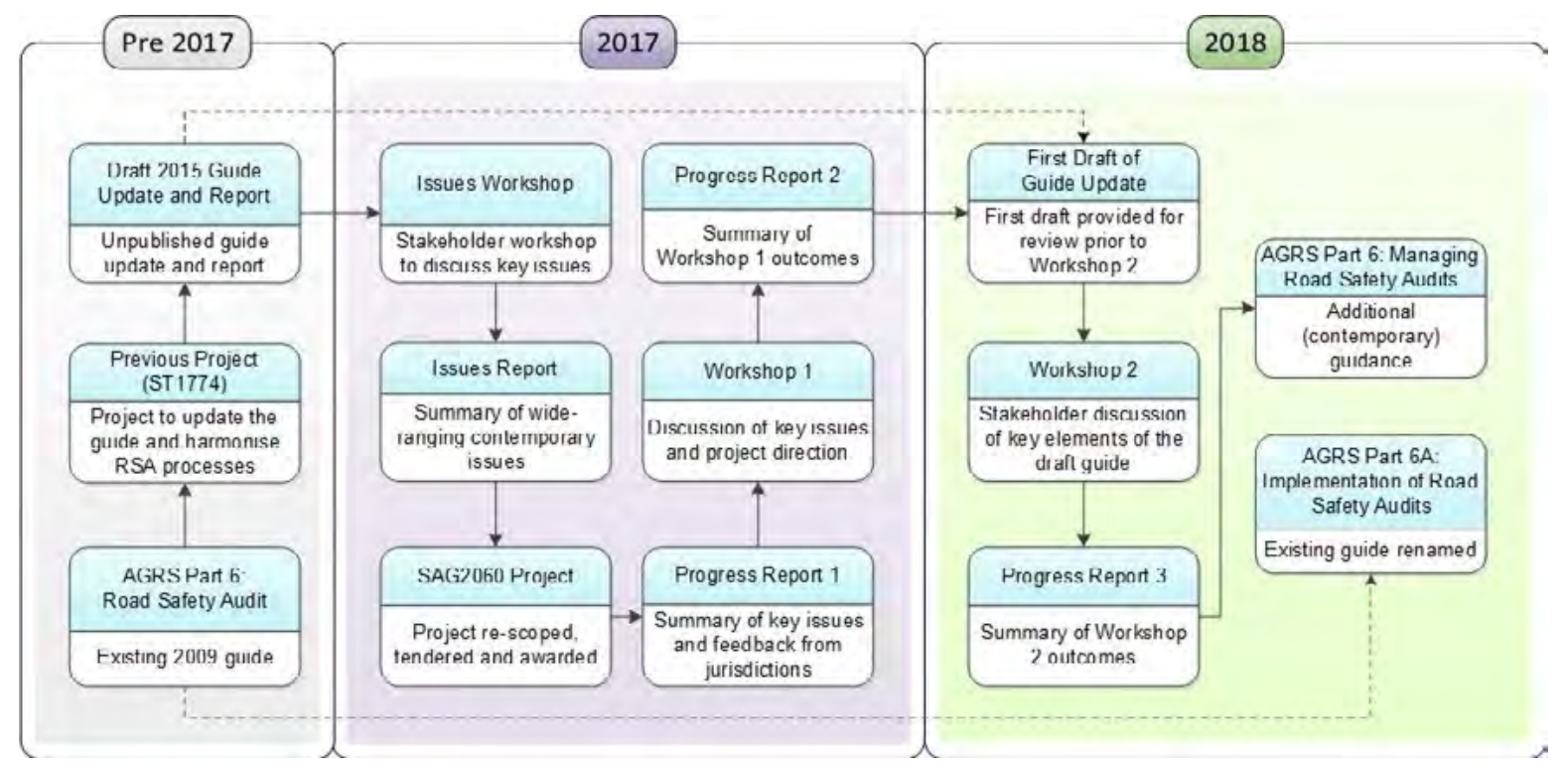

Figure 1. Project methods and key milestones (Karndacharuk and Hiller 2018) 


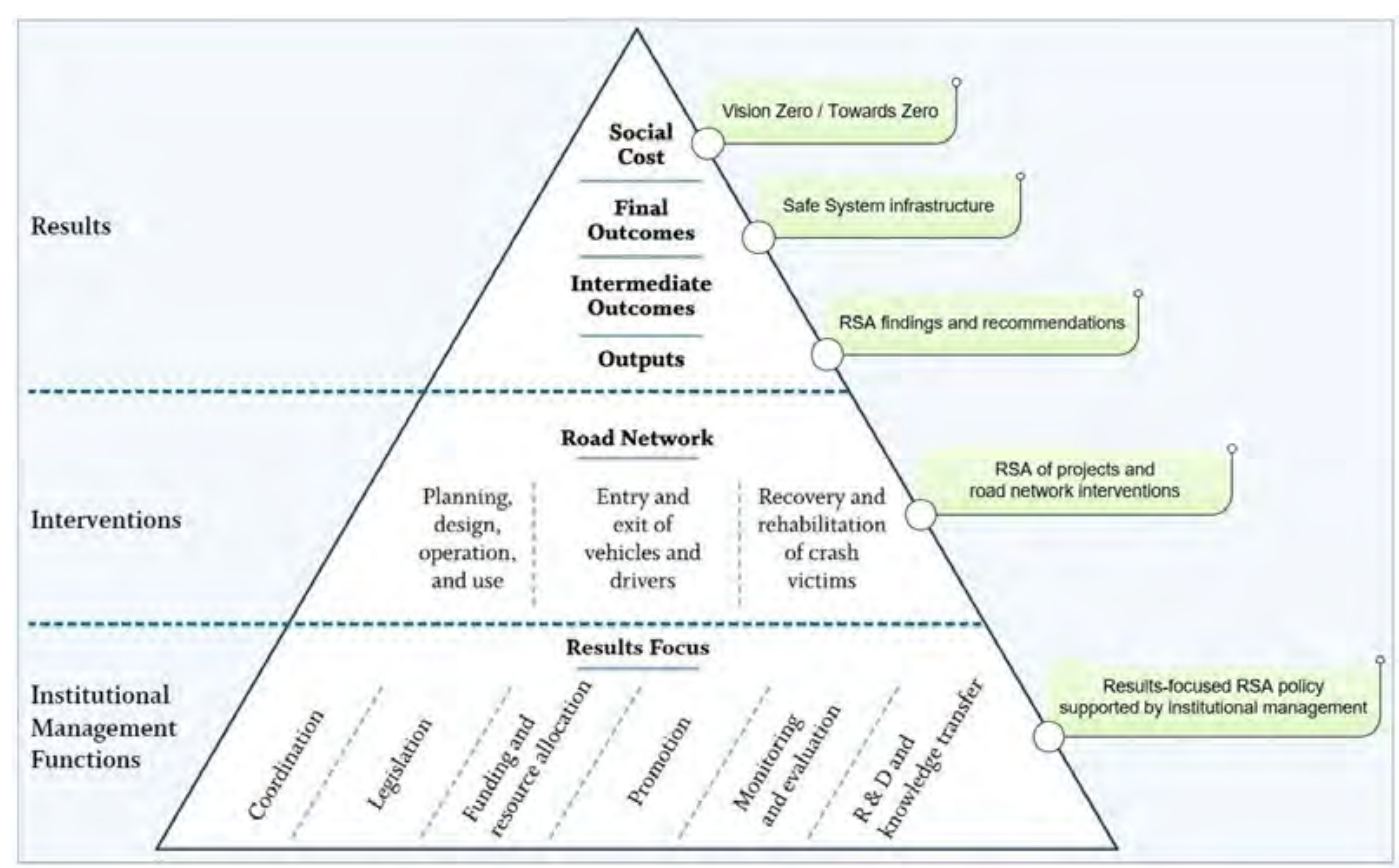

Figure 2. RSA practice in road safety management system (Based on Bliss and Breen 2013)

around interventions alone, and largely ignore the issues of institutional ownership and accountability for results (Bliss and Breen 2013). Figure 2 shows how RSA activities fit within the RSM system.

With the 'Vision Zero' objectives of long-term elimination of deaths and serious injuries, the audit of road transport projects to ensure the safe planning, design, operation and use of the road network is a product of an institute (or jurisdiction) with a Safe System result focus. To align with the RSM system, the key objectives of an effective intervention (World Road Association 2015) for the RSA practice and policy development can be outlined as follows:

- $\quad$ Shifting of focus from crash prevention to death and serious injury prevention;

- $\quad$ Placing an emphasis on the implementation of evidence based approaches to:

- Reduce exposure to the fatal and serious injury (FSI) risk;

- Prevent FSI;

- Mitigate the severity of injury when a crash occurs;

- $\quad$ Reduce the consequence of injury.

In other words, the jurisdictional policy framework for RSA with effective institutional management (through coordination, legislation, funding and resource allocation, promotion, monitoring and evaluation and research and development, and knowledge transfer) will contribute to the ultimate goal of a Safe System where road users are no longer exposed to death or serious injury on the road network.

\section{RSA in Network-level Road Safety Management}

Road safety practitioners emphasise the need to consciously plan to achieve road safety and have traditionally set out to consider and address all crash types and severities (minor, serious and fatal injury) through a blend of reactive and proactive/predictive approaches, where:

- $\quad$ Reactive policies and associated activities focus on the analysis of crashes which have occurred to prevent the same/similar crash mechanisms and severities from occurring again at that same location. Activities within this category traditionally include crash investigation and the identification and treatment of crash locations (Austroads 2015a).

- Proactive policies and associated activities focus on identifying and/or predicting risks and hazards at a location with the potential to result in crashes. The aim is to mitigate (eliminate or reduce) the risks such that foreseeable crashes do not occur at a location. The commissioning and conduct of an RSA of a design plan or at an operational location falls within this category.

Mass action treatment programs on existing homogeneous lengths of road would also fall within this category. The development of predictive tools, including most recently Australian National Risk Assessment Model (ANRAM), as summarised in Austroads (2018b), now permit risk profiles to be determined. These techniques enable the identification of locations where certain crashes can be reasonably expected to occur and allow mitigation to take place before the crashes occur. 


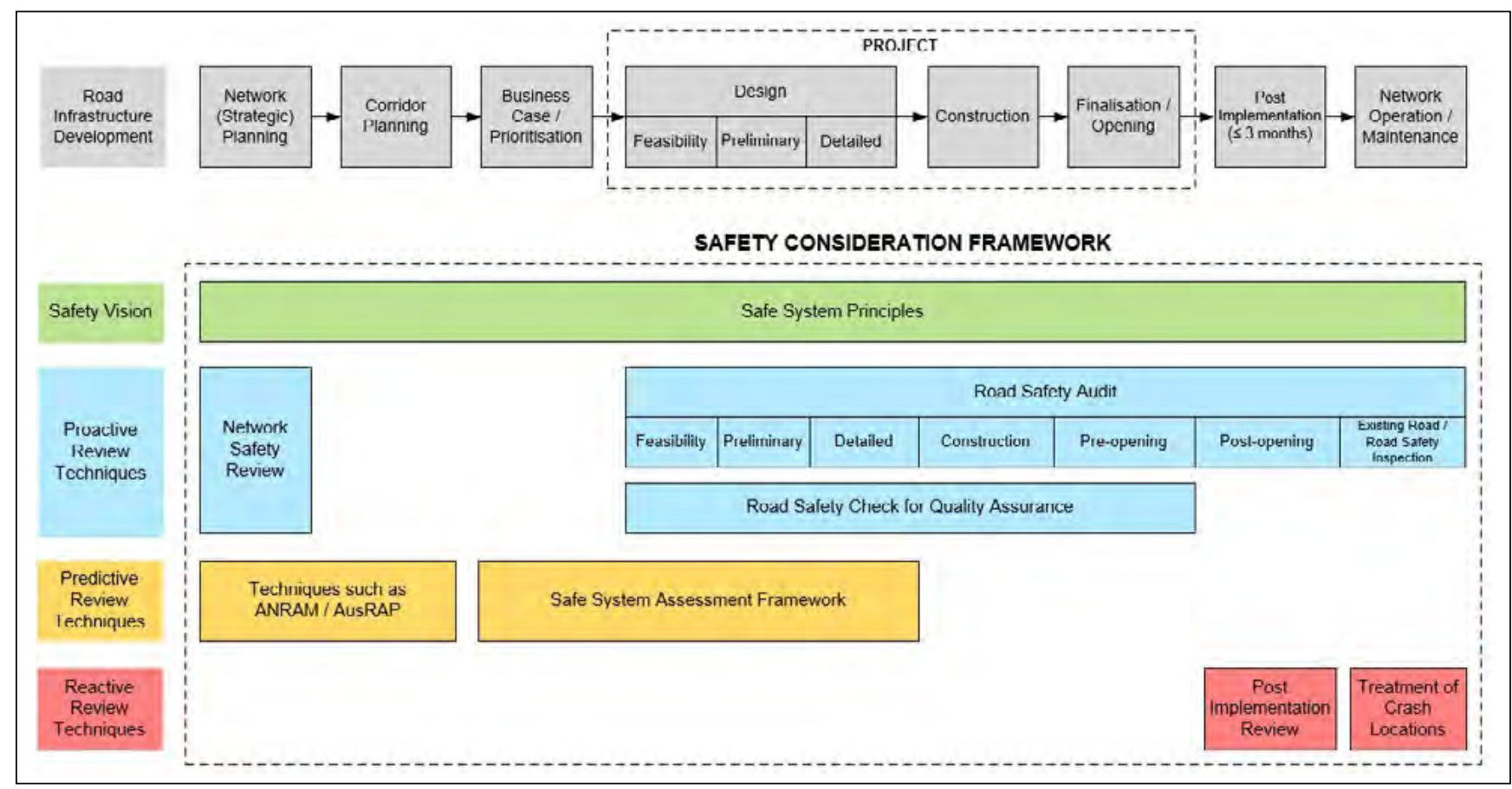

Figure 3. Various approaches and techniques for network and project level road safety management in road infrastructure development life cycle (Austroads 2019)

This traditional approach continues to serve road agencies well and has evolved significantly with time. Rather than contemplating on all types and severities of crashes, the focus now is on eliminating and preventing fatal and serious injury crashes. This concept is often linked to an aspirational, longer-term target of achieving zero fatalities or serious injuries across a road network guided by the Safe System approach to road safety.

Over the last decade, Austroads has researched and published extensively on the principles of how to deliver a Safe System, culminating with the publication of Towards Safe System Infrastructure - A Compendium of Current Knowledge (Austroads 2018b). It is important to note that the traditional and contemporary approaches can complement each other, and this is reflected in the compendium where the conduct of RSAs and adoption of a risk assessment tool known as the Safe System Assessment (SSA) within a Safe System Assessment Framework (SSAF) is recommended.

Figure 3 illustrates the traditional and contemporary approaches to network-level road safety management, showing reactive, proactive and predictive safety review techniques and how they can interrelate.

The diagram illustrates the various stages of road infrastructure development activities in the top components (grey boxes), setting out network-level decisions (e.g. the planning of a network and corridors within it) preceding and influencing project-level processes (i.e. from design to construction and to opening) and then on-going operational and maintenance demands. The top components are then aligned vertically with the following road-safety-related activities:
- The application of a safety vision (green boxes) - and the Safe System approach, which applies throughout the process;

- $\quad$ Proactive (blue boxes) - network safety reviews, road safety audits and road safety checks;

- $\quad$ Predictive (orange boxes) - risk assessment models/ tools, including the Australian National Risk Assessment Model (ANRAM) and SSAF;

- $\quad$ Reactive (red boxes) - including post-implementation reviews and treatment of crash locations (blackspot engineering).

Design stage audits and SSAF are shown independently, but can also be applied concurrently, and have been found to complement each other. The SSAF enables the assessment of major crash types in relatoin to key sources of risk i.e. crash severity, exposure and likelihood (Austroads 2016).

\section{Safe System Integration}

While RSAs are proven to reduce road trauma, they have traditionally focused on identifying risks and hazards associated with all crash types and severities. The contemporary management approach that prioritises eliminating FSI crashes, recognises the limits of the human body to withstand crash forces and clearly acknowledges human fallibility.

Practical and anecdotal evidence is that many of the planning and network decisions that affect road safety have often already been made even prior to conducting RSAs at the earliest design stages, often without inputs from a road safety and traffic management specialist. This is in contrast to Safe System principles, which can and should be applied throughout the network lifespan. 
The additional annotation "IMPORTANT" shall be used to provide emphasis to any road safety audit finding that has the potential to result in fatal or serious injury or findings that are likely to result in the following crash types above the related speed environment: head-on $(>70 \mathrm{~km} / \mathrm{h})$, right angle $(>50 \mathrm{~km} / \mathrm{h})$, run off road impact object $(>40 \mathrm{~km} / \mathrm{h})$, and crashes involving vulnerable road users $(>30 \mathrm{~km} / \mathrm{h})$, as these crash types are known to result in higher severity outcomes at relatively lower speed environments.

The exposure and likelihood of crash occurrence shall then be considered for all findings deemed "IMPORTANT" and evaluated based on an auditors professional judgement. Auditors should consider factors such as, traffic volumes and movements, speed environment, crash history and the road environment, and apply road safety engineering and crash investigation experience to determine the likelihood of crash occurrence. The likelihood of crash occurrence shall be considered either "VERY HIGH", "HIGH", "MODERATE" or "LOW" and this additional annotation shall be displayed following the "IMPORTANT" annotation on applicable findings.

Figure 4. Western Australia's system to rate RSA findings based on crash severity, exposure and likelihood (Main Roads Western Australia 2015)

\section{Embedding Safe System Principles in RSA Practice}

For any project, there is a responsibility on the road authority and project manager to maximise alignment with Safe System principles. This can be achieved by applying the principles to the existing RSA processes. The focus of the audit will be on key crash types (leading to fatal and serious injuries) and kinetic energy generation and their management (whereby critical speed thresholds, also known as Safe System speeds, are introduced). The predominant crash types that result in deaths and serious injuries in Australia and New Zealand (Austroads 2016, Marsh \& De Roos 2016, Tate \& Brodie 2014) are:

- head-on (crashes that occur when one vehicle crosses onto the opposing side and impacts another vehicle, including head-on crashes at intersections);

- intersection (crashes at intersections including sideimpacts involving vehicles from adjacent directions, turning vehicles crashes);

- $\quad$ run-off-road (crashes that occur when a vehicle leaves the carriageway without impacting another vehicle, including run-off-road crashes at intersections);

- $\quad$ vulnerable road user (crashes involving pedestrians, cyclists, motorcyclists, the elderly, children and people with special needs).

Rear-end crashes are also an important cause of serious injury based on an analysis of all injuries from road crashes in Australia and New Zealand between 2001 and 2010 (Austroads 2015b).

When undertaking an audit, the following key questions should be raised for each of the safety risks or hazards identified. An affirmative response reflects a high severity risk, and as such is the focus of the subsequent risk assessment (Main Roads Western Australia 2015, Marsh \& De Roos 2016):

- Is it possible to have a head-on crash at a speed greater than $70 \mathrm{~km} / \mathrm{h}$ ?
- Is it possible to have an intersection (right-angle) crash at a speed greater than $50 \mathrm{~km} / \mathrm{h}$ ?

- Is it possible to have a run-off-road (side-on) crash at a speed greater than $40 \mathrm{~km} / \mathrm{h}$ ?

- Is it possible to have a vulnerable road user (pedestrian, cyclist and motorcyclist) crash at a speed greater than $30 \mathrm{~km} / \mathrm{h}$ ?

A ranking or scoring system (e.g. high/medium/low) that considers crash severity, crash exposure and crash likelihood can be developed to rate the risks identified in an RSA considering Safe System principles. An example from Main Roads Western Australia (2015) is provided in Figure 4.

\section{Safe System Assessment (SSA)}

The SSA is an assessment tool which considers and quantifies the degree of alignment of a particular design or concept with Safe System principles with the objective of minimising fatal and serious injury (Austroads 2016). It is also sometimes referred to as a measure of Safe System compliance.

The SSA is founded on the Safe System Assessment Framework (SSAF) which in turn has a Safe System Matrix as its 'engine room'. This ensures consistent consideration of major crash types and prompts an assessment of the three components of risk management as they apply to each crash type, namely crash severity, road user exposure and crash likelihood.

When SSAs are undertaken at the early planning and design stages, the need for feasibility stage RSAs (and to a lesser degree preliminary design stage) is lessened. It is possible that an SSA can replace a feasibility or preliminary design RSA. If that is the case, the SSA should follow the key principles of undertaking RSAs. Key principles such as utilising an independent and qualified team and providing a detailed brief are discussed in the following sections of this paper.

It is also important for the subsequent RSAs undertaken at the later stages in the project development and network 


\section{How should we regard treatments?}

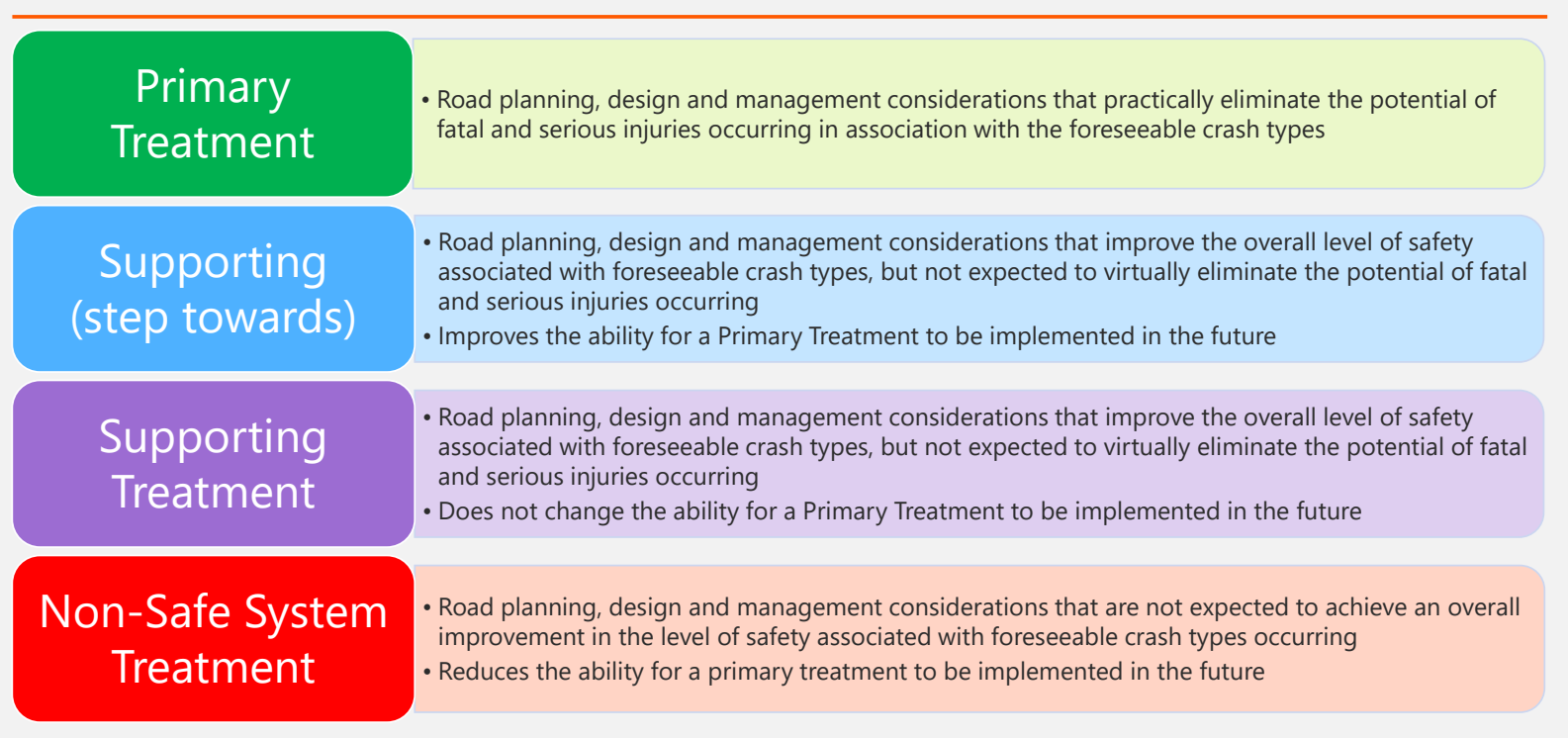

Figure 5. Hierarchy of primary and supportive treatment options (Austroads 2018a)

management cycle to refer to the earlier SSA findings. This is to ensure that the project has not been adjusted or new design features have not been included to lessen alignment with Safe System principles.

\section{Treatment Options}

Most jurisdictions and project managers request the audit team to provide RSA recommendations (often in the form of physical infrastructure treatments) to eliminate or reduce the risks identified. It is essential that the treatment option(s) recommended are clearly identified and designed to mitigate a specific risk. Further guidance and options are provided in Austroads (2016) and practitioner tools such as the Road Safety Engineering Toolkit.

It is important to distinguish treatments that provide a high alignment with Safe System outcomes from those that assist in delivering general safety improvements. As shown in Figure 5, a hierarchy of primary and supportive treatment options has been developed (Austroads 2018a). If recommended treatment options are provided in an audit report, the treatments should be categorised into the four Safe System categories. Austroads guidance provides a comprehensive list of treatment options for various key crash types and whether the option affects severity, exposure or likelihood.

\section{Contemporary Guidance in the Audit Process}

This section provides clarity on the pressing (contemporary) issues as identified throughout the Austroads project with regard to the procurement, commissioning and undertaking of audits. These issues also apply to the conduct of emerging risk assessment tools such as SSAs.

The focus of the guidance is for those who perform a 'client' or asset owner role in the audit and risk assessment process. Further information about the guidance can be found in Austroads (2019).

\section{Clearly Defining Roles and Responsibilities}

Participants in the RSA process can be generally divided into two groups as shown in Figure 6. The client team represents the organisation that commissions a transport infrastructure development project, most typically a state or local road transport agency. The client team can identify a project sponsor that is ultimately responsible for the financing of the project delivery and as a result often represents the asset owner or asset manager. The project manager is also responsible for procuring, administering and managing the RSA component of the project, which includes

- Drafting and issuing an audit brief

- Identifying and commissioning an audit team

- Liaising with the project designer and the audit team

- Keeping the project sponsor informed, especially with respect to any concerns

- $\quad$ Seeking specialist input, where required, from other disciplines (e.g. strategic planners, network operators, safety engineers, traffic management engineers, asset managers), either within their own organisation or 


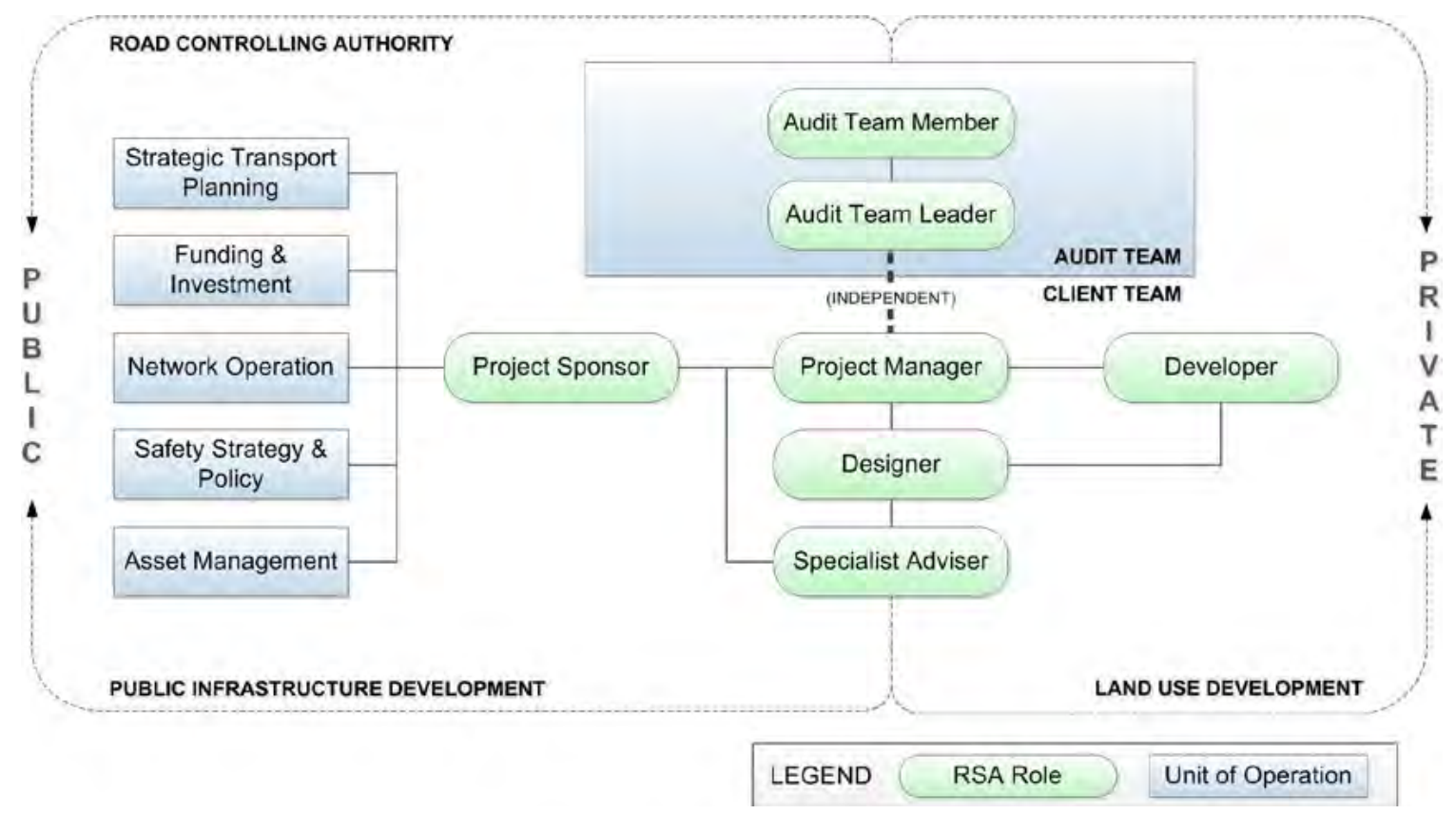

Figure 6. Key roles of client and audit teams in the RSA process (Karndacharuk and Hiller 2018)

procured externally, including in the implementation of the Safe System

- Considering and respond to the audit findings

- Closing out the RSA by implementing agreed actions to address the identified risks

- Monitoring the performance of the RSA process

- Keeping and retaining records of the audit and its findings.

With larger, complex projects commissioned by the public sector or development banks, the client team's project manager can be an externally appointed professional.

The audit team consists of at least two members who understand the Safe System approach and meet the requirements of the local RSA policy in terms of professional scope, knowledge, skills and experience (as a minimum, experience in road safety engineering or crash investigation, and knowledge of road design or traffic engineering principles), which often includes a formal accreditation requirement. An audit team leader is appointed and is ultimately responsible for the undertaking of the audit and its completion, which includes liaison with the client team.

Private commercial land-use developments often involve the design and provision of new roads or modification of existing roads. While in such instances the developer is effectively the client for the RSA process, involvement of delegates from the road transport authority (e.g. road safety engineer or consent specialist) is required given so that the audit findings are responded to from the perspective of the ultimate asset owner.

\section{Independence of an RSA}

What constitutes the independence of audit teams and the process in general, and how to ensure this, have been the subject of recent consideration and debate. This is because the integrity of the audit team must be safeguarded so that it is capable and unhindered in providing objective, impartial and credible judgement in the conduct of an RSA. Potential risks if auditors are not independent and/or have a vested interest can be as follows:

- $\quad$ Risks and hazards are ignored or not properly identified (in terms of exposure, likelihood and severity) and subsequently mitigated.

- Unethical behaviour, breaches of confidentiality and malpractice are not reported.

- $\quad$ Explanations are accepted without checking.

- Undeserved positive feedback is given.

- $\quad$ Records are falsified, incomplete or not kept.

While the concept of auditors being independent of the design team is recognised, in practice, the following signs of dependence can exist in the relationship between the audit team and the client team, which should be recognised and addressed:

- The audit team promotes certain positions held by the project manager or project sponsor/developer.

- The audit team applies limited professional scepticism due to over sympathy.

- $\quad$ The audit team is requested or pressured to effectively design/re-design countermeasures in response to preferred treatment recommendations. 
In the context of a public infrastructure project (undertaken by a government agency), the relationship between the project manager and the audit team leader is of particular importance. This is because of the central role the project manager plays in representing the interests of the client organisation (road transport agency authority) in the project development lifecycle and, at the same time, engaging with the audit team leader in a transparent and unbiased manner. It follows that a public-sector project client/sponsor should typically ensure that it has the final say or a right of veto over the appointments within the audit team. As well as supporting the independence principles of audits, this ensures that crash risks are responded to from the perspective of the ultimate asset owner and given the duty of care they ultimately assume.

\section{Preparing an Effective Brief}

Preparing an effective brief, including a clear statement of the audit scope and the desired outputs, is critical in the process of procuring and managing audits. The audit brief needs to set out:

- general information

- $\quad$ Stage (timing) of the audit (e.g. preliminary design, pre-opening)

- Project location and descriptions

- Contact details of the client and audit teams

- $\quad$ Project background

- $\quad$ List of relevant documents (e.g. plans, drawings and visualisation)

- List of previous audits, SSAs and corrective action reports

- Key road and traffic characteristics (e.g. volumes, speed environment and crash data)

- $\quad$ Project requirements

- A clear requirement that the audit should be carried out with a focus on Safe System principles

- An instruction to carry out the audit in accordance with a recognised guidance document and/or local policy

- On-site inspections to cover relevant road conditions and/or specific road user groups (e.g. thematic audits)

- Timeframe and milestones (including provision for commencement and completion meetings)

\section{- $\quad$ Specific considerations}

- Out-of-scope items

- Audit team composition and particular expertise (e.g. additional expertise required in human factors or a vulnerable road user group)

- Use of control data, namely evidence-based sources such as Austroads guidelines and research publications, to support the audit findings
A template of the typical brief should be developed to ensure consistency in engaging the audit team. The brief template should identify whether recommendations for treatment options to address issues are required. If so, the recommendations are to be presented in accordance with their alignment with Safe System principles.

\section{Responding to Findings and Closing Out the RSA}

When considering the results of an audit, it is critical for the project manager to consider each finding, the importance assigned to it and its alignment with the Safe System principles. For each finding, the project manager must document the rationale and decision-making process in all the decisions ultimately reached. In doing so, the project manager may seek input from the design team and specialist advisors. Any contentious or outstanding issues should be identified for discussion during an interactive completion meeting.

This is an identified area of much concern and poor practice. There are three general options for a client in responding to an audit finding and the associated recommendation/s:

1. Accept the finding and recommendation in its entirety - the next step is straightforward and involves documenting the proposed action(s) in a corrective action report and implementing the agreed changes accordingly.

2. Accept the finding and recommendation in part only - the project manager reaches this decision by undertaking a local context and risk assessment, considering

- Outcomes from the audit team

- The project sponsor and designer's assessment of the risk

- Severity of the harm and effectiveness of the suggested treatments (including improving on the recommendation)

- Cost and effectiveness of potential alternative treatments.

Often, due to constraints, only certain aspects of the risk can be addressed through the implementation of the selected treatment(s) in stages (e.g. short, medium and long term). As such, the project manager is required to recognise and document the residual risk associated with the design or certain elements of the road network.

3. Reject the finding and take no action - a project manager may decide to reject the finding and take no action, but should do so cautiously. In these circumstances, it is the project manager's responsibility to justify and document the decision with supporting rationale and evidence.

With regard to the keeping of risk registers to formally log unaddressed risks and issues identified during audits, the 
concept is likely to receive further consideration in the future consolidation of the RSA guidance. Formally recording unaddressed risks is considered to be a much more positive outcome than having a number of audit reports that are not being closed out and ultimately ignored.

\section{Conclusions}

This paper presents recently collated guidance to road safety practitioners in commissioning and managing audits, primarily through energy management considerations and the SSA method. The guidance places the responsibility of maximising alignment with Safe System principles on the road transport agency through the development of a policy framework and regulatory procedures in utilising the RSA and the interrelated proactive and reactive road safety management techniques.

Clarity in the roles, relationships and independence of the client team, project sponsor, project manager, audit team and audit team leader, together with advice on the important factors in managing an RSA (e.g. the brief and closing out the audit) will help encourage the deligent conduct of all audits, including those in a recent road safety paradigm, to achieve Safe System outcomes.

\section{Acknowledgements}

The authors thank the Austroads SAG2060 Project Reference Group and the ARRB Safe Systems and Human Factors team for guidance and technical input.

\section{References}

Australian Transport Council. (2011). National road safety strategy 2011-2020. Canberra, ACT: ATC.

Austroads. (2009). Guide to road safety: part 6: road safety audit. Sydney, NSW: Austroads.

Austroads. (2015a). Guide to road safety: part 8: treatment of crash locations. Sydney, NSW: Austroads.

Austroads. (2015b). Road fatalities and serious injuries in Australia and New Zealand 2001-10. Sydney, NSW: Austroads.

Austroads. (2015c). Safety management systems for road agencies: ISO 39001 and the next step towards a safe road transport system. Sydney, NSW: Austroads.

Austroads. (2016). Safe system assessment framework. Sydney, NSW: Austroads.
Austroads. (2017a). Guide to road design: part 4A: unsignalised and signalised intersections. Sydney, NSW: Austroads.

Austroads. (2017b). Guide to traffic management: part 6: intersections, interchanges and crossings. Sydney, NSW: Austroads.

Austroads. (2017c). Road transport management framework and principles. Sydney, NSW: Austroads.

Austroads. (2018a). Safe System training materials. Sydney, NSW: Austroads.

Austroads. (2018b). Towards Safe System infrastructure: a compendium of current knowledge. Sydney, NSW: Austroads.

Austroads. (2019). Guide to road safety part 6: managing road safety audits. Sydney, NSW: Austroads.

Bliss, T. \& Breen, J. (2013). Road safety management capacity reviews and safe system projects guidelines. Washington, DC, USA: World Bank Group.

International Organization for Standardization. (2012). Road traffic safety (RTS) management systems: requirements with guidance for use, ISO 39001:2012. Geneva, Switzerland: ISO.

Karndacharuk, A. \& Hiller, P. (2018). Update to AGRS part 6: road safety audit project summary. Vermont South, Vic.: ARRB Group.

Main Roads Western Australia. (2015). Policy and guidelines for road safety audit. Perth, WA: MRWA.

Marsh, F. \& De Roos, M. (2016). Principles of road design under a Safe System. Journal of the Australasian College of Road Safety, 27(3), 30-8.

Ministry of Transport. (2010). Safer journeys: New Zealand's road safety strategy 2010 - 2020. Wellington, New Zealand: Ministry of Transport.

Tate, F. \& Brodie, C. (2014). Developing an optimised safety management philosophy reflecting the Safe System in a constrained environment. Paper presented at the 4th International Safer Roads Conference. Cheltenham, UK, WDM, Bristol, UK.

United Nations Road Safety Collaboration. (2011). Global plan for the decade of action for road safety 2011-2020. Geneva, Switzerland: World Health Organization.

World Road Association. (2015). Road safety manual: a manual for practitioners and decision makers on implementing safe system infrastructure. Paris, France: World Road Association/PIARC. 


\section{"Together we can improve road safety"}

\section{AGPS) ROAD SAFEATY}

\section{Become a member of the College today!}

The Australasian College of Road Safety (ACRS) is the peak membership association focussed on saving lives and injuries on our roads.

\section{What membership benefits do we provide?}

- Communication - weekly e-newsletters, quarterly peer-reviewed journal, social platforms (Linkedln and Facebook), media releases... We keep you up to date!

- Professionalism - Awards, Code of Professional Conduct.... We reward innovations to save lives and injuries!

- Accreditation - Register of Road Safety Professionals.... We support our experts!

- Networking - National conference, Chapter events, social platforms.... We keep you connected!

- Advocacy - International, AustralasiaOn, National and Chapterbased advocacy.... We talk to those in leadership positions on your behalf!

\section{Who can be members?}

In a word: Everyone!

Individuals contribute a variety of views and perspectives.

A range of businesses bring expertise and innovations which contribute to road safety.

Community organisations can use their membership to join with others to promote changes to improve road safety. Success stories are shared with other Councils and groups.

The College promotes government programs and initiatives, coordinating activities between agencies and across communities. This collaboration builds strong road safety messages and achieves greater results by sharing resources.

Police and emergency services contribute valuable perspectives to the road safety issues in local regions.

ACRS provides researchers and academics, with a forum for discussion, advocacy and collaboration across disciplines, agencies and on an international scale.

\section{How can you support the College and our work to reduce road trauma?}

There are a variety of ways to showcase your support in reducing road trauma, including:

\section{- Membership}

All people and organisations are responsible for road safety and we encourage an inclusive environment via our diverse membership.

\section{- Sponsorship (e.g. events and awards)}

Showcase your support to combat road trauma and be associated with a prestigious organisation endorsed by the Governor-General of Australia.

\section{- Attending events}

A myriad of events are linked in the weekly e-newsletter - take your pick!

\section{To become a member, contact the College:}

\section{Australasian College of Road Safety}

Phone: (02) 62902509

Email - Finance and Administration:

faa@acrs.org.au 


\section{Now available \\ Heavy vehicle \\ data visualisations}

Heavy vehicle data and trend analysis from 2008 to 2017 is now available on the interactive statistics page on the Centre for Road Safety website.

The interactive statistics page featuring the latest release in heavy vehicle data offers a wide range of filters and parameters to drill down and explore.

Industry and road safety practitioners are able to review patterns, trends and correlations in heavy vehicle crash data.

\section{With access to the data profiles including:}

- fatalities and fatal crashes

- crash type

- casualty type

- vehicle type
- driver of heavy vehicle details

- crash map

- crash location

- driver residency profiles.

The release of the heavy vehicle data has the ability to impact effective changes to reduce heavy vehicle crashes and fatalities within current and future road safety programs.

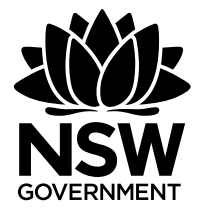
interactivecrashstats to explore the data today. 


\section{Journal of the Australasian College of Road Safety (JACRS)}

Visit the JACRS website at:

www.acrs.org.au/publications/journals/

Australasian College of Road Safety Inc.

ACRS, PO Box 198, Mawson ACT 2607 Australia

Tel 0262902509

Fax 0262900914

Email ceo@acrs.org.au

Head Office

Pearce Centre, Collett Place, Pearce ACT Australia

Visit the College website at www.acrs.org.au

\section{Proudly sponsored by}

LB Australia

NSW Transport Centre for Road Safety

and New Zealand Transport Agency

\section{(6) LBRUSTRALIA}

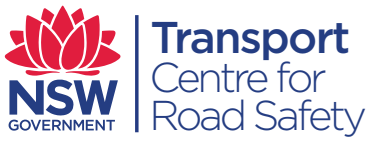

